Portland State University

PDXScholar

$1-1-1979$

\title{
Welfare stigmatization and the elderly: the case of the Supplemental Security Income program
}

Peter Jic-Leung Man

Portland State University

Follow this and additional works at: https://pdxscholar.library.pdx.edu/open_access_etds Let us know how access to this document benefits you.

\section{Recommended Citation}

Man, Peter Jic-Leung, "Welfare stigmatization and the elderly: the case of the Supplemental Security Income program" (1979). Dissertations and Theses. Paper 834.

https://doi.org/10.15760/etd.834

This Dissertation is brought to you for free and open access. It has been accepted for inclusion in Dissertations and Theses by an authorized administrator of PDXScholar. Please contact us if we can make this document more accessible: pdxscholar@pdx.edu. 
WELFARE STIGMATIZATION AND THE ELDERLY: THE CASE OF THE SUPPLEMENTAL SECURITY INCOME PROGRAM

by

PETER JIC-LEUNG MAN

A dissertation submitted in partial fulfillment of the requirement for the degree of

\author{
DOCTOR OF PHILOSOPHY \\ in \\ URBAN STUDIES
}

Portland State University

1979 


\section{TO THE OFFICE OF GRADUATE STUDIES AND RESEARCH:}

The members of the Committee approve the dissertation of Peter Jic-Leung Man presented December 11, 1979.
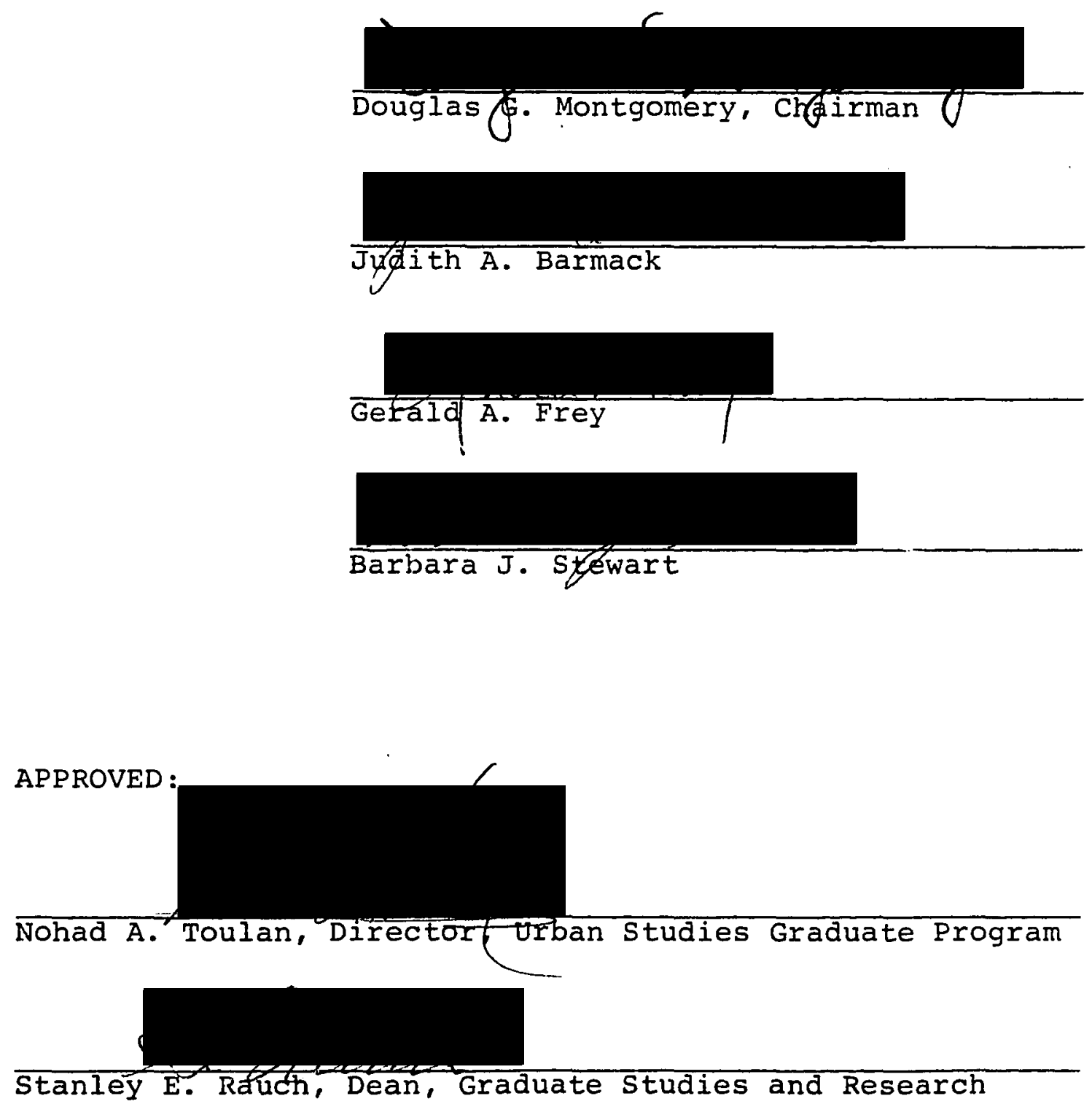
AN ABSTRACT OF THE DISSERTATION OF Peter Jic-Leung Man for the Doctor of Philosophy in Urban Studies presented December $11,1979$.

Title: Welfare Stigmatization and the Elderly: The Case of the Supplemental Security Income Program.

APPROVED BY MEMBERS OF THE DISSERTATION COMMITTEE:
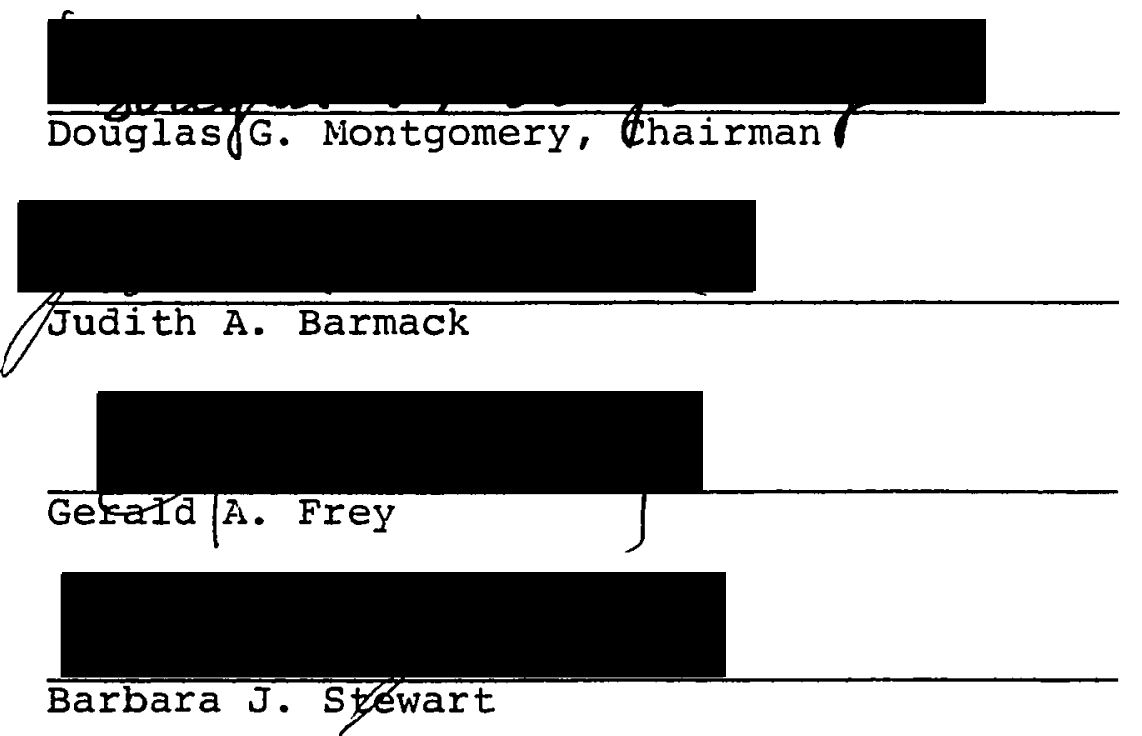

Policy-makers and others historically have assumed that welfare programs should give assistance to the poor and carry stigma. This attitude in part developed from the English Poor Laws tradition in which poverty was considered a negative condition. Labeling theory has often been used to explain the process of welfare stigmatization. Once an individual is labeled as a deviant, such as a welfare recipient, a selffulfilling prophecy is initiated. Others perceive and respond 
to the individual as a deviant and the individual also internalized the stigma attached to such a role. The stigma attached to public dependency becomes an outcome of this labeling process.

This study identifies the relationship between welfare stigma and the elderly and has three objectives. First, it challenges the usefulness of labeling theory in explaining the perception of welfare stigma among elderly recipients. Second, it analyzes why different levels of stigma are attached to different public assistance programs. Third, it examines why some recipients feel more stigmatized than others. Historically, the elderly poor have been identified as the deserving poor and provided for under most social programs. Because of differential treatment between the elderly poor and the able-bodied poor, this study contends that these groups develop different self-images as welfare recipients. A single welfare image applied indiscriminately to both groups results in a poor fit. Instead of internalizing the negative image from the outside community, the elderly may have internalized the deserving poor image and subsequently perceive their welfare status as less stigmatized.

Congress established the Supplemental security Income (SSI) program in 1972 to replace the state-run old Age Assistance (OAA) program. By placing SSI under the social security Administration, this new program seeks to provide additional income with less stigma to the aged poor. 
Data for this study come from two separate surveys: a local survey of 400 respondents and a national survey of 8600 respondents. The most important dependent variable in this study is welfare stigma. It is operationally defined by three indicators: 1) whether recipients feel bothered in receiving assistance; 2) whether recipients feel embarrassed to admit their welfare status; and 3) whether recipients perceive community disrespect for thier welfare status. Factor analysis enabled a welfare stigma index to be constructed using the above three items.

The often cited welfare stigma was not substantiated by the data. Elderly recipients of both OAA and SSI had low stigma feelings. Labeling theory, while useful in explaining relfare stigma of other poor subgroups, is not applicable to the elderly. Significantly less stigma was found to be associated with SSI than with OAA. Other findings supporting the SSI program include: more recipients had confidence in the Social Security Administration than in local welfare agencies; more were satisfied with the performance of SSI than with OAA; more non-recipients expressed a willingness to use SSI. In contrast to findings of many studies, this study found that some demographic variables, such as education and socioeconomic status, were significantly related to stigma.

This study has theoretical and practical significance. First, it demonstrates that labeling theory is not useful in explaining stigma perception of the elderly. Second, it 
provides important baseline data to judge future performance of SSI and other similar programs. The analysis calls for the need to design effective social programs on a universalistic rather than class-specific basis. Options for change in the income-maintenance programs in the 1980's are discussed and include an analysis of the two-tier proposal. 


\section{ACKNOIVLEDGEMENTS}

This dissertation would not have been possible without the assistance of a number of individuals. The chairman of my committee, Dr. Douglas G. Montgomery, provided continual support, encouragement, and advice from the inception of this study to its conclusion. Dr. Barbara J. Sterart provided invaluable assistance in the quantitative portion of this work. Drs. Judith A. Barmack and Gerald A. Frey were most helpful in their constructive criticisms of this dissertation. Special thanks are in order for both Dr. James E. Weiss and Dr. Nohad A. Toulan for their guidance and unfailing support. My work has also benefitted from the advice and suggestions of Mr. Edrard A. Schafer during the data analysis of my study. I gratefully acknoriledge the financial support of Multnomah County and $M r$. Dan Davis. Without their fellowship awards, this study could not have been completed.

I would like to thank the Institute on Aging, Portland State University and Dr. Thomas Tissue of the Social security Administration for alloring me to use their data freely.

Finally, my wife hally deserves a special note of appreciation. Her toleration, understanding, and encouragement made the completion of this work possible. 
TABLE OF CONTENTS

PAGE

ACKNOWLEDGEMENTS . . . . . . . . . . . . . . . ii LIST OF TABLES . . . . . . . . . . . . . . . . vii FIGURE 1 . . . . . . . . . . . . . . . . . ix

\section{CHAPTER}

I INTRODUCTION •. . . . . . . . . . . . 1

II LITERATURE REVIEW . . . . . . . . . . 8

Introduction . . . . . . . . . 8

Historical Development of Income-

Maintenance Programs for the Poor. 10

Income-Maintenance Programs Before 1935

The Social Security Act of 1935

Income-Maintenance Frograms: 19351972

President Nixon's Welfare Reform

Attitudes Toward the Poor . . . . . 22

Attitudes of the Poor . . . . . . . 32

Welfare and Stigma . . . . . . . 40

Labeling Theory and Welfare Stigma . . 48

Summary . . . . . . . . . . 55

III THE STUDY PROBLEM . . . . . . . . . . . 60 
CHAPTER

PAGE

IV METHODOLOGY . . . . . . . . . . . 69

Data and Limitations . . . . . . 69

The Samples . . . . . . . . . . 71

Analysis . . . . . . . . . . 78

$\mathrm{V}$ CONSTRUCTION OF INDEXES . . . . . . . . . 83

The Stigma Index . . . . . . . . 83

The SES Index . . . . . . . . . 101

VI PERCEPTION OF STIGMA . . . . . . . . 105

Introduction . . . . . . . . . 105

Comparison of Stigma Indicators . . . . 106

Comparison of OAA and SSI Recipients . . 113

Comparison of National and Local

Samples . . . . . . . . . . 118

Summary . . . . . . . . . . . 121

VII DEMOGRAPHICS AND STIGMA PERCEPTION • . • . . 123

Introduction . . . . . . . . . 123

Age and Stigma . . . . . . . . . 126

Sex and Stigma . . . . . . . . . 130

Education and Stigma . . . . . . . 134

Socioeconomic Status and Stigma . . . . 137

Length of Time on Assistance and
Stigma . . . . . . . . . . . 140

Blaming the Poor for Poverty and
Stigma . . . . . . . . . . . 144

Summary . . . . . . . . . . . . . 146 
VIII RATING OF AGENCIES AND PROGRAMS . . . . . . . 149

Introduction . . . . . . . . . . . 149

Social Security Administration and Local Welfare Departments. . . . 150

Performance of OAA and SSI . . . . . 153

Future Use of OAA and SSI . . . . . . 156

Summary . . . . . . . . . . . . 161

IX CONCLUSIONS AND IMPIICATIONS OF STUDY • • • • 163

Summary of Findings . . . . . . . . 163

Perception of stigma

Demographics and Stigma

Rating of Agencies and Programs

Implications of study . . . . . . . .

Labeling Theory and the Elderly

The Need to Study Other Groups

A Basis for Future Program

Evaluation

Universal vs. Class-Specific

Programs

One Basis to Restructure Social

Security 


\section{LIST OF TABLES}

TABLE

PAGE

I Interviews and Noninterviews, SLIAD Survey, 1973 and 1974 . . . . . . . . . . 77

II Correlation Matrix of Stigma Items, National

$$
\text { Sample - OAA . . . . . . . . . . . . }
$$

II Factor Matrix Using Principal Factor, National Sample - OAA . . . . . . . 88

IV Factor-Score Coefficient Matrix . . . . . . 89

$\mathrm{V}$ Frequency Distribution of Stigma Index,

National Sample - OAA . . . . . . . . 91

VI Correlation Coefficient Matrix of Stigma

$$
\text { Index, National Sample - OAA . . . . . }
$$

VII Correlation Matrix of Stigma Items,

National Sample - SSI . . . . . . . .

VIII Factor Matrix Using Principal Factor,

National Sample - SSI . . . . . . . 93

IX Factor-Score Coefficient Matrix . . . . . . . 94

$x$ Frequency Distribution of Stigma Index,

National Sample - SSI . . . . . . . .

XI Correlation Coefficient Matrix of Stigma

$$
\text { Index, National Sample - SSI . . . . . }
$$

XII Correlation Matrix of Stigma Items, 
viii

TABIE

PAGE

XIII Factor Matrix Using Principal Factor,

Local Sample - OAA . . . . . . . . 97

XIV Factor-Score Coefficient Matrix . . . . . . . 98

XV Frequency Distribution of Stigma Index,

Local Sample - OAA . . . . . . . . 99

XVI Correlation Coefficient Matrix of Stigma Index,

Local Sample - OAA . . . . . . . . 100

XVII Selected Characteristics of SES Indexes . . . 104

XVIII Responses to stigma Items for OAA and SSI

Recipients, National Sample . . . . . 108

XIX Responses to stigma Items for OAA Recipients,

Local Sample. . . . . . . . . . . . 110

XX Frequency Distribution of New SSI Index,

Using OAA Weights, National Sample. . . . 115

XXI T-test for Difference in OAA Stigma and SSI

Stigma, National Sample . . . . . . . 116

XXII Distribution of Age-Groups, National and

Local Samples . . . . . . . . . . 126

XXIII Length of Time on Welfare for OAA Recipients,

National Sample . . . . . . . . . 140

XXIV Blaming Poverty as Individual's Fault,

Local Sample . . . . . . . . . . . 144

XXV Confidence in SSA and Local Welfare

Departments, Local Sample . . . . . . . 151 
XXVI T-test for Difference in Confidence in

SSA and Welfare Departments,

Local Sample . . . . . . . . . . 152

XXVII Satisfaction with Performance of OAA and

SSI Programs, National Sample . . . . 154

XXVIII T-test Comparing Satisfaction of

Performance in OAA and SSI,

National Sample .......... . 155

XXIX To Use OAA and SSI in Future,

National Sample . . . . . . . . 157

XXX T-test Comparing Future Use of OAA and SSI,

National Sample . . . . . . . . 158

XXXI To Use OAA and SSI in Future,

Local Sample. . . . . . . . . . 159

XXXII T-test Comparing Future Use of OAA and SSI, Local Sample. . . . . . . . . . 160

\section{FIGURE}

1. Illustration of Sample Selection and Interview Attrition Process for Local Sample . . . 73 


\section{CHAPTER I}

\section{INTRODUCTION}

Policy-makers and others have assumed that welfare programs should give assistance to the poor and at the same time carry stigma. This developed from a tradition established by the English Poor Laws in which poverty was considered a negative condition. Scholars have argued that the stigma from welfare recipiency would be a major deterrent to participation in welfare programs by potential beneficiaries. Labeling theory, used widely in the stuay of delinquency and mental illness, has often been used to explain the process of welfare stigmatization. According to this perspective, deviance is an outcome of societal reaction, or labeling by official control bodies. Once labeled as a deviant, such as a welfare recipient, a selffulfilling prophecy is initiated. Others perceive and respona to the individual as a deviant and, more importantly, the individual internalizes the stigma attached to such a role. The primary objective of this study is to examine empirically the usefulness of the labeling theory in explaining the stigma of the elderly. The secondary objective of this study seeks to understand why different amounts of stigma are attached to different public assistance programs. Third, this study also examines why some welfare recipients feel 
more stigmatized than others.

Instead of studying the general population, this study concentrates on the elderly poor, especially their experience with the Old Age Assistance (OAA) program and the Supplemental Security Income (SSI) program. Of all age groups in the total population, the elderly have the highest incidence of poverty, generally resulting from the inadequacy of fixed income in a period of rapid inflation (Pechman, et. al., 1968: 17). OAA was first started as a state welfare program in the eariy 20 th century and was partially funded by the federal government after 1935. Because of the social stigma attached to welfare programs, it was believed that many older Americans did not apply for benefits in the OAA program. SSI was established by Congress in 1972 as a federal program to replace $O A A$ and other categorical aid programs for the blind and disabled. The problem of providing additional income for these groups and yet avoiding the social stigma of the welfare recipient provided the underlying basis for establishment of the SSI program. It was thought that this program would better meet the needs of the eligible elderly who were not receiving assistance. These assumptions will be critically analyzed from data collected in two surveys. In particular, this study examines the way elderly welfare recipients perceive stigma and compares them with other poor groups. Whether or not SSI has actually reduced stigma in public assistance will also be examined. 
Chapter II reviews relevant literature on incomemaintenance programs and attitudes peopie have toward them. Topics examined include a description of the historical development of income-maintenance programs in this country, attitudes toward the poor and attitudes of the poor, welfare and stigma, and the relationship between labeling theory and welfare stigma. An understanding of the history of welfare programs is important because the development of categorical aid programs reflected different pubiic attitudes and different treatment toward the classes of poor people. Past research and studies concerning how the public views the poor and welfare programs and attitudes held by the poor themselves are also reviewed. Whether or not the public has an ambivalent attitude toward the poor is examined. This chapter also analyzes how the poor view welfare programs and whether or not they share the negative attitudes of the general public. The relationship between welfare and stigma is compared and contrasted. This chapter concludes with a review of labeling theory and its application in explaining welfare stigma.

Chapter III presents the study problem. The different attitudes people have toward social security and welfare are compared. The reasons for the success of and respect toward the Social Security Administration are discussed. The purpose of designing SSI as a stigma-free program is also analyzed. Finally, the argument that welfare stigma is a legitimate 
concern and an important topic of inquiry is presented.

In Chapter IV, the study design is presented. First, the sources of data from two separate surveys and their limitations are noted. seccnd, the ways of two samples were drawn as discussed. Finally, the analysis strategy is presented.

Chapter $\mathrm{V}$ presents the theoretical underpinnings and construction of two indexes which are to be used in later analysis. The most important dependent variable in this study is welfare stigma. Stigma has been defined and measured in a variety of ways. Following Goffman (1963), this study defines stigma as attributes that are deeply discrediting, whether they are physical deformities, blemishes of character, or characteristics of race, nation, and religion. Operationally, this study measures stigma feelings in terms of three indicators: (1) bothered in accepting public aid; (2) embarrassed to admit welfare aid status; and (3) perceived community disrespect for welfare recipients. A welfare stigma index is constructed for different groups of recipients in the two samples based on the above three items. The technique of factor analysis is used in building the stigma index. The second index constructed in this chapter is a socioeconomic status (SES) index. First developed by the U.S. Census Bureau, this SES index is based on the former occupation of the recipient, with education and income for that occupation adjusted.

Chapter VI begins the actual data anlysis. First, 
stigma feelings for both samples are examined. The purpose of this analysis is to compare the stigma perceived by elderly recipients and the stigma reported in other studies. It is suggested in this study that elderly recipients do not have high stigma feelings. The elderly traditionally have been regarajed as the "deserving poor" and have enjoyed a special moral place in society. For this reason, it is possible for them to internalize this "deserving poor" image instead of the stigma normally attached to welfare recipiency. Second, the different in stigma between OAA and SSI recipients is compared and contrasted. Because of the various changes in the SSI program, including its location within the social Security Administration, it is hypothesized that SSI recipients would have less stigma than OAA recipients. Finally, the difference in stigma between the national sample and the local sample is also compared. Despite different sample sizes, it is hypothesized that there is no significant difference in stigma between the two samples.

Chapter VII concentrates on the testing of relationships between demographic and personal variables and stigma. Many past research studies have found that background characteristics of recipients are not differentiating factors in predicting their stigma perception. It is suggested in this study that the elderly may behave differently. It is therefore important to find out why some recipients have more stigma feelings than others. The five demographic/personal character- 
istics explored are age, sex, education, socioeconomic status, and length of time on assistance. One non-demographic variable that is also examined in this chapter is whether or not recipients agree that poverty is their own fault.

Chapter VIII discusses the recipients' feelings about public assistance agencies and programs. The old OAA program was administered by local welfare agencies while the new SSI program falls under the jurisaiction of the social security Administration. It is generally recognized that SSA has a long and distinguished record of efficiency in its operation of the Social Security program. Location of the SSI program within SSA was meant to overcome resistance and stigma attachea to welfare. It is hypothesized in this study that recipients would have more confjdence in the Social Security Administration than in local welfare agencies. Another hypothesis tested is the rating of the OAA and SSI programs by their recipients. Because of the many advantages in the new SSI program, it is hypothesized that recipients are more satisfied with SSI than with OAA. The last hypothesis to be tested concerns the rating Of OAA and SSI by the non-recipients. The new SSI program was designed with the view that more potential beneficiaries who were reluctant to use OAA would now be more willing to use SSI. It is therefore hypothesized that current non-recipients would be more willing to use SSI than OAA in the future. The concluding chapter, Chapter IX, summarizes the major findings and examines the significance of this study. Impor- 
tant findings presented include the level of stigma perception by the elderly, difference between OAA and SSI recipients, difference between the national and local samples, relationships between demographic characteristics and stigma, and rating of agencies and programs. It was found that the elderly recipients in this study did not have high intensity of stigma feelings, and that the new SSI program did show an improvement in terms of stigma reduction. Recipients in the local sample, however, showed more stigma than recipients in the national sample. Certain demographic and personal ciaracteristics such as education and socioeconomic status, and to a lesser extent sex and length of time on assistance were found to be related to stigma. More recipients were satisfied with the performance of SSI and the Social Security Administration than $O A A$ and local welfare agencies. More current non-recipients would use SSI than OAA in the future if they need public assistance.

This study has both theoretical and practical significance. On the theoretical side, this study challenges the usefulness of labeling theory in explaining welfare stigma as experienced by the elderly. Practically, this study offers useful baseline data for the new SSI program and provides a guide for future welfare reform efforts. 
CHAPTER II

\section{LITERATURE REVIEW}

INTRODUCTION

Relevant literature on public income-maintenance programs and attitudes people have toward these programs are reviewed in the five sections of this chapter. In the first section the historical development of income-maintenance programs for the poor in this country is discussed. This historical review begins with the l9th century when helping the poor was mainly the responsibility of state and local governments and concludes in 1972 when the Supplemental security Income (SSI) program was established by Congress. Development of social insurance programs and welfare programs are contrasted and the public's differential treatments toward various categorical aids programs are noted.

The second section of this chapter reviews literature concerning attitudes people have toward welfare. Specifically past research and studies relating to attitudes the general public have toward the poor and welfare programs are addressed. The public seems to be ambivalent toward the poor. On the one hand, the public seems to sympathize with the poor and support welfare programs. Yet on the other hand, the poor are disliked and perceived as less worthy than the non-poor. 
The third section examines attitudes the poor have of themselves and welfare programs. Do the poor share the generally negative attitudes the public have toward them and welfare programs? Do they suffer from a lowered selfesteem and react by not using welfare? Do members of ghetto communities react differently and accept welfare gladly? A review of relevant literature suggests that these questions have affirmative answers.

The fourth section explores the relationships between welfare and stigma. Erving Goffman's conceptualization of stigma is detailed. Goffman identifies three types of stigma and discusses how the stigma of poverty resembles two of these types. The relationship between welfare recipiency and stigmatization is noted. David Matza suggests welfare recipients are the disreputable poor; Lewis Coser argues that they are degraded and declassified; and Bernard Beck considers welfare as a residual moral category. The lack of reciprocity is offered as an explanation of anti-welfare feelings.

The last section examines welfare stigma and labeling theory. Labeling theory has often been used to explain welfare stigmatization. The major tenents of this approach are reviewed and the application to welfare stigma noted. A related concept, culture of poverty, is discussed as well. 


\section{HISTORICAL DEVELOPMENT OF INCOME-MAINTENANCE PROGRAMS FOR THE POOR}

The conditions of welfare in a society reflect theories of poverty, which are deeply embedded in the moral, social, economical and political fabric. There are several types of theories of poverty (Handler, 1972). The older, but still dominant theory is the pathological idea of poverty. This theory finds the explanation of poverty in the characteristics of the poor themselves, in individual character defects or family pathology. There are variations of this theory, e.g. moral failure, psychological explanations, culture of poverty, etc. It is within the poor themselves that one will find the explanation of poverty.

An alternative theory views poverty in terms of the structural conditions in society under which the poor live: lack of adequate jobs, poor education and housing, etc. The "deviant" characteristics, according to this theory, are only adaptations to hostile environment. A third theory starts from the pathological perspective, but reaches different policy consequences. Poverty may be caused by individual characteristics, but a distinction can be made according to the nature of these characteristics. The basis of distinction is fault. 
According to this theory, a person who cannot work because of a physical handicap differs from one who refused to work voluntarily. Much of the welfare policy in the United States reflects conflict over changing perceptions of the moral qualities of those who seek relief. A brief description of the historical development of income-maintenance programs for the poor in this country illustrates this point. special attention is given to programs concerning the aged poor.

Income Maintenance Programs; Before 1935

Before 1935, the federal government followed a classical laissez faire policy toward the poor. Assisting the poor was primarily the responsibility of state and local governments. The aged poor is a case in point. During the late 19 th and early 20 th centuries, federal assistance for the aged poor did not exist. This was partly due to the fact that the aged did not suffer as much in their economic status in earlier years. The family's activity on the farm and the family were important factors in this regard (Pechman, et. al., 1968: 28-31). First, the family farm--the predominant economic institution in the 19th century--permitted the individual to reduce his work effort gradually as he grew older. Rural population in the United States accounted for 72 percent of the total population in 1880, compared with less than 27 percent in 1970 
(Pechman, et. al., 1968: 28; U.S. Census of Population, 1970). Second, the average family in the primarily rural society of the last century was much larger than it is today. Household size declined from 5.04 persons in 1880 to 3.11 in 1970 . When an individual with many children could no longer work, he could plan on financial assistance from each grown child. These factors, together with shorter life expectancy, made the problem of economic support of the aged much less severe than it is today.

As the country developed and as more people became concentrated in cities as part of the industrial work force, problems of dependency became serious. Increasing industrialization, while a source of the growing prosperity, was detrimental to the relative status of the aged. The factory was not an appropriate environment in which the aged worker could gradually curtail his work effort. Moreover, the industrial city transformed the family structure and reduced the availability of family support of the aged. Fanilies in the city found children less economically advantageous than did families on the farm, and the size of families declined sharply. As a result, aged parents had fewer children to support them. Family ties were also weakened by the shift from a rural to an urban economic and social base.

At the same time, medical advances steadily increased life expectancy. The number of aged grew not only absolutely but also as a proportion of the total population. 
Life expectancy of white males at birth increased from 48.2 years in 1900 to 69.4 years in 1975 ; for white females, the rise was from 51.1 years to 77.2 years (U.S. Census Bureau, 1949: 45; 1977: 65). The number of persons aged 65 and over increased from 1.7 million in 1880 to 24 million in 1978. In relative terms, the growth was from 3.4 to 11 percent of the total population (U.S. Census Bureau, 1960: 10). As a result of increasing urbanization, smaller families, and longer life expectancy, the problem of providing economic support for the aged became more severe than before. Whereas the care of an aged parent was usually not a great economic burden for a large family in a rural society, the burden becomes increasingly great for a small family in an urban society.

Efforts to assist the aged poor and other poor groups were first started by state and local governments. The late 19 th and early 20 th centuries brought the initial "categorical aids". Historically, the term categorical aids refers to the 19 th century process of making special provisions for certain categories of the poor (Handler and Hollingsworth, 1971:16). The development of categories reflected different attitudes and different treatment toward the classes of poor.

The first of the current categorical aid programs, Aid to the Blind, was enacted in ohio in 1898. A few years later, Illinois and Missouri started assistance programs 
for needy mothers and children. In 1915, Alaska pioneered the first program to assist the needy aged. By 1935, 30 states had plans for assisting their elderly residents (Iynn, 1977: 58-59).

From the earliest days of Aid to Dependent Children $(A D C)$ the recipients, as a class, never fully qualified as members of the "deserving poor", in the same way that the blind, the disabled, and the aged qualified. There was no general agreement or standard that determined which widows were deserving. Consequently, the decision of whether to give aid was left to local administrators who applied the community sense of morality. The heart of ADC philosophy is the pathological theory of poverty. The goal of the program is reformation, to change the poor so that they can function in society without the need of welfare, rather than changing the structural conditions of society to accomodate the needs of the people.

In contrast to ADC, no moral issue for the "deserving poor", such as the aged, was involved in assistance programs. When the old Age Assistance Program was started, it represented a more liberal program in terms of coverage and benefits and yet was a simply administered program. In comparison with $A D C$, fewer conditions were attached to $O A A$ and applications were routinely processed. There was little investigation, and needs and payments were relatively fixed. Poverty was still attributed to individual characteristics (old age), but fault was not present. Giving aid to this group did not conflict 
the moral issue of work. People accepted the idea that poverty among the aged was not due to a lack of virtue, since they had already made their contribution to society.

\section{The Social Security Act of 1935}

The Depression in the 1930's eliminated the jobs and savings of millions of people in the United States, and strained the ability of the states to heip the poor. Though many New Deal programs provided federal relief and emergency assistance to local governments and individuals, there was growing pressure on the federal government to provide more permanent forms of income security.

In response to these cumulative trends and the Depression, proposals to aid the poor, particularly the aged, gained tremendous political support during the early 1930's. As a result, Congress in the $1935^{\circ}$ Social security Act establishea two new federally assisted systems of income support: a social insurance system of old age insurance and unemployment insurance, and a public assistance or welfare system. The latter was a series of programs to provide public assistance to special classes of the needy: Old Age Assistance, Aid to the Blind, and Aid to Dependent Children. The old age provisions in the Act were a first attempt to solve the needs of the aged for economic security in general, as well as a reaction to the specific short-run crisis of the depression; and a 
compromise measure to blunt the political appeal of the expensive and essentially unworkable Townsend Plan, whose basic tenet was a flat benefit payment of $\$ 200$ per month to all the aged over 60 (which exceeded average earnings of the employed at that time) (Pechman, et. al., 1968: 32). The old age and unemployment insurance systems were designed as compulsory, contributory programs for those with labor force attachment, providing income protection as an earned right without a means test. The public assistance programs provided federal matching grants to states, which in turn were responsible for administering their own public assistance programs within federally established limitations and regulations.

Congress apparently hoped in 1935 that once the social insurance system matured, the public assistance programs, especially old Age Assistance, would gradually become small residual programs (Steiner, 1977; Pechman, et. al.. 1968). What actually happened in public assistance is that the number of OAA recipients declined relative to the growth in population of persons aged 65 and over. But the growth in the ADC rate among children under 18 increased significantly. Public assistance was not ended as the character of the ADC rolls changed (Stiner, 1966:23). Public assistance since 1957 changed and grew as there have been more recipients of ADC than of any other category of assistance. But these ADC cases are not composed of 
widows and orphans (which are covered by social insurance). Many are deserted mothers and deserted children or are mothers with their illegitimate children. Survivor's insurance becomes irrelevant in this situation, while unemployment insurance serves only the bread winner. The groups who benefited from public assistance lie either outside the insurance spectrum or are largely unemployable.

\section{Income-Maintenance Programs: 1935-1972}

Between 1935 and 1972, while numerous modifications were made in the income-maintenance programs, there was no major breakthrough in cash assistance programs. At the legislative level, the basic structure and substantive decisions enacted in 1935 remained the same for 35 years. Legislative activities pursued were minor and primarily a step-by-step liberalization of the various programs. Social Security coverage and benefits were extended and raised periodically, with proportionately larger increases for wage earners at the bottom of the earning scale. Over these years, average benefits and the federal contribution to other categorical aid programs rose steadily. Wide disparities in benefits among these state-administered programs developed. For instance, the amount paid for basic needs to an aged couple with no other income ranged from a low $\$ 97$ a month to a high of $\$ 350$ a month (Lynn, 1977: 72). Among the substantive changes in the cash aid programs 
was a new public assistance program in 1950--Aid to the Permanently and Totally Disabled (APTD). In 1961, the federal government allowed states to provide AFDC payments to intact families if the husband was unemployed. This major substantive change was optional and many states chose not to follow it. As of 1970, half of the states had no program of aid to families with unemployed fathers (AFDC-UF) which may have become one of the most important programs for the poor (Feagin, 1975: 60-61). This reluctance identifies the basic philosophy which supported public assistance developed between the $1930^{\prime} \mathrm{s}$ and the early 1970's in the United States.

During this period, Congress authorized a number of non-cash programs to be used not only by recipients of cash assistance but also by other poor persons not eligible for cash aid. An example was the Medicaid program authorized in 1965. Those receiving categorical assistance (aged, blind, disabled, and AFDC recipients) automatically qualified for this program. Other in-kind and social service programs were introduced in the 1960's, inciliding the federal food stamp program in 1964, and others during the war on Poverty program period.

Few domestic policy developments of the postwar period had the drama associated with President Johnson's War on Poverty. This "War" was not guided by an "income strategy" emphasizing increased benefits, wider eligibility, and improved equity for cash transfer programs, but by a 
"service strategy" that emphasized investments in human capital and the expansion of the human services. One key development was that for the first time an agency of the government (Office of Economic Opportunity) was established to represent and act as an advocate for the poor (Lynn, 1977:66). Concern began to be focused on poverty as a social problem. Inevitably, the new national awareness of and concern for poverty influenced the course of developments in many areas of national policy including the incomemaintenance system.

President Nixon's Welfare Reform

A major round of welfare reform occurred in 1972 when Congress passed HR 1. Started in 1969, President Nixon proposed a new welfare plan which rivaled preceding programs on welfare reform. (For a detailed discussion, see Moynihan, 1973; Burke, 1974). The Nixon initiative, the Family Assistance Plan (FAP), called for the most extensive structural changes in public assistance since the original Social Security Act was passed in 1935.

The Family Assistance Plan suggested two central changes in public assistance (Marmor and Rein, 1973). First, it proposed a federal program of cash assistance to poor families, including intact families with male heads. It would be nationwide in scope with standard eligibility. This would guarantee $\$ 1600$ per year to a family of 
four and partially replace the program of Aid to Families with Dependent Children. Second, FAP would enlarge the federal role in other assistance programs to adults (aid to the aged, blind and disabled). A nationwide benefit level would be established, and for the first time, states would be required to meet uniform standards of eligibility and administration. In short, FAP would expand assistance coverage to working-poor intact families as well as increase. federalization of diverse federal-state programs in terms of standards, financing, and administration.

FAP was indeed a "quantum jump" in American politics (Burke, 1974: xi), and forced Congress to confront welfare discrimination against poor fathers who chose to stay with their families and work at low wages. This new program would partially correct several inequities of the welfare system, one of which being that it often restricted aid to female-headed families (except in the case of the aged, blind and disabled, and states with AFDC-UF). Inadvertently the system provided financial inducement for fathers to leave the home and create broken families.

Research analysis showed that the family-splitting phenomenon varied. It was noted to occur. Generally the family-splitting incentive was higher the larger the family, the greater the number of benefits, and the higher the father's earnings. In 1974, the first national study of welfare's incentives for family splitting was undertaken. The study, based on 1972 data for 100 counties, showed that on an 
average, a hypothetical family of five would gain more than $\$ 3000$ in net income per year if the father "deserted". For many low-income families the financial gain from splitting up outweighed the costs of setting up second households by the families (Burke, 1974: 207).

That FAP came from a Republican President was indeed a bold departure from the past. It almost became a law. Introduced in 1969 FAP passed the House twice (in 1970 and 1971), only to die in the senate. However, this reform effort was not completely fruitless. In October 1972, Congress did pass HR 1 , which guaranteed a minimum income to the "deserving poor"--the aged, blind and disabled. This new program, called Supplemental Security Income (SSI), was to be administered by the Social Security Administration and to be federally financed from general revenue. The outcome of the 1972 legislation showed once again this country's preference to aid the "deserving poor" instead of the able-bodied poor.

Although SSI is the only holdover of Nixon's FAP, it is not without its own significance. SSI provides uniform administration and standard eligibility in all states. It provides higher income and wider coverage for the recipients and represents a turn from service to income strategy. SSI enhances the image of public assistance by being attached to the Social Security Administration, and brings relief to the Social Security system. 


\section{ATTITUDES TOWARD THE POOR}

A survey of literature reveals that American society is characterized by seemingly ambivalent attitudes toward the poor. On the one hand, government and the public decry poverty and devise programs to eradicate it. On the other hand, the poor are disliked and perceived as inherently less worthy than others. Poverty and welfare continue to be a most complex and psychologically "loaded" social issue (Ogren, 1973: 107). Perhaps this is one reason why public attitudes display a lack of congruity and considerable inconsistency.

A 1970 Social Security Administration study examined public opinion poll data from 1935 to 1965 concerning people's attitudes toward income-maintenance programs (Schiltz, 1970). This survey found that the American public overwhelmingly accepted income-maintenance programs for the poor during this thirty-year period. Thirteen national surveys undertaken by three survey agencies (Roper, Gallup, and National Opinion Research Center) reveal that support for the old-age programs increased steadily from two-thirds of the population in 1936 to a nearly unanimous 96 percent in 1944 . When asked about increase or decrease of welfare expenditures, the SSA study shows that in seven of the ten surveys between 
1940 and 1964, the public generally recommended an increase rather than a decrease in welfare expenditures (Schlitz, 1970: 152). Joe Feagin, in his 1969 nationwide survey of 1017 respondents, also reported that although only 10 percent of the sample were optimistic about the nation's ability to eradicate poverty, three-fourths of the respondents said they favored "an all-out Federal effort to get rid of poverty" (Feagin, 1972b).

In a 1970 study of 1984 respondents in California, Evelyn Ogren (1973) found that the majority of respondents believed that the causes of poverty were either environmental or stemmed from factors beyond a person's control. Only 11 percent of the respondents disparaged poor people as lazy, poor money managers, hippies, and so forth. Seventysix percent of them believed that the American society had an obligation to keep the poor from living a substandard life and an overwhelming majority agreed that the poor were entitled to welfare assistance (Ogren, 1973: 103). Another comprehensive study of attitudes was the nationwide survey conducted by Louis Harris for the Committee on Government Operations of the United States Senate in 1973. Results of the Harris survey indicated that the public did accept the role of government in the Iives of people and that 89 percent of the public agreed that the "federal government has a deep responsibility for seeing to it that the poor are taken care of, that no one 
goes hungry, and that every person achieves a minimum standard of living" (Katz, 1975: 14). In another Harris nationwide survey taken in 1976,94 percent of the public agreed with the view that "it is not right to let people who need welfare go hungry." Seventy-four percent of the people interviewed agreed that "many women whose husbands have left them with several children have no choice but to go on welfare" (Anderson, 1978: 60).

Behind this seemingly high support for the poor and the assistance programs, the general population holds a deep resentment against the poor. Most of the United States' patterns of dealing with the poor originated in England. The English Poor Laws marked the beginning of government involvement in social welfare in the west and had significant impact upon subsequent social welfare legislation and policies in the United States. The most notable point of the "Poor Laws" is the belief that people should be punished for not working. Contemporary society still punishes the poor, although the penalty now consists primarily of stigma and economic deprivation (Heise, 1977). One result is that the public generally believes that welfare is bad and that welfare recipients are stigmatized (see Handler and Hollingsworth, 1969, 1971; Piven and Cloward, 1972; Spitzer, 1977; Katz, 1975; Tropman, 1977; Ogren, 1973; Alston and Dean, 1972; Heise, 1977; Feagin, 1972; Gottleib, 1974; Kerbo, 1976; Anderson, 1978; Waxman, 1977; Street, et. 
al., 1979). The extent to which the poor are thought of as having weak character and being responsible for their own conditions is conspicuous in a number of studies.

Feagin, in his 1969 study of American attitudes toward poverty and the poor, found that respondents' answers about the causes of poverty fell into three general categories: individualistic explanation, which placed responsibilities for poverty squarely on the shoulders of poor people themselves; structural explanations, which blamed external social and economic forces; and fatalistic explanations, which laid poverty to illness, bad luck, and so forth (Feagin, 1972, 1975). Results showed that individualistic factors were considered more important than were structural or fatalistic factors in explaining why people were poor (Feagin, 1972: 103).

Blaming the poor for their poverty was often linked to the "economic self-interest" thesis (Williamson, 1974a). According to this thesis, those at higher socioeconomic levels benefit more than those at lower levels from the existing distribution of resources and opportunities. Beliefs that can be used to justify the existing distribution are therefore likely to be most favorably received by those at higher socioeconomic levels and least favorably received by those at lower levels. Blaming the poor for their poverty is one such belief. According to Williamson, it is in the economic self-interest of those at the upper 
end of the socioeconomic distribution to find fault with the poor so that the "dirty jobs" will get done. However, Williamson's study of 300 Boston white women in 1972 only weakly supports this economic self-interest thesis. The results were not consistent with the position that socioeconomic status was the major determinantin blaming the poor for their poverty (Williamson, 1974a: 643). Despite this weak relationship between socioeconomic level and blaming-the-poor-for-their-poverty, various polls and studies did show that the public as a whole held the poor responsible for their poverty.

In a 1974 study of 300 white and 300 black women in Baltimore, Kallen and Miller found that over threefourths of their respondents agreed with the items "There are too many people receiving welfare who should be working" and "I don't see any reason why a person who is able to work should get welfare money" (Kallen and Miller, 1971: 87). Similarly, Joe Feagin reported that in his nationwide study, 84 percent of the sample agreed with the first statement (Feaqin, 1975: 104).

In a 1964 study, a nationwide survey of American political beliefs conducted by the Gallup and Harris organizations, found that the majority of Americans saw "lack of effort" as the major source of poverty (Waxman, 1977: 72). Results from this and other studies point to the general belief that the poor are lazy or morally deficient 
and that "welfare cheating" is widespread. Such negative evaluations expressed by the general population seem to be both persistent and deep. A 1969 study of AFDC recipients showed that caseworkers were nearly unanimous in the belief that the community held negative stereotypes about AFDC recipients. The caseworkers themselves viewed welfare recipients in a more favorable light (Katz, 1975: 9).

A 1961 University of Michigan survey found that the terms "welfare" and "relief" evoked a downgrading connotation, flowing at least in part from the popular belief that welfare "chiseling" was widespread (Schiltz, $1970: 155)$.

Three nationwide opinion polls produced results consistent with the general suspicion that there was too much welfare abuse. In 1964 the national Gallup poll asked the following question about welfare: "What proportion of persons do you think are on relief for dishonest reasons--most, some, hardly any, or none?" Seven percent answered "most", while 61 percent more said "some". By 1969, the number of people in the United States who felt that welfare recipients were abusing the system had grown. In a 1969 nationwide poll investigating American attitudes toward poverty and the poor, 71 percent of the public agreed that "many people getting welfare are not honest about their need." And in 1976 the national Harris 
survey found that the public's suspicion of welfare cheating had climbed. Eighty-nine percent agreed that "too many people on welfare cheat by getting money they are not entitled to" (Anderson, 1978: 62).

A number of recent polls also reveal that by substantial margins, the public is in favor of cutting government spenaing on welfare programs. In 1974, a national poll conaucted by the National Opinion Research Center revealed that 42 percent of the public tinought the United states was spending too much on welfare; 32 percent said it was about right; and only 22 percent thought we were not spending enough. A national Roper poll taken in 1973 showed that 48 percent of Americans thought we were spending too much money on welfare. The same question was repeated in 1974 and 49 percent agreed; only 19 percent thought we were spending too little. The more recent national poll of the public attitude toward government spending on welfare was conducted by Harris in 1976. A surprising 58 percent replied that they felt it would be only a "moderate loss" or "hardly a loss at all" if the federal government cut back its programs in welfare by one-third of what it is today (Anderson, 1978: 61).

Attitudes toward welfare cuts may also be related to the rapidly expanding welfare rolls, especially in the AFDC program. In 1950, there were 2.8 million recipients in OAA programs, compared with only 2.2 million AFDC recipients 
(U.S. Census Bureau, 1977). By 1960, the number of AFDC recipients had reached more than 3 million while the OAA rolls declined to 2.3 million recipients. However, the biggest change occurred during the 1960 to 1970 decade. In this period, OAA declined approximately 15 percent to just over 2 million recipients in 1970. The AFDC program, on the other hand, showed rapid growth during the same period. During this ten-year period, the size of AFDC more than tripled, with 9.7 million recipients in 1970. The growth of AFDC has slowed considerably since the early 1970's, but more than 10 million recipients received assistance in 1978 , compared with 4.2 million aged, blinc, and disabled recipients in the SSI program (Social Security Bulletin, June, 1979). These programs are also costly.

The AFDC program has shown rapid growth in terns of expenditures in this thirty-year period. In 1950, total expenditures were nearly $\$ 1.5$ billion for the OAA program, compared with only $\$ 556$ million for AFDC. In 1965, costs of the AFDC program for the first time surpassed the OAA program. In 1970, expenditures for AFDC were more than $\$ 4.8$ billion, while OAA expenditures were less than $\$ 1.9$ billion. In 1978, the AFDC program expended $\$ 10$ billion, in comparison with the $\$ 6.6$ billion for SSI. The rapid growth in welfare programs, in terms of both the number of people served and dollar expenditures, has added to the negative attitudes 
toward welfare. This is particularly true of the AFDC program since it has become the largest cash assistance program, the costliest, and the most controversial in history. It is often cited as "the crisis" in welfare (Handler, 1972). Thus, in light of the rapid growth of welfare programs, it was not surprising to find that many respondents in public opinion polls favor welfare cuts.

Looked at individually, these polls and studies appear to give ambivalent results. The overwhelming majority of Americans seem to have a generous attitude toward the poor and favor government welfare programs for those who cannot care for themselves, while at the same time distrusting tine poor and favoring large cuts in welfare spending. However, when those polls are viewed together, a somewhat different perspective seems to emerge. As Anderson points out, the seemingly ambivalent attitude of the public toward welfare is understandable if one keeps two things separate. First, the overwhelming majority of Americans have no basic quarrel with government welfare programs for poor people. Second, a large majority of Americans also believe that many people now receiving welfare are cheating, getting money or services they are not entitled to, and could be working (Anderson, 1978: 63). Thus, the public favors help for those who cannot help themselves, but not for those who can. This underscores the strong value Americans place on work and self-reliance. 
The approach to welfare for the deserving is favored by the overwhelming majority of the public. 


\section{ATTITUDES OF THE POOR}

Studies concerning the poor's attitudes toward poverty and welfare are reviewed in this section, followed by a discussion of welfare stigma and the labeling process. Do the poor, especially the welfare recipients, share the generally negative views of the public toward poverty and welfare programs? Do the poor internalize the dis-esteem of the larger community and react in terms of labels or some other ascribed characteristics? Do they avoid welfare assistance or is it accepted qladly?

Studies seem to show that the poor themselves generally share the negative attitudes the public has toward the poor and welfare programs. A Gallup poll conducted in 1969, for example, showed that up to 84 percent of the poor queried thought that their poverty was due to lack of effort, or a combination of lack of effort and unfortunate circumstances. One result of such a belief by the poor was the lowered self-esteem of welfare recipients. One indication of lowered self-esteem of welfare recipients comes from scott Briar's study of AFDC-U couples in California. The position these recipients adopted toward the welfare agency was not that of a rights-bearing citizen claiming benefits to which he was entitled by law, but that of "a suppliant seeking in the words of a number of recipients, 'a little help to tide us over until we can get back on our feet 
again'." (Briar, 1966: 53). The majority of the recipients also defended the social worker's close scrutiny of their lives and their control on how the assistance money should be spent. The recipients' attempt to preserve self-esteem was described by Briar as follows:

our respondents almost never (and almost respondents never) referred to welfare recipients as "we" but as "they". This characteristic estrangement--also manifest in a tendency to view oneself as an atypical recipient, a self-conception which seemed to be held by nearly all the recipients interviewed--reflects the desire of these recipients to dissociate themselves from the image they have of other recipients. (Briar, 1966: 51).

Another indication of lowered self-esteem is evident from stuaies showing low participation rates among those who were eligible for public assistance. Piven and Cloward (1972) assert in their controversial book, Regulating the Poor, that stigma has been used to regulate the poor. They contend that the dependent poor were degraded by the welfare officials through various practices to deter them from seeking aid. Their studies in a number of northern cities showed that for every person on the AFDC rolls, there was another who was apparently eligible but not receiving assistance (Piven and Cloward, 1972: 160). Street, et. al., (1979) also point out that only 50 percent of those who presumably would be eligible were on the public assistance rolls in the early 1970's, due to stigmatization that attached to the welfare recipient's role, although 
the current participation rate could be as high as 90 percent. Norman Wyers (1976) also reported underutilization in public assistance, food stamp, and school lunch programs in rural Jackson County, oregon. Of the three deterrents-stigma, information, and time--that Wyers identified, the impact of information costs appeared to be the greatest deterrent, followea by stigma and time. Wyers suspected, however, that information costs were not as serious a problem as was stigma costs. For instance, Wyers contended, both information and time costs may in reality be masks for stigma costs. Rather than reporting shame or embarrassment, individuals may elect to report the inconvenience of time costs or lack of information (Wyers, 1976: 44). Charles Percy, in his investigation of growing old in America, also reported old people's reluctance to apply for assistance. Quoting a welfare aide in New Jersey, Percy wrote: "These are very independent, very proud people and it's difficult to convince them to go on welfare. Some feel it would be a stigma. They spent their whole lives fending for themselves and now they don't want to feel dependent. It's hard to break old habits; they wonder what the neighbors will think" (Percy, 1972: 19). Much of the reason for potential eligibiles to resist public assistance was pride. This was evident in another study that showed that one half of New York City's AFDC recipients who agreed that "getting money from welfare makes a person 
feel ashamed" (Steiner, 1971: 4).

However, the underutilization of welfare is not evident in the lower-class neighborhood or the ghetto. Bernard Beck asserted that the urban ghetto is likely to produce a subcultural isolation (the culture of poverty to be discussed later) capable of reinforcing welfare dependency, in the sense of making it possible for people to enter "welfare careers" without feeling a moral burden in doing so. This is similar to what Chaim Waxman describes as one of the ways a homogeneous minority group would adjust to stigma. According to Waxman, a stigmatized minority group, like members of a ghetto, may reject the statushonor system of the dominant group and maintain its own system where it has the most honor and the dominant group the least (Waxman, 1977: 92). The segregated ghetto has the mechanism by which persons who could consider welfare careers could find themselves mutually reinforcing one another and mutually legitimating the pursuit of such a career while at the same time inhibiting awareness of the moral judgment of members of the greater society. As a result, welfare utilization in ghetto communities is different. Interaction in a ghetto neighborhood is often intense and knowledge about welfare permeates this kind of community. Welfare is not only known and used but also accepted. Louis Kriesberg found that only 5 percent of all the mothers he studied (including 
nonwelfare mothers) said they would think worse of mothers for going on welfare (Rein, 1974: 55). The stigma that supposedly acts as a deterrent to the use of welfare in some other types of areas may not be a pertinent factor here. Rein reported that there is a difference between stigma from the overall community and stigma from one's own community, particularly if it is a ghetto community. Although stigma may flow from the outside community to the welfare recipients, the effect may be nullified by the lack of stigma in the immediate environment (Rein, 1974, 56).

Despite the fact that welfare is used and accepted by members of the ghetto community, recipients of public assistance are still often stigmatized. Stigma is associated with public assistance from the perspective of labeling theory. Following labeling theory, rules are created by social groups and breaking these rules constitutes deviance. People breaking such rules are labeled as outsiders or deviants (Williamson, 1974b). From this point of view, deviance is not a quality of the act the person commits, but rather a consequence of the application by others of rules and sanctions. As a consequence of the labeling process, individuals internalize the stigma attached to such roles and develop a deviant self-image based upon the image of themselves they perceive through the actions of others (Horan and Austin, 1974: 648-650). 
Receipt of public assistance may provide enough visibility to have oneself labeled, and perceived of as being stigmatized. Results from studies seem to support this contention. Kerbo, in his 1972 study of 103 AFDC recipients, reported results which support the stigma internalization thesis. He found that those respondents who felt greater stigma appeared more inclined to be passive, and that recipients accepting the traditional ideology of blaming the poor for poverty were most likely to feel stigmatized by receiving welfare (Kerbo, 1976: 177-179). The findings of this study lend support to the argument that it is the traditional ethic of blaming the poor which is at the root of this stigma. Kerbo's study also found that greater feelings of stigma led to a passive, uncritical orientation toward the welfare system (what Coser calls the "welfare role"). Horan and Austin, from their study of AFDC recipients in a Southern community, concentrated their attention on the social bases of welfare stigma. Using path analysis, they found that more education and longer welfare history had positive effects on feelings of stigma. In another study, Larry Wells examined welfare embarrassment which is a negative and emotionally painful manifestation of a recipient's difficulty in accepting the implications of his new status. The sample consists of 256 new old Age Assistance recipients in California. More than 
half of the respondents felt embarrassed in receiving welfare aid (Wells, 1972: 198). Similar findings are supported by Handler and Hollingsworth's 1967 study of Wisconsin AFDC recipients. They found that more than 50 percent of their respondents possessed some feelings of stigma, especially among the black respondents. As a result of the internalization process, the stigmatized individual responded to the denial of acceptance by "finding that some of his own attributes warrant it" (Handler and Hollingsworth, $1969: 2)$.

A review of past studies suggests that the poor themselves share the public's negative attitudes of the poor and welfare programs. Briar's study showed that welfare respondents tried to dissociate themselves from other recipients by referring to welfare recipients as "they", not "we". Another indication of lowered self-esteem was evident from studies showing low participation rates in welfare programs among those who were eligible for public assistance. Stigma was often cited for such low participation, although Wyers' study also identified information and time costs as important reasons for non-participation. However, welfare underutilization is not evident in segregated urban ghettos. Interaction in a ghetto neighborhood is often intense and knowledge about welfare permeates this kind of community. The stigma that supposedly acts as a deterrent to the use of welfare in the larger community may not be a pertinent factor here. Despite the 
fact that welfare is used and accepted by members of the ghetto community, studies have shown the welfare recipients are still often stigmatized outside of ghettos. More often than not, welfare recipients share the public's generally negative attitudes toward the poor and welfare programs. 
WELFARE AND STIGMA

Erving Goffman (1963) is one of the leading researchers who has studied stigma, its conceptualization, and its effects on social relationship. According to Goffman, when we meet someone for the first time, we immediately form certain impressions and evaluations of that individual. We then proceed to relate to him on the basis of expectations derived from these impressions and evaluations. When we realize that he is not the individual we thought him to be, the whole nature of our relationship must be shifted accordingly. It is in terms of this process that stigma becomes important:

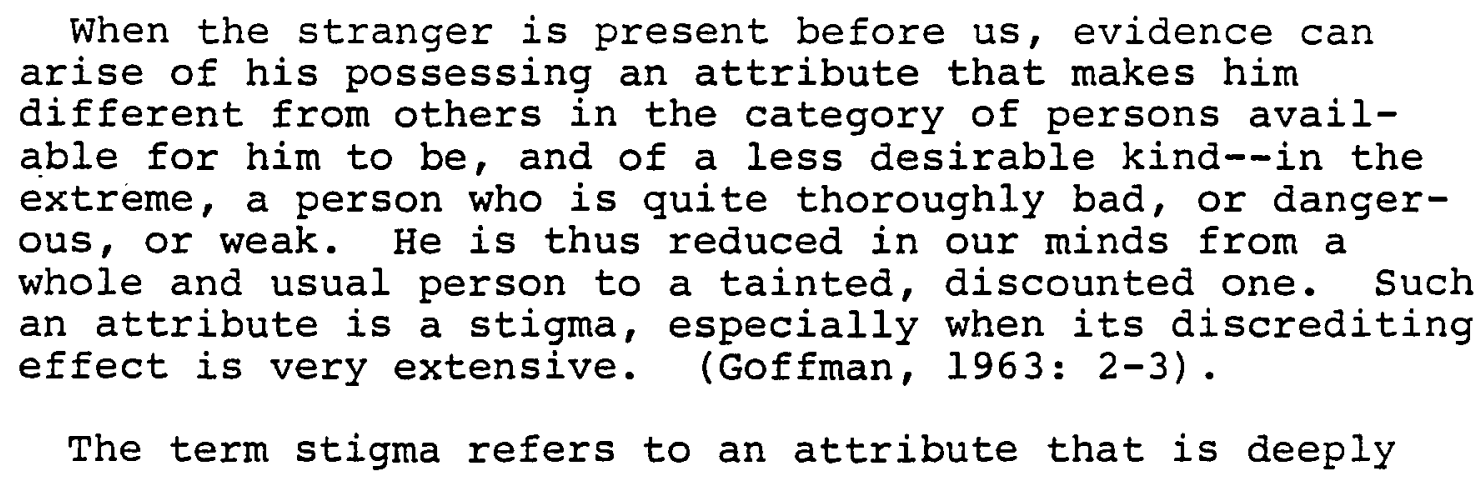
able for him to be, and of a less desirable kind--in the extreme, a person who is quite thoroughly bad, or dangerous, or weak. He is thus reduced in our minds from a whole and usual person to a tainted, discounted one. Such an attribute is a stigma, especially when its discrediting effect is very extensive. (Goffman, 1963: 2-3).

The term stigma refers to an attribute that is deeply discrediting. However, it is not the attribute, per se, that is a stigma, but the "definition of the situation" or the social perception of the attribute which deems it a stigma In this regard, stigma is defined by what Goffman calls "language of relationship"--that is, in the social context. Goffman identifies three types of stigma. First, there are physical deformities of the body. Second, there are 
"blemishes of individual character" such as mental disorder, alcoholism, imprisonment, addiction, homosexuality, unemployment, suicidal attempts, and radical social behavior. The third type of stigma that Goffman identifies includes the stigma of race, nation, and religion (Goffman, 1963: 4). With all three types of stigma, the process and the effect are the same: they interface with what otherwise might have been a normal social relationship. In each case, the individual possesses a stigma, an "undesired differentness from what we had anticipated." According to Goffman, the central feature of the stigmatized individual's situation in life is acceptance". Those who have dealings with him fail to accord him the respect and regard which the uncontaminated aspects of his social identity have led them to anticipate extending, and have led him to anticipate receiving (Goffman, 1963: 8). The stigma of poverty is a special type of stigma which attributes to the poor a status of being "less than human". While the stigma of poverty cannot be pigeonholed neatly into any of Goffman's three types, it has at times resembled the "blemishes of individual character" type. Moreover, in recent years it has taken on a strong dosage of "tribal stigma of race", because of the strong identification or association in the minds of the welfare poor with blacks (Waxman, 1977: 70).

The stigma of poverty that society identifies with the welfare recipients has been emphasized by David Matza's 
conception of "the disreputable poor". The term disreputable introduces no personal judgement but takes into account the judgements made by other members of the society. Being a recipient of welfare assistance is seen as sufficient evidence that the individual is morally defective, not to be trusted and should be constrained in some way by society. Receipt of welfare is sufficient to be labeled and stigmatized.

Matza (1966) conceives the varieties of poverty as concentric circles: the widest circle is composed of all the poor; an intermediary circle, considerably smaller, consists of those who are poor and on welfare assistance; and the smallest circle, the disreputable poor, represents those who are poor, sporadically or permanently on welfare, and, additionally, suffer the special defects and stigma of demoralization. Disreputable, in this regard, is intended to distinguish a segment of the poor rather than to describe all those who are poor (Matza, 1966: 628). Disreputable poverty is where ciemoralization appears as a key feature.

Matza enumerates five characteristics common among AFDC recipients that make them disreputable: (1) illegitimacy; (2) absence of the father due to imprisonment; (3) absence of the father due to desertion and separation without a court decree; (4) lack of status conferred by the man's occupation; and (5) long-term dependency (Matza, 1966: 628-632). Matza claims that this disrepute demoralizes recipients. Lewis Coser (1965) goes further in suggesting that 
public assistance is given only at the price of degradation. In modern societies, according to Coser, the deprived are assigned to the core category of the poor when they receive assistance. Thus, the acceptance of assistance symbolizes a man's formal declassification. The poor are indeed recognized as having a special status in society, but it is a status that is marked only by negative attributes; that is, by what the status-holder does not have. This distinguishes him from any other status-holder in that it does not carry with it the expectation of a social contribution (Coser, 1965: 142). Coser contends that to receive assistance means to be stigmatized and to be removed from the ordinary run of men. Once a person is assigned to the status of the poor, his role is changed. For instance, his right to privacy is denied to him; he is open to scrutiny by social workers; his home territory is invaded; and money from assistance cannot be spent freely. Coser observes that the poor are treated in this respect much like children who have to account to their parents for their wise use of their pocket money; the poor are therefore infantilized through such procedures (Coser, 1965: 145). Thus, Coser argues that degradation is implicit in the situation of assistance since the ordinarily conceived rights of privacy and maturity are partly taken away from them. Irrespective of whether sanctions are taken, the negative moral judgements of officials and the wider society they represent are, as Matza puts it, subtly cued or loudly proclaimed (Matza, 1966: 
656).

Another dimension of the relationship between recipient and society in explaining the morally reprehensive connotation of welfare, is Beck's consideration of welfare as a "moral category" (Beck, 1967).

Beck asserts that there is a folk theory of the structure of society which claims that the accepted way of life works well for everyone. Although for long periods of time reality contradicts this, it does not appreciably affect the members' attachment to the ideal. Society, however, must find a way of accounting for the group of "roleless" people, who are "in the population but outside the positions and careers specified by the Theory" (Beck, 1967: 261). Such an explanation must not violate the belief in the efficacy of the system. The discrepancy is explained by the motivation and character of the people found within the residual category, by their lack of motivation, moral strength, and the like. Thus, people in the residual category have "defaulted on the system rather than being the victims of an inadequately articulated system" (Beck, 1967: 264). A public scandal to the "structure" is thereby avoided.

Beck also asserts that welfare is a categorization of a residual, morally suspect career. As a moral category, welfare is closely related to the nature of rewards and the ways one can deserve to be rewarded. In modern societies, the major source of rewards is through the world of work. 
Welfare is provided to people who have not participated in the system through an automatic reward which carries the stigma of being undeserved. Beck indicates that the institution of welfare in a Western society includes distinctive norms about the proper attitude with which benefits are to be provided to persons: the attitude recipients should show for thebenefits, the kind of treatment permitted to or required of participants in welfare activities, and the self-image to which participants are entitled (Beck, 1967: 266).

The point of acquiring rewards through work is echoed by Rainwater (1974). Rainwater points out that having a job provides "validation" and increases the individual's sense of well-being in several ways. Other than providing the economic resources, a job also provides a set of contacts with others to whom a person can be "someone" (instead of being roleless). The experience of work provides a sense of mastery, of personal effectiveness, which increases the individual's sense of personal well-being. A cause of the poor's lowered selfesteem is not being able to participate in the validating activities of social and economic exchange that a job provides so that welfare becomes "a way of life" (Rainwater, 1974: 31). American society places those who need assistance in the position that most feel that to apply for aid is to be avoided at all costs. Welfare assistance carries neither the connotation of a right nor a contract. There has been no reciprocal arrangement leading to this aid. This lack of 
reciprocity is offered as one possible source for explaining antiwelfare feelings (Gottlieb, 1974: 15).

The strength of this reciprocity is suggested by Gouldner (1960) who describes the norm of reciprocity as a universal attribute that exercises great influence on all kinds of personal interactions. According to Gouldner, reciprocity implied both rights and obligations based on past actions: "We owe others certain things because of what they have previously done for us" (Gouldner, 1960: 17). Gouldner suggests that a norm of reciprocity makes two interrelated demands: (1) people should help those who have helped them; and (2) people should not injure those who have helped them. Certain circumstances allow for the norm of reciprocity to be suspended. Society identifies these different groups. The aged and disabled may be exempt, but not so the ablebodied person who has made no contribution in a reciprocal arrangement (Gottlieb, 1974: 16).

In summary, Goffman defined stigma as attributes that were deeply discrediting. Goffman identified three types of stigma and the stigma of poverty at times resembled two of them. The relationship between welfare and stigma was emphasized by Coser, Matza, and Beck. The receipt of welfare was seen as sufficient evidence that the individual was morally defective. Rainwater and Gouldner contend that with welfare comes a stigma because the aid is not acquired through work or other reciprocal arrangements. This lack of reciprocity has 
been offered as one possible source for explaining antiwelfare feelings. 


\section{LABELING THEORY AND WELFARE STIGMA}

Labeling theory has often been used to explain welfare stigmatization. This theoretical approach has found wide use in the study of both delinquency and mental illness, and attention is focused on the behavioral implications of public identification of an individual as deviant. A major tenet of this approach identifies deviance as an outcome of societal reaction, or labeling by official control bodies. Definitions cause deviant careers by generating the symbolic processes that define the individual negatively. Once stamped as inferior or morally unfit, these individuals undergo a transformation of status.

Working within a normative approach, Davis observes, this approach typically follows the rule breaker as he or she is separated out, processed through the social control agencies, confronted with the formal degradation ceremonies, institutionalized or imprisoned, and subsequently stigmatized with a deviant identity (Davis, 1975: 172). The effect of such legal processing is a durable, if not permanent, loss of status. The "outsider" is created by the forces of law or tradition which also reflect in the rules created by social groups. Becker defines this process as:

All social groups makes rules and attempt, at some times and under some circumstances, to enforce them. 
Social rules define situations and the kind of behavior appropriate to them, specifying some actions as "right" and forbidding others as "wrong". When a rule is enforced the person who is supposed to have broken it may be seen as a special kind of person, one who cannot be trusted to live by the rules agreed on by the group. He is regarded as an outsider (Becker, 1963: 1).

Deviance, in this approach is situational and contingent. It is an outcome of official decisions in a particular context. Deviance results not as a quality of the act the individual commits, but rather a consequence of the application by others of the rules and sanctions.

Once a person is stigmatized by being labeled a deviant, a self-fulfilling prophecy is initiated with others perceiving and responding to the person as a deviant. More importantly, as a consequence of the labeling operation, the individual internalizes the stigma attached to such roles--the development of a deviantself-image based upon the image of themselves they perceive through the actions of others (Horan and Austin, 1974: 649).

Following the labeling approach, the stigma associated with public assistance is the outcome of this labeling process. A number of researchers believe that the. labeling approach provides a useful framework in the analysis of welfare stigma (Horan and Austin, 1974; Williamson, 1974b; Piven and Cloward, 1973; Beck, 1967; Waxman, 1977). From the perspective of labeling theory, stigma is associated with public assistance and recipients are labeled as deviants. Welfare recipients have been defined as psychologically impaired, motivationally 
impoverished, and morally irresponsible. Welfare recipiency alone does not make it deviant. Mechanisms of social labeling must also come into play. While families and peer groups may be highly instrumental in shaping deviant outcomes, formal organizations such as the court and the welfare agency, are important "deviant-dispensing" systems that grind out offenders (Davis, 1975: 180). This is similar to what streets and his associates (1979) call the welfare functionaries who administer and perpetuate poverty. Social welfare bureaucratization and professionalization, according to streets, et. al., can be illustrated in the ways in which agencies define the roles of poor persons who carry with them social labels, such as AFDC mothers.

According to the labeling theorists, institutional power implies the application of stigmatizing labels that push the rule breakers into further deviant behavior, a deviant way of life, and a deviant identity. Once labeled, the acts of the welfare recipients are interpreted in accordance with the deviant status to which persons have been assigned. That such an interpretation or association may be unfounded to a great extent is irrelevant in terms of the stigma label. What is important is the language of relationship. "If a situation is defined as real, it is real in its consequences" (Waxman, 1977: 70). Goffman suggests that the behavior of the stigmatized individual is, to a great extent, a self-fulfilling prophecy as the person having a stigma adjusts to the role prescription 
of how an individual with that stigma is supposed to behave. Merton describes it:

The self-fulfilling prophecy is, in the beginning, a false definition of the situation evoking a new behavior which makes the original false conception come true. The specious validity of the self-fulfilling prophecy perpetuates a reign of terror. For the prophet will cite the actual course of events as proof that he was right from the very beginning (1968: 423).

When the welfare recipients internalize the "spoiled identity" which the stigma label casts upon them, the selffulfilling prophecy is then set in motion. Such a reaction by members of a lower class are likely to result in a cluster of traits that has been described as the culture of poverty. The term "culture of poverty", coined by Oscar Lewis, is based on one of the two major conceptualizations of poverty in American society. One thcory fircia tire explanation of poverty in the characteristics of the poor themselves, in individual character defects or family pathology. A second theory of poverty blames poverty on the structural conditions in society under which the poor live. The culture-of-poverty concept generally falls under the rubric of the first of the two poverty theories. It refers to the lives of the poor who are seen as being different from the non-poor not only economically, but in many other aspects as well. According to this cultural perspective of poverty, the lower class shows patterns of behavior and values which are characteristically different from those of the dominant society and culture. Moreover, Lewis suggests that the culture of poverty transcends regional, 
rural-urban, and national differences and is passed down from generation to generation along family lines (Lewis, 1969: 187).

Lewis argues that the culture of poverty is both an adaptation and a reaction of the poor to their marginal position in a class-stratified, highly individualized, capitalistic society. It represents an effort to cope with feelings of hopelessness and despair that develop from the realization of the improbability of achieving success in terms of the values and goals of the larger society. The culture of poverty consists of at least seventy distinctive traits: such as chronic unemployment; the lack of saving; a short childhood and early initiation into sex; a high rate of illegitimacy and family disorganization; authoritarianism; and a pervasive sense of marginality and fatalism (Feagin, 1973: 147). The number of traits and the relationship between them may vary from society to society and from family to family.

Lewis believed that there is a distinction between poverty and the culture of poverty. There are degrees of poverty and many kinds of poor people. The culture of poverty refers to a way of life shared by poor people in given historical and social contexts. Because of the advanced technology, the high level of literacy, the development of mass media, and the relatively high aspiration level of all sectors of the population, Lewis believes that there is little culture of poverty in the United States. Lewis estimates that up to 20 percent of the population below the poverty line in the United states may have characteristics which would classify their 
way of life as that of a culture of poverty (Lewis, 1969: 196).

The concept of culture of poverty has been subject to criticism by a number of people. Rodman (1971) argues that while this approach can provide a useful way of cataloging poverty characteristics, it often leads to a stereotyped view of the poor which emphasizes negative aspects. The culture-of-poverty approach is also problematical in explaining the heterogeneity of life styles among the poor. Rodman suggests that there exists a "lower class value stretch" in which the lower class person, without abandoning the general values of the society, develops an alternative set of values (Waxman, 1977: 62). The result is that the members of the lower class have a wider range of values in comparison to others within the society. They share the general values of the society with members of other classes, but in addition they have stretched these values, or developed alternative values, which enable them to adjust to deprived circumstances.

The culture-of-poverty concept has also been critized by the structuralists or situationalists who maintain that the culture of poverty is not the cause but the result of the persistence of poverty (Waxman, 1977). According to the structural or the situational perspective, the behavior patterns of the poor are not seen as pathologies nor are they seen as being internally derived as the products of a unique value system. Rather, the behavior patterns of the poor are seen as 
normal results of situations where the dominant social structure poses unfavorable restrictions for the poor. Because the poor do share in the dominant values, they turn to behavior which becomes labeled as deviant and pathological. Thus, the unique patterns of behavior of the poor are inevitable consequences of their occupying an unfavorable position in a restrictive social structure. To effect a change in poverty, following this approach, does not require changing the poor, but rather changing their situation by correcting the restrictive social structure. 


\section{SUMIMARY}

Past research and studies have been discussed concerning the historical development of income-maintenance programs for the poor, attitudes toward the poor and attitudes of the poor, welfare and stigma, and the relationship between labeling theory and welfare stigma.

During the 19th century, the family farm and usually large families generally provided support for the aged poor. Industrialization and reduced househola size were two factors which reduced these sources of support. Before 1935, efforts to assist the aged poor and other poor groups were primarily the responsibility of state and local governments, in the form of categorical aid programs. The development of the categories reflected different public attitudes and different treatment toward the classes of poor. The aged, blind, and disabled were regarded as the "deserving poor" and treated more favorably than were the able-bodied poor. The 1935 Social Security Act emphasized the distinction and brought the federal government into public assistance by creating a social insurance system and a welfare system. Contrary to what Congress had initially planned, the welfare programs have not withered away or dwindled to small residual programs. Between 1935 and 1972, numerous modifications were made in the income-maintenance programs. Nixon's welfare reform 
proposal in 1969 was the major effort in overhauling the total welfare system. The lone part of Nixon's reform plan eventually legislated established the Supplemental Security Income program in 1972 .

A survey of relevant literature reveals that the public has a seemingly ambivalent attitude toward the poor. Numerous polls and studies show that the public overwheliningly accept income-maintenance programs for the poor and favor an all-out effort to end poverty. On the other hand, the poor are disliked and perceived as inherently less worthy than others. Behind this seemingly high support for the poor and assistance programs, studies also show that the general population holds a deep resentment against the poor. Such negative attituajes toward the poor may have been derived in part from the English Poor Laws which punished the poor for not working. Studies on American attitudes toward the poor usually find that the poor should be blamed for their poverty, welfare chiseling is widespread, and government spending on welfare programs should be cut back. When examined on an individual basis, these polls and studies appear to give ambivalent results. When these polls and studies are viewed together, however, a different perspective emerges. The public favors assistance for people who cannot help themselves, but not for people who can or should. This finding underscores the strong value Americans place on work and on individual self-reliance. The approach to welfare for the needy is favored by the majority of the 
public. Again, the public draws a distinction between the "deserving" poor and the "non-deserving" poor.

Studies show that the poor often share the negative attitudes of the general public and internalize the dis-esteem of the larger community. Researchers have argued that the stigma from welfare recipiency is a major deterrent to participation in welfare programs by recipients. No underutilization of welfare, however, is evident in ghetto communities. The segregated ghetto allows people to follow welfare career patterns and mutually reinforce..one another. This legitinatizes regular support from welfare while at the same time inhibiting awareness of the moral judgment of the larger community. The stigma that supposedly acts as a deterrent to the use of welfare may not be so strong a factor in the ghetto community. Despite the fact that welfare is used and accepted by members of the ghetto, studies show that recipients of public assistance in general are still stigmatized.

Erving Goffman is one of the few researchers who studied stigma, its conceptualization, and its effect on social relationship. Goffman defines stigma as attributes that are deeply discrediting. The stigma of poverty that society has of the welfare recipients also has been emphasized by Matza in his conception of the disreputable poor. Coser goes even further by suggesting that public assistance is forthcoming only at the price of degradation. The acceptance of welfare symbolizes a person's formal declassification. Beck considers 
welfare as a moral category and that welfare recipients carry the stigma of being undeserved because of their non-participation in the world of work. This point is also echoed by Rainwater, Gouldner and others who explain the general anti-welfare feelings from the standpoint of reciprocity. Welfare assistance carries neither the connotation of a right to claim benefits nor anything of the character of a contract. There has been no reciprocal arrangement leading to this aid. Certain groups, e.g. the aged and the disabled, however, may be exempt from the norm of reciprocity.

Labeling theory has been used to explain welfare stigmatization. This theoretical approach is found in the studies of delinquency and mental illness. Attention is focused on the behavioral implications of public identification of an individual as deviant. A major tenet of this approach is that deviance is an outcome of societal reaction, or labeling by official control bodies. Once an individual, such as a welfare recipient, is stigmatized by being labeled a deviant, a selffulfilling prophecy is initiated. Once labeled, the acts of the welfare recipient are interpreted in accordance with the deviant status to which the person has been assigned. Others perceive and respond to the person as a deviant. The individual also internalizes the stigma attached to the label and tends to develop a deviant self image. Such a reaction by menbers of a lower class are likely to result in a cluster of traits that has been described as the culture of poverty. 
This term, the "culture of poverty", coined by oscar Lewis, refers to lower class patterns of behavior and values which are different from those of the dominant society. Moreover, Lewis suggests that the culture of poverty transcends regional and national differences and is passed from generation to generation by families. Lewis argues that the culture of poverty is both an adaptation and a reaction of the poor to their marginal position in a class-stratified, highly individualized capitalistic society.

This culture of poverty concept has been criticized by a number of people. Some argue that the concept often leads to a stereotyped view of the poor that emphasizes negative aspects. The concept is also problematical in explaining the heterogeneity of life styles among the poor. The culture of poverty concept has also been criticized by the structuralists or situationalists who maintain that the culture of poverty is not the cause but the result of the persistence of poverty. According to this structural perspective, the unique patterns of behavior of the poor are an inevitable consequence of their occupying an unfavorable position in a restrictive social structure. Structural changes, rather than changing the poor, are needed to effect a change in poverty. 


\section{CHAPTER III}

\section{THE STUDY PROBLEM}

The traditional forms of state and local welfare assistance for the aged, blind, and disabled recipients were shifted to the new federal supplemental security Income (SSI) program in January, 1974. The shift from state and local welfare programs to a nationwide income-maintenance system was initiated for procedural and administrative advantages as well as to benefit individual recipients. The program was deliberately designed so that the participants would be free as far as possible from any stigma of being dependent on welfare. This theme is the central concern of this study. This chapter outlines the study problem: the relationship between welfare stigmatization and the elderly. First, people's perceptions of Social Security and welfare are examined, including the public's view of the Social security Administration. Second, the purpose of designing SSI as a stigma-free program is analyzeä. Finally, the argument that welfare stigma is a legitimate concern and a topic of inquiry is presented.

Social security is most commonly viewed as a system of mandatory insurance. While different in important aspects from private insurance, it is still presented in an image of insurance nonetheless. This analogy shapes the image of social 
Security and influences the prevailing body of beliefs and opinions which govern people's understanding of the system. This identification as insurance has played a major part in developing public support.

The analogy between Social security and private insurance is suggested in a number of ways (Pechman, et. al., 1968). One is by the very titles--social insurance, old-age and survivors insurance, and disability insurance. Contributions are paid by workers and employers into a trust fund; interest is credited on trust fund balances; and benefits are formally based on the worker's earnings.

When the structure of the system is examined, the insurance analogy is no longer applicable to the developed system. The relationship between individual contributions and benefits received is extremely tenuous. As a group present beneficiaries receive far larger benefits than the taxes they paid, especially the lower-earning groups. The essential difference between private insurance and Social security relates to whether an individual in the labor force is paying for his own future benefits (Pechman, et. al., 1968: 70). In individual insurance, each person's premiums are contractually tied to his future benefits. In social security, the level of payroll taxation is set to defray the costs of benefits for the currently retired. The money which workers currently pay into the funds is paid out concurrently as benefits to the current beneficiaries. Therefore, the presentation of social security 
as closely analogous to private insurance is farfetched. Hollister (1974) calls it a social myth fostered by the illusion of a contributory system. Hollister asserts that if one makes explicit the system's function, the system would become a political football (Hollister, 1974: 38). While social security is not strictly insurance in many aspects, the social security system is perhaps the most successful social program in terms of its public acceptance ever enacted by the federal government. Because of its overwhelming acceptance by the public, the social security system has become a permanent government institution. One major reason behind its acceptance is the belief that benefits are earned rights to which no stigma attaches. This contrasts with welfare programs such as AFDC or Old Age Assistance (OAA). OAA has always been perceived as welfare by the public and has not been classed with Social security.

While social security is a universal program benefiting both the poor and the non-poor, OAA is a means-tested program for the poor only. Social security is seen as an earned right to which any worker covered is entitled upon retirement, whether blue-collar, white-collar, or professional. This carries no stigma partly because it is seen as a benefit that is distributed equally and is not a class-specific benefit. As such, it is a benefit with which both the non-poor and poor can identify. It falls into what steiner (1971) calls the subtle technique which spreads benefits across a broad spectrum of the population. 
Part of the success of the Social security system is attributable to the efficient operation of the social security Administration. Of all the federal and state assistance and welfare programs, the public image of the Social Security Administration (SSA) as a government insurance agency has remained strong and untarnished. SSA has a long and distinguished record of efficiency and its operation of the social security program has helped to create wide acceptability of the program. Checking of facts by SSA has been done with due care for the rights and sensitivities of its beneficiaries, with the clear assumption that they are honest people; this is rarely the image of public assistance (Williams, 1973: 13).

On the other hand, welfare programs and local welfare departments have never enjoyed similar high levels of support and acceptance. Because welfare benefits are not earned, welfare recipients are often subject to capricious and degrading means tests. Subject to such features as lien laws and relative responsibility requirements, many poor people are viewed as ineligible for aid or discouraged from applying because of the punitive nature of welfare programs. Means tests, at least in the suspecting and demeaning manner in which they are often administrated, are an indication of the stigmatization which welfare recipients are subject to. While the stigma of poverty has been applied to the entire lower class, the receipt of assistance makes the process of stigmatization very visible. Gottlieb (1974) points out that the 
stigma attached to the welfare check is almost as tangible as the paper it is written on. Potential welfare applicants have to cross a personal and psychological barrier in addition to the legal barrier.

Unlike the Social Security Administration, local welfare agencies do not have high levels of support from the public. one reason is because a public welfare agency faces ambiguities and conflicts over goals. Charged with helping the poor, it must exercise surveillance over poor individuals. Iike the prison system, public welfare agencies derive a lower status in the public mind because of the fact of working with a disesteemed clientele (street, et. al., 1979: 98).

This is the background in which the supplemental security Income (SSI) program was established. This new program promises to alleviate part of the "welfare problem" encountered by the needy aged, blind, and disabled. Specifically, the SSI program aims to reduce the welfare stigma in several ways (Tissue, 1978). A great deal of distance is put between the new program and the old welfare programs. SSI serves the aged, bliI 1 , and disabled only--people who occupy a special moral place in society. Welfare's most controversial beneficiaries--recipients of AFDC-are excluded. Administrative responsibility has been shifted from local welfare agencies to the federal social security Administration. Procedurally, sSI has been organized as a straightforward anō businesslike operation. Intake is routinized and a recipient's personal life is of no concern. 
to SSA. Rules for administering the program are explicit and nationally uniform. Instead of calculating financial need on a case-by-case basis, a presumptive need standard is applied in all cases throughout the federal system.

By dissolving welfare caseloads and reconstituting membership under a new federal authority, it was hoped that recipients would escape the welfare stigma associated with public assistance in the past. Although SSI includes a means test, the test is limited to a mathematical determination of income and assets and not on a human investigation of individual recipient circumstances.

It is not by accident that SSI is operated by the Social Security Administration. Congress sought to make SSI less demeaning than welfare and therefore more acceptable to recipients and the general public. The ideology of Social Security is cast in terms of its benefits being earned as a matter of right. By locating SSI within the Social security Administration, emphasis is placed upon all recipients as deserving (having a right to) SSI payments. This, in essence, compares SSI to Social security and distinguishes it from welfare. The prestige of Social Security Administration was viewed as being able to remove the less than impartial staterun public assistance image to the new federal program. People who were reluctant to apply for welfare would now be more willing to apply for SSI. If SSI could attain the dignity and sense of entitlement of Social Security, the acceptability 
of the program would be more enhanced in the eyes of the recipients and general society.

Williamson's study of 230 white women in Boston suggests that the initiation of a federal guaranteed income program would reduce the stigma for many of those presently on state welfare. However, the data also suggest that the stigma level would remain considerably above that found in a program such as Social security (Williamson, 1974b). While the supplemental Security Income program is not exactly a guaranteed income program, it is a considerable improvement over previous categorical assistance programs and has the same objective of reducing stigma for the recipients. Whether or not stigma has been reduced in the new SSI program depends to a large extent on how the recipients themselves view the program. This is why a study of SSI recipients is important. This study particularly focuses on the elderly group of recipients.

A study of the stigma associated with public assistance can be approached from two perspectives: either from the stigma felt by those who are recipients or from the public's perceptions of this stigma. Because the perception of one influences the other, it is useful to study both groups. When only one group is available to analyze, the preferred focus of analysis of stigma has been with the recipients themselves (Handler and Hollingsworth, 1969, 1971; Briar, 1966; Williamson, 1974b). This is the approach taken by the current study, i.e. stigma perception is examined from the point of view of the recipients. 
Research with labeling theory has found that once a person is labeled a deviant, a self-fulfilling prophecy is developed. The individual internalizes the stigma attached to such a role. To what extent is this true with elderly recipients of SSI? The aged poor have consistently been viewed as deserving and have been given support by most poverty programs. As such, one would believe it would be possible for elderly recipients to internalize the "worthy poor" image instead of the welfare stigma. What effect would the introduction of the SSI program have on the recipients' perception of stigma? As an unbiased federal program, does SSI represent a step forward in terms of reducing welfare stigma? These are some of the questions this study examines.

While this study seeks to understand the relationship between welfare stigma and the elderly, its specific objectives are three-fold. First and foremost, this study examines the usefulness of labeling theory in explaining the stigma perception of the elderly. Second, different amounts of stigma attached to different assistance programs are compared and contrasted. Third, this study also examines why some recipients feel more stigmatized than others.

Much of the research literature has simply assumed the link between public labeling and individual perception of stigmatization. Most of the work based on the labeling perspective has been intuitive or theoretical. There has been very little systematic evaluation and testing of tinis perspec- 
tive. Rather than assuming that recipients respond theoretically to the labeling experience, this study uses the individual's perception of stigma as a measure of the effect of the labeling process on the individual. One result of this study is to initiate empirical research into the determinants and consequences of welfare stigma. 
CHAPTER IV

METHODOLOGY

DATA AND IIMITATIONS

Data for this study is taken from two surveys, one by the Institute on Aging (IOA) at Portland State University, and the other by the Social security Administration. The IOA's Supplemental security Income study collected its data between 1975 and 1977 and drew all its 400 respondents from Multnomah County, Oregon. The Social Security Administration collected data from its Survey of the Low-Income Aged and Disabled (SLIAD Survey) in 1973 and 1974 through a nationwide sample of 17,551 respondents.

In both studies, indepth personal interviews were conducted and a wide variety of questions were asked. Areas covered include demographics; personal history; environmental, social and econoraic questions; health and health care utilization; and attitude responses. For the purpose of this study, emphasis is placed on attitudinal responses of respondents toward assistance programs. To augment the analysis, relevant questions from other sections of the data sources as weli as various secondary sources were used for interpretative and comparative purposes. 
There are basically two limitations in the data when used together, i.e. different sample sizes and different time periods involved. The local sample has only 400 respondents whereas the national sample has over 17,000 respondents (although not all cases were used). However, the SSA study involved both aged and disabled respondents while only aged respondents were included in the local study. For the sake of comparability, only the aged portion of national sample $(n=8594)$ was used in this study. Although the difference in subsequent sample sizes is still great, such a difference in itself should not nullify the validity of the analysis. One possible effect of the small sample size in the local study might be that the results cannot be readily generalized to other communities.

The second limitation in the data sources concerns different time periods used. The Social security Administration collected its data in 1973 (final year of state-run OAA) and in 1974 (first year of federal SSI) for its national study. This is a two-stage before-and-after survey. There is no problem with this time frame because respondents were asked their attitudes toward programs still in effect. However, this cannot be said of the local SSI study where the field work was done between 1975 and 1977. This presents two problems. First, the two data sources refer to different time periods (73-74 versus 7577), thus subjecting the validity of comparison to what Campbell and Stanley call history, maturation and other confounding effects. 
The seriousness of this problem is somewhat reduced, partly because of the fact that the two studies are not treated as experimental designs and partly because only data from the first two years in the local sample are used. A second problem with the local sample is that the first wave interviews were conducted some 18 months after the inception of the SSI program. When respondents were asked about items concerning the old OAA program, they had to rely on their short-term memories which sometimes can be a problem in historical studies. Certain items cannot be directly compared with the national sample because of the different time frames.

\section{THE SAMPLES}

The respondents of the local SSI study were drawn from a group of elderly who participated in a study conducted by IOA over the May 1972 to June 1973 period. This earlier project, an evaluation of an Areawide Model Project for the elderIy in Multnomah County, identified the study population through an elaborate intake, screening, social service needs assessment, and follow-up process. More than 2700 persons were screened and 2106 were selected for the study on the basis of some general characteristics $(65$ years of age or older; no younger person in the household; and an income of not more than $\$ 250$ per month). Additionally, the study population was screened according to theoretically determined high priority criteria (dominant physical disorders; severely restricted mobility; 
little or no social contact; and no linkage to social services). As a result of focusing on these criteria, the chosen study population is atypical of the elderly population as a whole. They are very similar to the marginally subsisting urban elder1y. In sum, almost 900 of the highest priority members of the study population were traced. From this group, 400, or about $45 \%$, were contacted and interviewed to make up the SSI survey sample. The same group was traced and reinterviewed in 1976 and 1977. Figure 1 on the following page details the sample selection process from 1973 through 1977. 


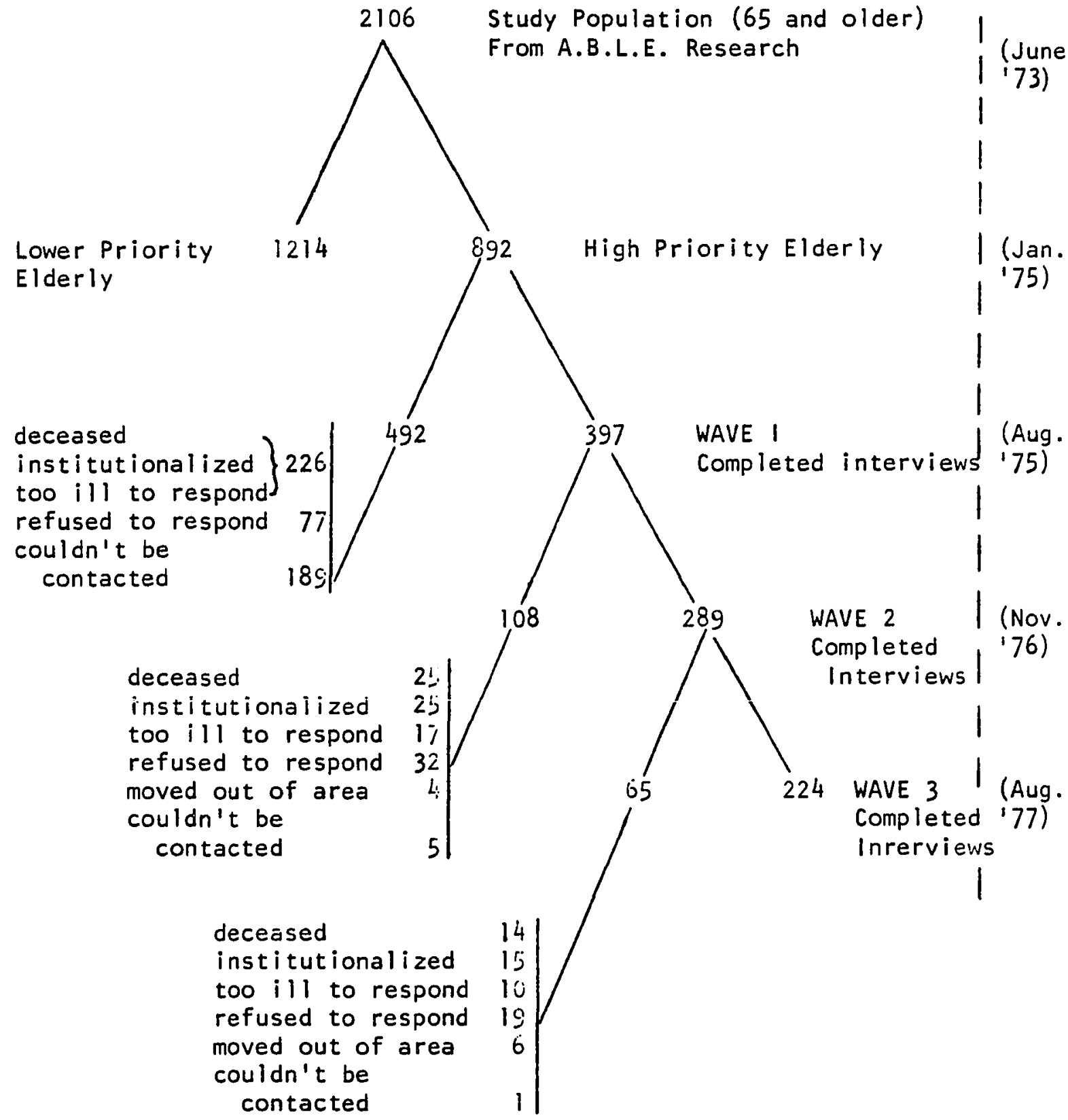

Figure 1. Illustration of Sample Selection and Interview Attrition Process for Local Sample. 
The national sample for SSA's Survey of the Low-Income Aged and Disabled (SLIAD) was obtained through a different process. Since development of an original sampling frame was out of the question because of budgetary and time limitations, the sampling resources immediately available were located and tailored to SLIAD's needs. The individuals automatically eligible and those potentially eligible for the supplemental Security Income program formed the study population of SLIAD. They are represented by four national samples. Two samples are of aged and disabled persons who in 1973 received welfare payments under the Old Age Assistance (OAA), Aid to Blind (AB), and Aid to the Permanently and Totally Disabled (APTD) programs; two others are of low-income aged and disabled persons in the general population. Only the sample selection process for the aged samples is described because they form the basis of analysis of this study. Sample selection for the blind and disabled followed a similar process and were not used in this study. The Social Security Administration developed a stratified multistage cluster design to select individuals for the welfare aged. The sampling frame was the lists of OAA recipients submitted to SSA by state welfare agencies as part of the transfer of caseloads from state programs to the new federal SSI program. The recipient population was grouped into primary sampling units (PSU) similar to those used by the Census Bureau for the Current Population Surveys. The U.S. was divided into different strata and sub-strata with the final selection taking into 
consideration the size of the welfare population and the size of the census population. A total of 6200 cases were selected and 5192 interviews completed in 1973.

Obtaining a national sample for the low-income aged in the general population was more difficult. Since no agency maintained current and comprehensive rosters of old and poor people who did not receive public assistance, the list of 50 , 000 households in the Census Bureau's Current Population Surveys was used to generate cases for the low-income aged. An individual was defined as "aged" if he or she had reached his or her 65 th birthday. Low income was defined as annual income below $\$ 5000$ for single persons and below $\$ 6500$ for married couples. In all, the screening process identified 4805 eligible cases and 3402 interviews were completed in 1973.

The two national samples yielded a total of 8594 completed interviews out of 11005 cases. 2411 cases were lost due to various reasons such as unable to contact, deaths, institutionalization, refusals, etc. Whenever it was possible, the interview was conducted with the designated sample person. If the sample person was at home but unable to participate due to poor health, a proxy person intimately acquainted with the sample person was selected. The proxy was asked about the sample person's objective circumstances and experience but was not required to estimate his attitudes, preferences, or opinions. All sample members who had completed the 1973 questionnaire were traced and reinterviewed. Of the 8594 
cases, 7641 interviews were completed in 1974. Table I shows the number of interviews and noninterviews for both years. 
TABLE I

INTERVIEWS AND NONINTERVIEWS, SLIAD SURVEY, 1973 AND 1974

\begin{tabular}{|c|c|c|c|c|c|c|c|c|}
\hline & \multirow{2}{*}{$\begin{array}{l}\text { Total } \\
\text { Cases } \\
\text { Selected }\end{array}$} & \multirow[b]{2}{*}{$\begin{array}{l}\text { Inter- } \\
\text { Views }\end{array}$} & \multicolumn{6}{|c|}{ Noninterviews by reasons } \\
\hline & & & $\begin{array}{l}\text { Cannot } \\
\text { Contact }\end{array}$ & $\begin{array}{l}\text { Institut- } \\
\text { ionalized }\end{array}$ & Deceased & Refused & 0thers & Spouse \\
\hline $\begin{array}{l}\text { Welfare aged: } \\
\qquad 1973\end{array}$ & 6200 & 5192 & 119 & 410 & 319 & 48 & 112 & \\
\hline 1974 & 5192 & 4599 & 35 & 205 & 308 & 19 & 26 & \\
\hline \multicolumn{9}{|l|}{$\begin{array}{l}\text { General Popula- } \\
\text { tion aged: }\end{array}$} \\
\hline 1973 & 4805 & 3402 & 190 & 52 & 74 & 109 & 47 & 931 \\
\hline 1974 & 3402 & 3042 & 7 & 62 & 163 & 104 & 24 & \\
\hline \multicolumn{9}{|l|}{ Total in sample: } \\
\hline 1973 & 11005 & 8594 & 309 & 462 & 393 & 157 & 159 & 931 \\
\hline 1974 & 8594 & 7641 & 42 & 267 & 471 & 123 & 50 & \\
\hline
\end{tabular}




\begin{abstract}
ANALYSIS
For a given research design, there are usually alternative statistical tests available, and it is necessary to employ some rationale for choosing among them. In choosing a statistical test, there are a number of decisions to make, such as the manner in which the sample was drawn, the nature of the population from which the sample was drawn, as well as the levels of measurement of the variables involved. When certain assumptions are met, parametric tests are usually more powerful than nonparametric tests in terms of rejecting the null hypothesis when it is false. However, there are usually more assumptions that have to be met in using parametric tests, such as normal distribution of populations, measurement of at least interval level, etc. When some of these conditions cannot be met, it becomes a choice of either using a more powerful parametric test while violating some of its assumptions, or using a less powerful nonparametric test. The position taken in this study is that if slight deviation in meeting the assumptions underlying parametric tests did not have radical effects on the findings, parametric tests would be used. Specifically, the following techniques were used.
\end{abstract}


Frequencies and Crosstabulations. Preceding all the other statistical techniques, an initial examination of the distribution of responses to the relevant questions were made. The absolute and relative frequencies provide a simple description of the study samples. For example, percentage distributions were used to describe respondents' feelings of stigma in the three items making up the stigma index. Additionally, other summary statistics of central tendency and dispersion provide clues for the use of more sophisticated techniques.

Crosstabulations, on the other hand, can be used to examine the relationship between two or more variables, provided their distributions do not involve too many categories. The chi-square statistic can be used as a measure of statistical dependence between two variables whereas the contingency coefficient and similar statistics are measures of the strength of association. Like frequencies, crosstabulations also provide clues on the use of more powerful statistical techniques.

Correlations and Regressions. The Pearson product moment correlation, a parametric measure of association, were used whenever the variables were of a continuous or wellordered nature. The correlation coefficient can be understood as indicating the extent to which variables $X$ and $Y$ covary, in relation to the total amount of variation in both 
$X$ and $Y$. The sign (positive or negative) indicates the direction of the relationship; a positive sign indicates that there is a direct relationship between variables $X$ and $Y$ and $a$ negative sign indicates an inverse relationship. The absolute value of the coefficient, $r$, indicates the strength of the relationship; $r=1$ indicates a perfect linear relationship and $r=0$ indicates that there is no linear relationship. If $r$ is squared, the resulting number, $r^{2}$, can be interpreted as the proportion of variance that the variables have in common.

Correlation analysis was used extensively in the data analysis. For instance, $r$ was used to test the relationship between age and stigma. Depending on the sign and value of $i$, one could tell whether or not the age of the respondents was statistically related to feelings of stigma.

The use of bivariate correlation analysis can be extended to multivariate analysis, such as multiple regression. Multiple regression allows one to study the linear relationship between a number of independent variables and one dependent variable while taking into account the interrelationship among the independent variables. The basic concept of multiple regression is to produce a linear combination of independent variables which will correlate as highly as possible with the dependent variable. This linear combination can then be used to "predict" values of the dependent variable from known values of the independent variables. Multiple 
Regression also provides understanding of the relation of each independent variable with the dependent variable, by examining the regression coefficients and the beta weights. Another type of useful information yielded in multiple regression is the multiple correlation coefficient. The square of its value, $\mathrm{R}^{2}$, multiplied by 100 indicates the percent of variance in the dependent variable that is predictable on the basis of the independent variable.

Path Analysis. Although longitudinal analysis is not the primary concern of this study, an attempt was made to use path analysis. Path analysis was used to decompose the relative effect of a set of demographic variables on the stigma variable in the analysis. Path analysis uses the technique of multiple regression to decompose and evaluate the causal relationship within an ordered, closed system. The decomposition can be separated into two components: the unique, direct effect of one variable on another, and an effect mediated by intervening variables (the indirect effect). These effects are combined to derive a weight (path coefficient) for each causal link specified in the model.

Factor Analysis. Factor analysis is another extension of correlation and regression techniques. The most distinctive characteristic of factor analysis is its data-reduction capability. Given a number of variables and its correlation matrix, factor-analytic techniques enable one to determine 
whether the given set of variables can be reduced to a smaller set of common factors or underlying dimensions.

Common applications of factor analysis include exploratory uses, confirmatory uses, and uses as a measuring device. In the study, factor analysis was used in the construction of the stigma index from three variables. The procedure is described in the next chapter.

t-Tests. The t-test procedure is often used to determine whether the differences between two samples means on some measured characteristics (e.g. income) are large enough to conclude that the corresponding population means are actually different. This statistic can be used to compare either the means of two independent samples or the means of two variables from the same sample. The latter variation is known as t- test for correlated data or repeated-measures $t$-test. It was used in the current study to compare the stigma feelings of the OAA and SSI recipients in the national sample.

The sources of data, sampling methods, and the types of statistical techniques used in the study have been presented in this chapter. The following chapter focuses on the construction of indexes important to the study. 


\section{CHAPTER V \\ CONSTRUCTION OF INDEXES}

Two indexes were designed and built in this study. The first one was the stigmaindex, developed from a combination of three items. The second one was a socio-economic status (SES) index, constructed from recoding an item concerning the respondent's former occupation. The construction of each of these indexes and the theoretical underpinnings are described below.

\section{THE STIGMA INDEX}

The most important dependent variable in this study is welfare stigma. While the concept of welfare is easier to define or understand, stigma could mean different things to different people. Erving Goffman depicts stigma as an attribute that is deeply discrediting. For Goffman, a stigmatized person is reduced "from a whole and usual person to a tainted, discounted one" (Goffman, 1963:3). Nanette Davis, on the other hand, points out that stigma conjures up images of blemished selves and discredited bodily or moral attributes that automatically exclude the bearer from the competitive game by assigning labels of inferiority (Davis, 1975: 174). Elsewhere in the literature of stigma, stigma has been defined 
in terms of "shame and moral inferiority", "societal disapproval" (Handler and Hollingsworth, 1969, 1971; Tissue, 1978): "disrepute" (Matza, 1966); "lack of credentials", "rolelessness", "residuals" (Becker, 1967); "degradation" (Coser, 1965) and "embarrassment" (Wells, 1972; Goffman, 1956). Methodologically, there have been various attempts to measure stigma. Most of these attempts measured stigma in terms of two or three items that were presumed to represent different dimensions of the concept. An early attempt using this approach was made by Handler and Hollingsworth (1969, 1971), using two items. Their two items, with some variations, have been followed by many other later studies, including this one. In measuring the welfare stigma felt by AFDC recipients in Wisconsin, Handler and Hollingsworth utilized the following two items:

(1) Whether AFDC recipients feel embarrassed or uncomfortable about receiving welfare support when they are with friends or other people not on AFDC;

(2) What are the welfare recipients' perceptions of the community attitudes towards them, from very understanding to very hostile.

Handler and Hollingsworth did not construct a welfare stigma index from these two items, but used the two items separately in their analysis. 
Larry Wells, in his study of old Age Assistance recipients in California, used two items to measure welfare embarrassment (Wells, 1972). Besides the embarrassment item used earlier by Handler and Hollingsworth, Wells also designed a bother item in his study. The question was: "Are you ever bothered by the idea that you need help from the county now that you are older?" Again, no single index was constructed. Instead, respondents giving a positive response to either item were classified as welfare embarrassed.

In yet another study, Horan and Austin used two slightly different items in their study of welfare stigma (Horan and Austin, 1974). They built a stigma index from responses to two items:

(1) How often do you feel ashamed about being on welfare?

(2) How often do you feel bothered by being on welfare?

Responses fell from (1) "Never" to (4) "Always". The Welfare stigma Index was constructed by summing an individual's responses to the two questions and thus ranged from a low of two to a high of eight. It was treated as an interval-scale variable.

Harold Kerbo, in his study of AFDC recipients in a Midwestern urban area, followed Handler and Hollingsworth closely in his measurement of welfare stigma (Kerbo, 1976). In addition to the two items originally used by Handler and 
Hollingsworth (Embarrassment; community understanding/ hostility), Kerbo also used a third item to measure welfare stigma. This item was: "Have you or your children had any difficulties or problems with people or businesses in the community that you think happened because you are a welfare recipient?"

Kerbo build his welfare stigma index by totaling all three items. The range of responses were then dichotomized at the median to yield two groups, those feeling little or no stigma and those feeling high levels of stigma.

A more recent study of welfare stigma using the same approach was undertaken by Thomas Tissue (Tissue, 1978). The three items used to measure stigma associated with the Old Age Assistance program and the Supplemental security Income program were: (1) the bother item; (2) the embarrassment item; and (3) the community understanding/hostility items. However, no single index was constructed and the three items were treated separately in Tissue's analysis.

In another study of stigma, williamson used a different approach (Williamson, 1974b). In Williamson's study, stigma was not measured directly, but was assumed to exist in public aid programs. The study was designed to assess stigma associated with thirteen social welfare programs and proposals. 
As the standard for comparison, Unemployment Compensation was arbitrarily given a rating of 100. Respondents were asked to rate the amount of stigma associated with being a recipient of each of the other twelve programs relative to that associated with Unemployment Compensation. Findings of the study show that mean values range from 27 for social security to 137 for General Relief.

In this current study, a welfare stigma index was constructed using the technique of factor analysis. The index was constructed from these three items:

(I) Bothered in accepting public aid (Yes; No)

(2) Embarrassed to admit welfare aid status (Very embarrassed; somewhat embarrassed; not embarrassed)

(3) Community disrespect for welfare recipients (Yes; No)

Two data sets (from a national and a local sample respectively) have been used for this study and the above items were asked of three groups of recipients lold Age Assistance and Supplemental security Income recipients for the national sample, and old Age Assistance recipients for the local sample). As a result, three indexes were constructed. However, because of the fact that coding on one item was done differently between the national and the local sample, the subsequent national indexes and the local index cannot 
be compared directly. Construction of indexes for the national sample will be detailed first.

TABLE II

CORRELATION MATRIX OF STIGMA ITEMSNATIONAL SAMPLE, OA

$\begin{array}{llll} & \text { V577 } & \text { V578 } & \text { V579 } \\ \text { V577 } & 1.00000 & .51938 & .29385 \\ \text { V578 } & & 1.00000 & .40120 \\ \text { V579 } & & & 1.00000\end{array}$

V577 = Bothered to accept aid

V578 = Embarrassed to admit aid status

V579 = Perceived community disrespect

To use the factor analysis approach in building a composite index, the variables in question should have relatively high correlations and high loadings on a single factor. Correlations between the variables in the above table are rather high considering the distributions of the variables. The following table also shows that the variables load heavily on the factor.

TABLE III

FACTOR MATRIX USING PRINCIPAL FACTOR, NATIONAL SAMPLE--OAA

Factor 1

$\begin{array}{ll}\text { V577 } & .78709 \\ \text { V578 } & .84312 \\ \text { V579 } & .69737\end{array}$


In order to build the stigma index, the factor-score coefficient matrix was employed. While the factor loadings can be interpreted as correlations between variables and the factor, factor-score coefficients are weights to estimate the factor from variables. The stigma index in fact represents factor scores for the individual data cases calculated from the factor-score coefficient matrix. The factor-score coefficient matrix generated from the SPSS run is:

TABLE IV

FACTOR-SCORE COEFFICIENT MATRIX

Factor I

$\begin{array}{ll}\text { V577 } & .43325 \\ \text { V578 } & .46410 \\ \text { V579 } & .38387\end{array}$

To obtain factor scores for individual cases, one can either output the factor score records in a raw data file and add to the original file on a subsequent ADD VARIABLES run (see SPSS Manual, Section 11.2), or obtain the same results using a COMPUTE procedure:

COMPUTE

$$
\begin{aligned}
& \text { STIGMA INDEX } \\
&= F S C_{v 1}(\mathrm{~V} 1-\overline{\mathrm{V} 1}) / S D_{v 1}+ \\
& \mathrm{FSC}_{\mathrm{V} 2}(\mathrm{~V} 2-\overline{\mathrm{V} 2}) / \mathrm{SD}_{\mathrm{V} 2} \\
& \mathrm{FSC}_{\mathrm{V} 3}(\mathrm{~V} 3-\overline{\mathrm{V} 3}) / \mathrm{SD}_{\mathrm{V} 3}
\end{aligned}
$$

Where FSC = factor score coefficient

$\overline{V I}=$ mean of variable $I$

$S D_{v l}=$ standard deviation of variable $l$ 
For our current data, this new factor-scale variable (stigma index) could be constructed by substituting in the preceeding procedure the following values:

COMPUTE STIGMA INDEX

$$
\begin{array}{r}
=.43325 \times(V 577-1.7418) / .4377+ \\
.46410 \times(V 578-2.7397) / .5714+ \\
.38387 \times(V 579-1.8590) / .3480
\end{array}
$$

Since factor scores are standardized variables, one would expect to see a mean value of zero and a standard deviation of one for this newly created stigma index. The following frequency distribution does show the expected results: 
TABLE V

\begin{tabular}{|c|c|c|}
\hline \multicolumn{3}{|c|}{ FREQUENCY DISTRIBUTION OF STIGMA } \\
\hline & $\mathrm{N}$ & 8 \\
\hline-3.0946 & 129 & 3.4 \\
\hline-2.2824 & 114 & 3.0 \\
\hline-2.1048 & 19 & .5 \\
\hline-1.9916 & 86 & 2.3 \\
\hline-1.4702 & 65 & 1.7 \\
\hline-1.2926 & 32 & .8 \\
\hline-1.1975 & 204 & 5.4 \\
\hline-1.0019 & 20 & .5 \\
\hline-0.4804 & 176 & 4.6 \\
\hline-0.3673 & 382 & 10.1 \\
\hline-0.1897 & 130 & 3.4 \\
\hline \multirow[t]{2}{*}{0.6225} & 2438 & 64.2 \\
\hline & 3795 & 100.0 \\
\hline $\begin{aligned} \text { Mean } & =0.000 \\
\text { Mode } & =.623 \\
\text { ance } & =1.000\end{aligned}$ & $\begin{array}{c}\text { Median } \\
\text { S.D. }\end{array}$ & $\begin{array}{l}=.591 \\
=1.000\end{array}$ \\
\hline
\end{tabular}

After a scale or index has been constructed, it should be representative of the variables from which the index was constructed. One way to do this would be to check the correlation coefficients between each of the original variables and the index. High correlation coefficients generally mean that the index is representative of the variables. 


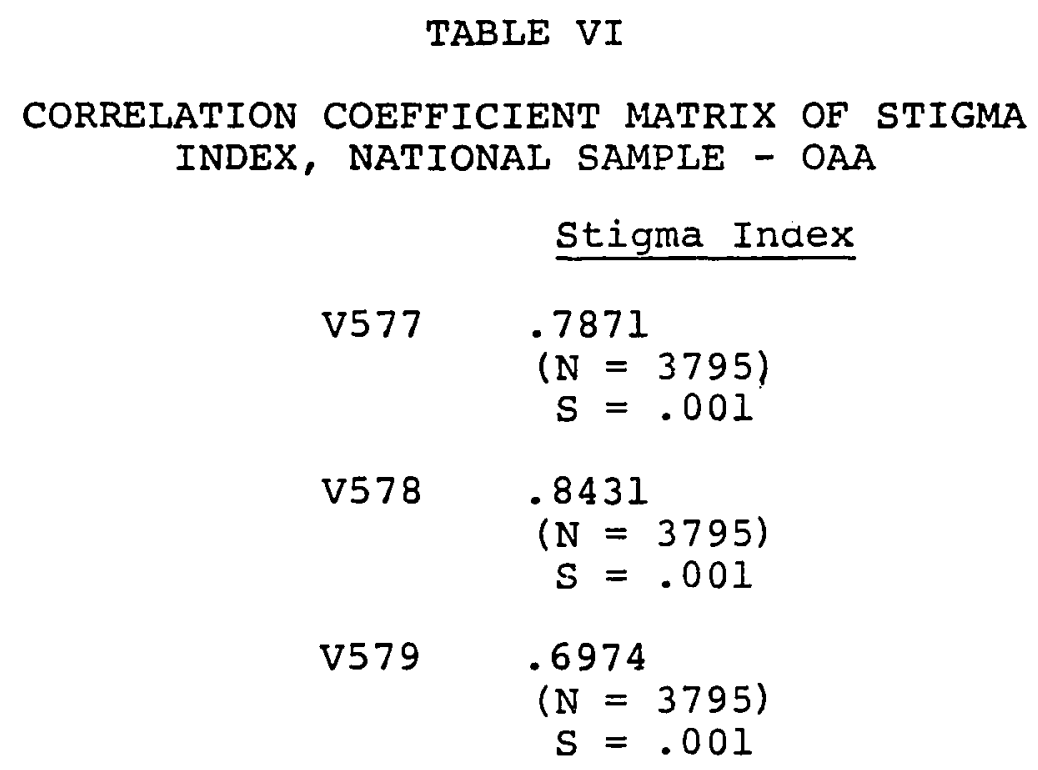

The above table shows that there are indeed high correlations between the variables and the stigma index, with values ranging from .70 to .84 . These high correlation coefficients thus indicate that the stigma index is a good representation of three variables involved. For each of the correlations, the significance of the relationship is beyond the .001 level.

Using the same factor analytical approach, stigma indexes were also constructed for the SSI recipients of the national sample and the OAA recipients of the local sample. The following tables show the procedure in constructing the stigma index for the SSI recipients of the national sample. 
TABLE VII

\begin{tabular}{cccc}
\multicolumn{4}{c}{ CORRELATION MATRIX OF STIGMA ITEMS, } \\
NATIONAL SAMPLE - SSI \\
VV965 & VV964 & VV967 \\
VV965 & 1.00000 & .34619 & .25110 \\
VV964 & & 1.00000 & .28601 \\
VV967 & & & 1.00000
\end{tabular}
Where VV965 = Bothered to accept aid VV964 = Embarrassed to admit aid status VV967 = Perceived community disrespect

Correlation coefficients for the SSI recipients were not as high as those for the OAA recipients. But these correlation coefficients are still substantial, considering the range of distribution of the variables (VV965 and VV967 = 1 , 2; VV964 = 1, 2, 3). When examining the factor loadings, the three variables all load substantially on the factor.

\section{TABLE VIII}

FACTOR MATRIX USING PRINCIPAL FACTOR, NATIONAL SAMPLE - SSI

\begin{tabular}{cc}
\multicolumn{3}{c}{ Factor 1} \\
VV965 & .73709 \\
VV964 & .76253 \\
VV967 & .68258
\end{tabular}

These loadings can be interpreted as correlations between the variables and the factor. The high loadings indicate that the factor is indeed a good representation of the 
three variables. As such, factor analysis is an appropriate technique to use in constructing the stigma index. The following factor-score coefficients are the weights used in building the index.

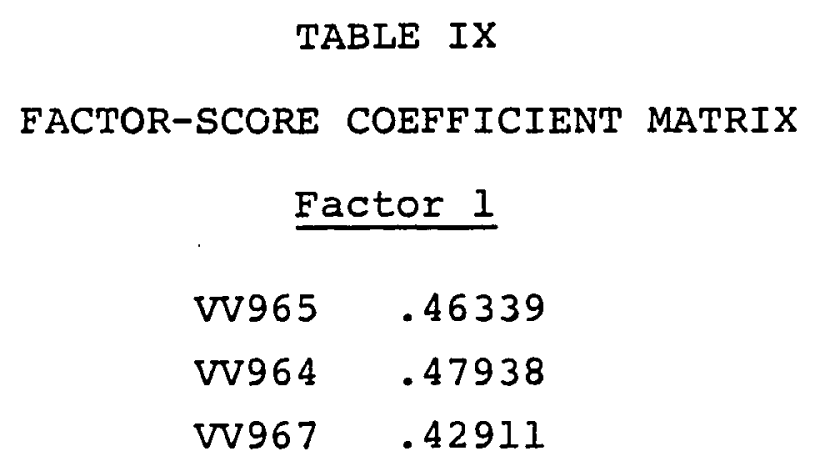

The following table shows the distribution of the new variable of stigma index. 
TABLE X

\begin{tabular}{|c|c|c|}
\hline \multicolumn{3}{|c|}{ FREQUENCY DISTRIBUTION OF STIGM } \\
\hline & $\mathrm{N}$ & 8 \\
\hline-4.8397 & 28 & 1.0 \\
\hline-3.6031 & 39 & 1.3 \\
\hline-3.4600 & 8 & .3 \\
\hline-3.4245 & 13 & .4 \\
\hline-2.3666 & 44 & 1.5 \\
\hline-2.2235 & 19 & .7 \\
\hline-2.1880 & 47 & 1.6 \\
\hline-2.0449 & 15 & .5 \\
\hline-1.1301 & 2 & .1 \\
\hline-.9869 & 153 & 5.3 \\
\hline-.9515 & 201 & 6.0 \\
\hline-.8083 & 55 & 1.9 \\
\hline .2496 & 5 & .2 \\
\hline .2851 & 3 & .1 \\
\hline .4282 & 2246 & 77.2 \\
\hline \multirow[t]{2}{*}{1.6647} & 32 & 1.1 \\
\hline & 2910 & 100.0 \\
\hline $\begin{aligned} \text { Mean } & =.000 \\
\text { Mode } & =.428 \\
\text { iance } & =1.000\end{aligned}$ & $\begin{array}{c}\text { Median } \\
\text { S.D. }\end{array}$ & $\begin{array}{l}=.423 \\
=1.000\end{array}$ \\
\hline
\end{tabular}

As expected, the new stigma variable has a mean value of zero and a standard deviation of one. Again, to check whether this newly created index is a good representation of the three original variables, a Pearson correlation run was made. 


\section{TABLE XI}

\section{CORRELATION COEFFICIENT MATRIX OF STIGMA INDEX, NATIONAL SAMPLE - SSI}

$\begin{array}{ll} & \text { Stigma Index } \\ \text { VV965 } & .7371 \\ & (N=2910) \\ & S=.001 \\ \text { VV964 } & .7625 \\ & (N=2910) \\ \text { VV967 } & S=.001 \\ & .6826 \\ & (N=2910) \\ & S=.001\end{array}$

These high correlation coefficients of three variables and the stigma index, with values ranging from .68 to .76 , do confirm the belief that the stigma index is a good representation of the three variables involved. Each of the three relationships is also significant beyond the .001 level.

The third and last welfare index was constructed for the OAA recipients of the local (Multnomah County) sample. Because of the fact that the three stigma items were not asked of the SSI recipients, a similar stigma index could not be constructed for this group.

The same factor-analytical technique was used in constructing this welfare stigma index. To do this, the first step again was to inspect the correlation coefficients between the three stigma variables. 
TABLE XII

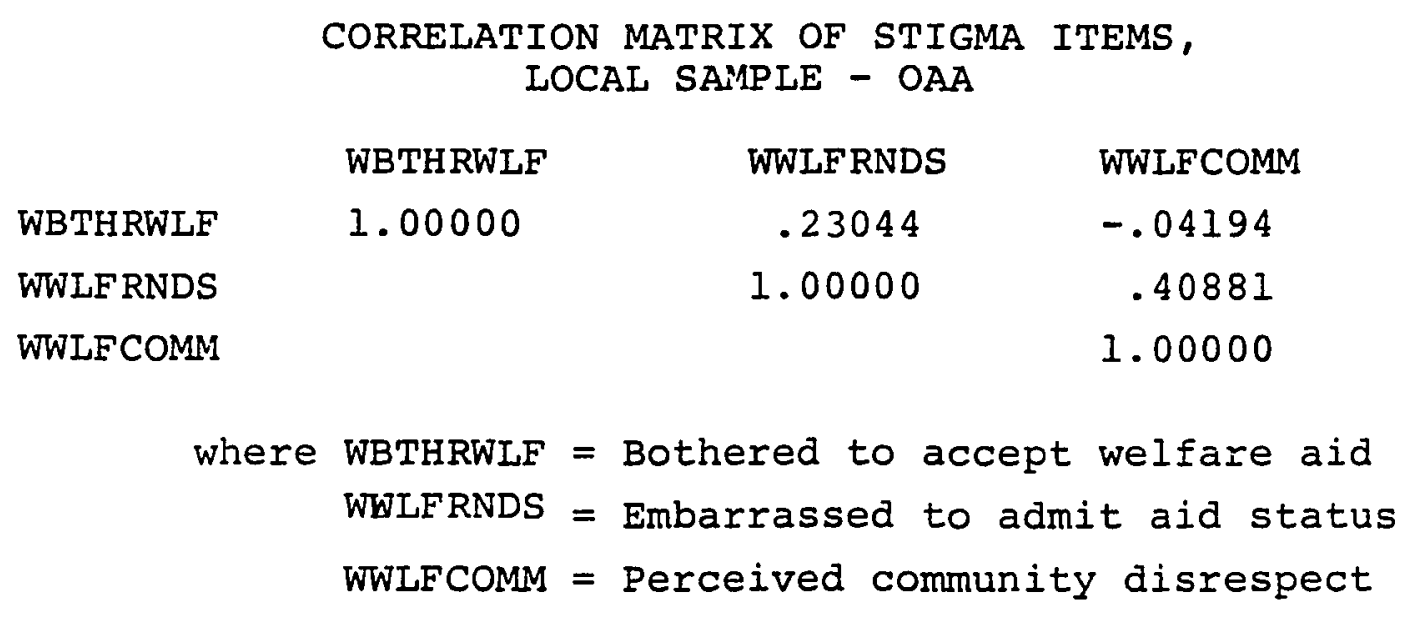

The above correlation matrix does show two relatively high coefficients. However, the correlation coefficient between the first and the third variable (bother and community disrespect) is low and negative. A possible explanation could be due to the small sample size $(\mathrm{N}=62)$. However, the factor loadings are quite substantial, as shown by the following table.

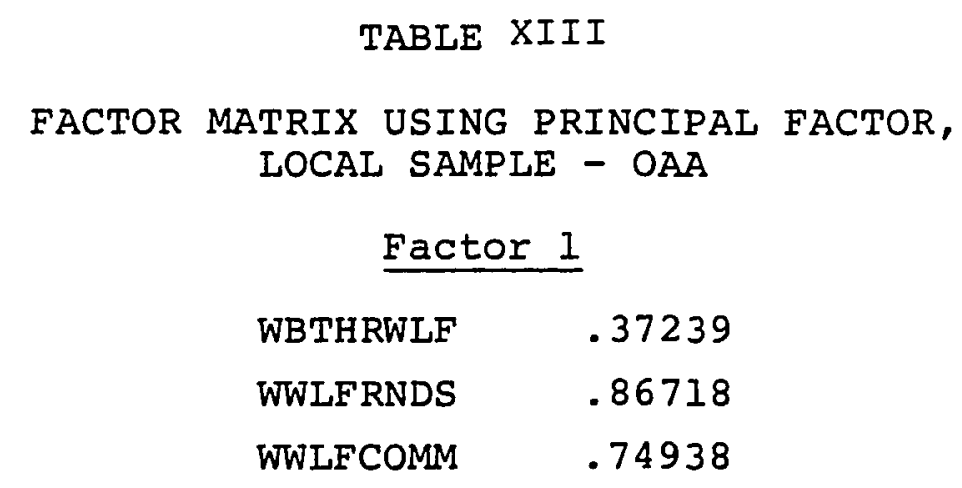

These factor loadings show the relationship between each of the variables and the factor. Even the weakest loading between the first variable and the factor has a value of 
.37. As such, the factor is still a good representation of the three variables involved. The following table shows the weights used in calculating factor scores for individual data cases.

TABIE XIV

FACTOR-SCORE COEFFICIENT MATRIX

Factor 1

WWBTHRWLF $\quad .25643$

WWLFRNDS $\quad .59713$

WWLFCOMM $\quad .51602$

As expected, the distributions of this newly created

stigma index show a mean value of zero and a standard deviation of one. 
TABLE XV

\section{FRQUENCY DISTRIBUTION OF STIGMA INDEX,} LOCAL SAMPLE - OAA

\begin{tabular}{rrr} 
& \multicolumn{1}{c}{$\mathrm{N}$} & $\frac{8}{7}$ \\
-1.5420 & 11 & 17.7 \\
-.9720 & 5 & 8.1 \\
-.9481 & 2 & 3.2 \\
-.4021 & 2 & 3.2 \\
-.3300 & 2 & 3.2 \\
.2580 & 7 & 11.3 \\
.2638 & 1 & 1.6 \\
.3120 & 1 & 1.6 \\
.3359 & 3 & 4.8 \\
.8819 & 5 & 8.1 \\
.9058 & 16 & 25.8 \\
1.4758 & 1 & 1.6 \\
& 6 & 9.7 \\
Mean $=.000$ & Median $=$ & 276 \\
Mode $=.882$ & S.D. $=1.000$
\end{tabular}

To check whether the newly created stigma index is a good representation of the three original stigma items, correlation coefficients between each of these variables and the index were observed. 
TABLE XVI

\section{CORRELATION COEFFICIENT MATRIX OF STIGMA INDEX, LOCAL SAMPLE - OAA}

\section{Stigma Index}

WBTHRWLF

.3724

$$
\begin{aligned}
(\mathrm{N} & =62) \\
\mathrm{S} & =.001
\end{aligned}
$$

WWLF RNDS

.8672

$(\mathrm{N}=62)$

$S=.001$

WWLFCOMM

.7494

$(\mathrm{N}=62)$

$\mathrm{S}=.001$

The above correlations show that the stigma index is a very good representation of the second and the third variable (with coefficients of .87 and .75 respectively) and a fair representation of the first variable $(r=37)$. However, all three re?ationships are significant beyond the .001 level. 


\section{THE SES INDEX}

One important independent variable in this study is the recipient's socioeconomic status. Variables often used to measure a person's socioeconomic status include income, education and occupation. The independent distributions of income, education, and occupation give only a partial picture of the general status patterns of the population. Depending on which of these items is used, different conclusions may be reached regarding a particular person's socioeconomic status.

Since any single item gives only a partial picture of the overall status picture of the population, many social scientists have concluded that socioeconomic status may best be measured by a summary index composed of several key characteristics. In this way, a person's socioeconomic level will not be represented as high or low simply because he ranks high or low on one single characteristic being used for measurement.

One of the major socioeconomic status scoring procedures was developed by Charles Nam and his associates at the Census Bureau in connection with the 1960 Census of Population (U.S. Census Bureau, 1963). Instead of stratifying occupations per se, this Census group decided that better results could be achieved by developing a multiple-item index of socio- 
economic status that combined independent ratings of education and income with ratings of occupations.

Basically, the procedures for deriving the scores involved these steps (Nam, et. al., 1975): (1) arraying occupations according to the median educational level of persons in the experienced civilian labor force; (2) arraying the occupations separately according to the median income level of each occupation; (3) by using the number of people engaged in each occupation as weights, determining the cumulative interval of persons in each occupation for each of the two arrays, and; (4) averaging the midpoints of the two cumulative distributions of occupants and dividing by the experienced labor force to get a status score for the occupation. The resulting score can take values between 0 and 100. A score indicates the appropriate percentage of persons in the experienced civilian labor force who are in occupations having combined average levels of education and income below that for the given occupation. The occupational scores obtained by this procedure indicate the position of the average person in a given occupation, based on the education and income distributions for that occupation. This approach is appropriate for the current study because detailed occupational categories were available in our data sets (which is required by this approach). Another reason for using this approach is because the income variable is not appropriate as far as constructing SE'S index is 
concerned. Most of our respondents were already retired and their current retirement incomes would not be indicative of the incomes associated with their occupations before retirement. Since this approach does not require the knowledge of their before-retirement income, we could obtain SES scores simply by knowing their occupations (with education and income already adjusted).

Are these SES scores stable over time? Research findings have pointed to the positive direction. While a minority of occupations have significantly increased or decreased their status, the vast majority have not altered their relative position in the stratification hierarchy (Nam and Powers, 1968). Nam and Powers compared the status scores for detailed occupations based on 1950 and 1960 data. They concluded that there was a high degree of stability of scores over the ten-year period, although for several specific occupations the status level changed significantly downward or upward. Using a list of 125 detailed occupations for comparison, the 1950-1960 correlation coefficient was .95, and the 1960-1970 coefficient was .97 . Even the correlation coefficient between scores in 1950 and 1970 was .91 (Nam, et. al., 1975: 571). As such, occupations did retain a remarkable degree of stability over the years.

The process of converting the detailed occupations into Census Bureau SES scores was a simple but tedious one. Since each occupation was already assigned a score by the Census 
Bureau, the job involved recoding each of the detailed occupations into its corresponding score. For example, respondents who were formerly social scientists were assigned an SES score of 96 and garbage collectors, a score of 24 . The following table shows some selected characteristics of the SES indexes for the national and the local samples.

TABLE XVII

\begin{tabular}{|c|c|c|}
\hline & $\begin{array}{l}\text { SES INDEX } \\
\text { NATIONAL SAMPLE }\end{array}$ & $\begin{array}{l}\text { SES INDEX } \\
\text { LOCAL SAMPLE } \\
\end{array}$ \\
\hline Mean & 37.959 & 51.077 \\
\hline Median & 32.031 & 50.250 \\
\hline Mode & 26.000 & 39.000 \\
\hline$S \cdot D$ & 26.607 & 24.554 \\
\hline Variance & 707.935 & 602.906 \\
\hline Kurtosis & -.870 & -1.237 \\
\hline skewness & .558 & .001 \\
\hline Minimum & 2.000 & 7.000 \\
\hline Maximum & 99.000 & 96.000 \\
\hline Range & 97.000 & 89.000 \\
\hline $\mathrm{N}$ & 7452 & 365 \\
\hline
\end{tabular}




\section{CHAPTER VI \\ PERCEPTION OF STIGMA}

INTRODUCTION

While the last chapter was concerned with the constrution of indexes, this chapter contains analysis and hypotheses testing. Questions examined include: were there intense feelings of stigma among $O A A$ and SSI recipients? Was there any less stigma associated with the new SSI program than with the old OAA Program? Did respondents in the national sample and the local sample perceive stigma similarly or was there a significant difference? As such, the main thrust of this chapter is to detail respondents perception of stigma, difference between $O A A$ and SSI recipients, and between the national sample and the local sample. 


\section{COMPARISON OF STIGMA INDICATORS}

This study seeks to understand the relationship between welfare stigma and the elderly recipients of the OAA and SSI programs. Review of relevant literature has generally shown that to receive public assistance means to be stigmatized. Theorists such as Goffman, Matza, Coser and Beck content that being a welfare recipient is discrediting, disreputable, degrading, and morally suspect. Such contention has also been confirmed by reserach findings of Briar (1966), Wyers (1976), Kerbo (1972), Wells (1972), and Handler and Hollingsworth

(1969). Studies of AFDC recipients by Kerbo (1972) and Horan and Austin (1974) showed substantial amount of stigma feelings reported by their respondents. Wells' (1972) study of welfare embarrassment also showed that more than 65 percent of his respondents felt embarrassed in receiving welfare aid. Similar findings are supported by Handler and Hollingsworth's 1967 study of AFDC recipients in Wisconsin. They found that more than 50 percent of their respondents possessed some feelings of stigma, especially among the black respondents. What about the respondents in our samples? Did they also feel stigmatized in receiving public assistance? Was there any difference in stigma perception between OAA and SSI recipients, and between the national and local samples? 
It is our contention that both OAA and SSI recipients did not have intense feelings of stigma. Historically, the aged poor have been regarded as the "deserving" or "worthy" poor and given generous support under most poverty programs. As such, one would believe it would be possible for the aged poor to internalize the "deserving poor" image instead of the generally negative welfare recipient image. In this regard, there is not a single welfare image, as is often assumed in welfare literature, but different welfare images perceived by recipients of different assistance programs. The national sample will be examined first.

In this study, stigma is defined by three aspects of recipient perception: Feeling bothered in receiving aid, being embarrassed to admit aid status before friends and relatives, and perceived community disrespect for aid recipients. While the first aspect taps the feelings of the recipient, the latter two indicators are designed to tap what the recipient thinks are the attitudes held by others. The following table shows the distributions of responses to the three stigma items by respondents of the national sample. 
TABLE XVIII

RESPONSES TO STIGMA ITEMS FOR OAA AND

SSI RECIPIENTS, NATIONAL SAMPLE

$\underline{O A A} \quad$ SSI

(1) Bothered to accept aid

Yes

$27.9 \% \quad 13.9 \%$

No

$\begin{array}{cc}\frac{72.1}{100.0} & \frac{86.1}{100.0} \\ N=4892 & N=4257\end{array}$

(2) Embarrassed to admit aid status

Very embarrassed

$8.1 \% \quad 2.9 \%$

Somewhat embarrassed

$14.3 \quad 6.4$

Not embarrassed

$\begin{array}{ll}\frac{77.6}{100.0} & \frac{90.7}{100.0} \\ N=4763 & N=4087\end{array}$

(3) Perceived community disrespect

Yes

No

\begin{tabular}{|c|c|}
\hline 14.18 & $9.6 \%$ \\
\hline 85.9 & 90.4 \\
\hline $\begin{array}{l}100.0 \\
N=3850\end{array}$ & $\begin{array}{l}100.0 \\
\mathrm{~N}=4026\end{array}$ \\
\hline
\end{tabular}

The most striking pattern to emerge from the above table is the lack of negative reactions to welfare recipiency in the national sample. The majority of the respondents did not feel bothered to accept assistance, nor did they feel embarrassed to admit their welfare status before friends and 
relatives. Following the same pattern, an overwhelming majority of the respondents did not perceive community disrespect for welfare recipients. For the OAA group, less than 28 percent said they felt bothered in accepting assistance and even less of them, 22.4 percent, reported that they were either very or somewhat embarrassed to admit their status. On the other hand, only slightly more than 14 percent perceived disrespect in the community.

The pattern was similar with the SSI recipients in the national sample, only with less respondents reporting feelings of stigma (the statistical test between the OAA and SSI groups to be performed later). Less than 14 percent of the SSI recipients said they felt bothered to accept assistance and only 9.3 percent reported feelings of embarrassment. In terms of perceived community disrespect, only 9.6 percent of the SSI recipients believed it was true. The proportion of recipients who were bothered by SSI status was only half that bothered by OAA status. There was an even more impressive decline in the proportion of recipients with feelings of embarrassment. Here the rates dropped from 22.4 percent to 9.3 percent. The decline in the perception of community hostility was more modest than that observed for being bothered or embarrassed. Still there was a drop of 4.5 percent. SSI appears to represent a real step forward in terms of reducing recipients' feelings of stigma. 
What about the local sample? Was the same pattern evident, or was there a major difference in terms of stigma feelings in the local sample? Distributions in the following table seem to show that respondents in the local sample felt more troubled by their welfare experience.

\section{TABLE XIX}

RESPONSES TO STIGMA ITEMS FOR

OAA RECIPIENTS, LOCAL SAMPLE

(1) Bothered to accept aid

Yes

No

(2) Embarrassed to admit aid status Very embarrassed

Somewhat embarrassed

Not embarrassed

(3) Perceived community disrespect

Disapprove

Neither

Approve

OAA

72.38

$\frac{27.7}{100.0}$

$(\mathrm{N}=83)$

\begin{tabular}{|c|}
\hline 33.38 \\
\hline 6.0 \\
\hline 60.7 \\
\hline $\begin{array}{l}100.0 \\
N=84)\end{array}$ \\
\hline
\end{tabular}

39.18

17.4

43.5

100.0

$(\mathrm{N}=28 I)$ 
Since the same stigma items were not asked of the SSI recipients in the local sample, comparisons could not be made between the OAA and SSI groups. In sharp contrast to the national sample, a much higher proportion of the OAA recipients in the local sample felt bothered in receiving assistance. In fact, more than 72 percent said that they felt bothered in accepting aid. However, the proportions of respondents reporting feelings of embarrassment or perceived community hostility were much lower (although still higher than those for the national sample). Slightly less than 40 percent said they were either very or somewhat embarrassed to admit their welfare status before friends or relatives, while about 39 percent believed that the community disapproved of welfare recipients. As a result, a clear pattern of stigma feelings was not evident in the local sample. While a majority of the respondents felt bothered, less than 40 percent of them had feelings of embarrassment or perceived community disapproval. As such, it could not be said that all or even most of welfare recipients in the local sample felt troubled or humiliated by their welfare experience.

When an individual is labeled "deviant", his response to the label may compose of two parts: self concept changes on the part of the individual, and changes in the definitions of him held by his immediate significant others, as well as the larger community (Horan and Austin, 1974:649). In the 
case of our local sample, the feelings of being bothered represented a change in self concept, while embarrassment feelings and perceived community disapproval represent what the recipient believed were attitudes held by his significant others and the larger community. While the OAA recipients felt uneasy in receiving assistance, they still believed that their friends and the larger community approved of them. 


\section{COMPARISON OF OAA AND SSI RECIPIENTS}

Another important question to be answered is: What kind of effect did the introduction of SSI have on recipients' perception of stigma? One important thesis of this study is that the introduction of a social security type program like the SSI program would indeed reduce the recipients' stigma feelings. The hypothesis was:

That OAA recipients have more intense feelings of stigma than SSI recipients.

This hypothesis could be tested with the national sample only since the stigma index was not built for the SSI group of the local sample. However, the two stigma indexes built for the national sample (see Chapter V) could not be compared directly. Although the same factor-analytical approach was used, different weights were used in constructing the OAA index and the SSI index. In order to compare these two indexes, the same weights must be used. One way would be to build a new SSI stigma index using weights used in building the original OAA index. Thus, using a SPSS COMPUTE procedure, a new SSI index was built: 
COMPUTE SSI INDEX

$$
\begin{array}{r}
=.43325 \times(\text { VV965 }-1.7418) / .4377+ \\
.46410 \times(\text { VV964 }-2.7397) / .5714+ \\
.38387 \times(\text { VV967 }-1.8590) / .3480
\end{array}
$$

where VV965 = Bothered to accept aid (SSI)

VV964 = Embarrassed to admit aid status (SSI)

VV964 = Perceived community disrespect (SSI)

.43325 = Factor score coefficient of "bothered" item (OAA)

$1.7418=$ Mean of "bothered" item (OAA)

.4377 = standard deviation of "bothered" item (OAA)

As a result of this computational procedure, a new SSI index was built with the following distribution found in Table XX.

This newly created index was used in comparing the difference in sticha feelings of the OAA and SSI recipients only. The previously constructed SSI index described in Chapter $V$ was used in all other hypotheses testing involving SSI stigma. 
TABLE XX

FREQUENCY DISTRIBUTIONS OF NEW SSI INDEX. USING OAA WEIGHTS, NATIONAL SAMPLE

$-3.0948$

$-2.2826$

$-2.1050$

$-1.9917$

$-1.4704$

$-1.2928$

$-1.1795$

$-1.0019$

$-0.6582$

$-0.4805$

$-0.3673$

$-0.1897$

0.3317

0.4449

0.6225

1.4347
$\mathrm{N}$

28

39

8

13

44

19

47

15

2

153

201

55

5

3

2246

$\frac{32}{2910}$

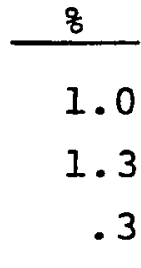

.4

1.5

.7

1.6

.5

.1

5.3

6.9

1.9

. 2

.1

77.2

1.1

100.0

$\begin{array}{ll}\text { Mean } & =.313 \\ \text { Mode } & =.623 \\ \text { Variance } & =.510\end{array}$

$$
\begin{aligned}
& \text { Median }=.607 \\
& \text { S.D. }=.714
\end{aligned}
$$


To test the difference in stigma between the OAA and SSI groups in the national sample, a paired samples t-test (correlated $t$-test) ras used. In using paired samples t-test, OAA stigma was the before treatment measurement and SSI stigma was the measurement after. Only recipients who had gone through both OAA and SSI programs were included in this test (most of the original OAA caseloads were transferred to the new SSI program). In this regard, SSI was the treatment. The purpose of this statistical test was to find out if there was a significant difference after the OAA recipients had been subjected to the SSI program.

The following table shows that the change in stigma feelings was indeed significant.

TABLE XXI

T-TEST FOR DIFFERENCE IN OAA STIGMA

AND SSI STIGMA, NATIONAL SAMPLE

OAA

STIGMA

iv

Mean

S.D.

S.E.

Mean difference

$r$

t value

D.F.

p (2-tail)
SSI

STIGMA

2227

.0151

.981

.021
.3283

.688

.015

$-.3132$

.356

$-15.13$

2226

$<.0001$ 
The table above shows a mean difference of -.3132 and a $\underline{t}$ value of -15.13 . The $\underline{t}$ value alone does not determine whether the relationship is significant or not, the degrees of freedom and whether it is a one-tailed or two-tailed test are also important. With 2226 degrees of freedom and a two-tailed test, a $t$ value of 1.96 was needed for the relationship to be significant at the .05 level. Since the $\underline{t}$ value was 15.13 , the relationship was significant beyond the .0001 level. In other words, there was a significant difference in stigma feelings between the OAA recipients and the SSI recipients.

Despite the fact that $O A A$ recipients in the national sample had low stigma perception, the introduction of the SSI program did further reduce recipients' stigma feelings, thus confirming our hypothesis. This finding was also supported by research of Williamson (1974b) and Tissue (1978), both finding that less stigma was connected with Social security type programs or proposals.

The problem of stigma has been one of the central rallying points of those who condemn the welfare system and seek to reform it or replace it altogether. Reform efforts aimed at creating rights and entitlements to welfare, making "need" the sole criterion for eligibility, introducing a simplified means test, and standardizing and routinizing administration have all been incorporated in the new SSI program. All such efforts are in part designed to reduce feelings of stigma for the recipients. Our findings seem to confirm such expectations, that there was less stigma associated with the new SSI program than with the old OAA program. 
COMPARISON OF NATIONAL AND LOCAL SAMPLES

How different are the national and local samples in stigma perception? Because of the fact that coding was done differently in one of the stigma items (perceived community disrespect), comparison could not be done with the stigma indexes. However, statistical tests could be performed on the other two items individually (since they were coded identically). The original hypothesis was:

There is no significant difference between the local sample and the national sample in terms of stigma.

A difference of proportions test was appropriate for the first stigma item: bothered in accepting assistance. Does the observed difference between the proportions from two independent samples represent a statistically significant difference? The test statistic is:

$$
z=\frac{\mathrm{P}_{1}-\mathrm{q}_{1}}{\sqrt{\frac{\mathrm{P}_{1} \mathrm{q}_{1}}{\mathrm{~N}_{1}}+\frac{\mathrm{P}_{2} \mathrm{q}_{2}}{\mathrm{~N}_{2}}}}
$$




$$
\text { where } \begin{aligned}
\mathrm{P}_{1} & =.723 \quad \begin{array}{l}
\text { (proportion answering "yes" in } \\
\text { bothered item in local sample) }
\end{array} \\
\mathrm{P}_{2} & =.279 \quad \begin{array}{l}
\text { (proportion answering "yes" in } \\
\text { bothered item in national sample) }
\end{array} \\
\mathrm{N}_{1} & =83 \quad(\mathrm{~N} \text { of local sample) } \\
\mathrm{N}_{2} & =4892 \text { ( } \text { of national sample) } \\
\mathrm{q}_{1} & =.277\left(1-\mathrm{P}_{1}\right) \\
\mathrm{q}_{2} & =.721 \quad\left(1-\mathrm{P}_{2}\right) \\
\mathrm{Z} & =\frac{.723-.279}{\sqrt{\frac{(.723)(.277)}{83}+\frac{(.279)(.721)}{4892}}} \\
& =8.96 \quad
\end{aligned}
$$

For the proportions to have a significant relationship at the .05 level, a $\mathrm{z}$ value of 1.96 was needed. Since the value of $Z$ was 8.96 , the difference between the two proportions was indeed statistically significant. The original hypothesis, that there was no significant difference between the local and national samples, was therefore rejected.

To test the second stigma item for the OAA recipients (embarrassed to admit aid status), a difference of means test would be appropriate. A significant test for the difference between two means requires the same logic as a test for proportions. The test statistic is:

$$
t=\frac{\bar{x}_{1}-\bar{x}_{2}}{\sqrt{\frac{s_{1}^{2}}{N_{1}}+\frac{s_{1}^{2}}{N_{2}}}}
$$




$$
\begin{aligned}
& \text { where } \begin{aligned}
\overline{\mathrm{x}}_{1} & =2.2738 \quad \text { (mean of local sample) } \\
\overline{\mathrm{x}}_{2} & =2.6943 \quad \text { (mean of national sample) } \\
\mathrm{S}_{1} & =.9359 \quad \text { (standard deviation of local sample) } \\
\mathrm{S}_{2} & =.6122 \quad \text { (standard deviation of national sample) } \\
\mathrm{N}_{1} & =84 \quad \text { (N of local sample) } \\
\mathrm{N}_{2} & =4763 \quad(\mathrm{~N} \text { of national sample) } \\
t & =\frac{2.2738-2.6943}{\sqrt{\frac{.9359^{2}}{84}+\frac{.6122^{2}}{4763}}} \\
& =4.10
\end{aligned}
\end{aligned}
$$

For the means to be statistically different at the .05 level, a computed $t$ value greater than or equal to 1.96 would be needed. Since the $t$ value was 4.10 , the means difference was indeed significant. The original hypothesis, that there was no significant difference between the local and national samples, was therefore rejected.

Thus, for both stigma items, we have to reject the original hypothesis. There was indeed a significant difference between the national and the local samples in stigma feelings in terms of the two items. Respondents in the local sample did have more intense feelings of stigma than their cohorts in the national sample. 
SUMMARY

Past research and studies have generally shown that welfare recipients are stigmatized and that they often internalize the stigma label. Findings from this chapter showed that this was not necessarily true. While the labeling theory as applied to welfare recipients could not thus be dismissed as useless or exaggerating, findings from this study did show that it could not be applied unquestioned to all welfare programs participants. Participants of welfare programs such as AFDC may feel stigmatized, as many studies have found. But this was not true of participants of the adult categorical aid programs such as OAA and SSI. In short, there was not a single welfare image that could be applied to all welfare recipients. Receipt of public assistance by the aged poor was not as degrading or unpleasant as was commonly assumed.

In examining individual stigma items in the national sample, less than 28 percent of the OAA recipients said they felt bothered in accepting welfare, and about 22 percent felt embarrassed. Following the same pattern, only 14 percent perceived disrespect in the community for welfare recipients. The pattern was similar with the SSI recipients in the national sample, with evenfewer recipients reporting feelings of stigma in the three items. The local sample did show some variability 
in the perception of stigma in terms of the three items. More than 72 percent of the OAA recipients said they were bothered in accepting welfare. However, less than 40 percent said they felt embarrassed or perceived disapproval from the community. Part of the difference between the national sample and the local sample could be due to the small sample size of the latter.

In comparing the SSI group and the OAA group of the national sample, a new stigma index was built using the same weights, means, and standard deviations previously used in building the OAA index. It was found that there was significantly less stigma associated with the new SSI program. This finding confirmed the hypothesis of this study and those who seeked to design the SSI program with less stigma attached to it.

Two stigma items (bother and embarrassment) were compared between the national and the local samples among the OAA recipients. The hypothesis that there was no significant difference between the two samples in stigma perception was not supported. In both stigma items, respondents in the local sample had more intense feelings of stigma than their cohorts in the national sample. 
CHAPTER VII

DEMOGRAPHICS AND STIGMA PERCEPTION

INTRODUCTION

In many past studies, it was found that personal and demographic characteristics were not discriminating factors in people's attitudes toward the poor and welfare as well as stigma perception, although a few studies came up with contrary findings. Ogren's 1970 study of some 2000 respondents in California found that personal characteristics such as age, education, income, and knowledge about welfare were not discriminating factors regarding attitudes toward welfare services (Ogren, 1973:106). Kallen and Miller's study of 300 white and 300 black women reached the same conclusion. Despite the difference between whites and blacks, the usual demographic characteristics did not appear to order attitudes toward welfare (Kallen and Miller, 1971). In analyzing data from a 1964 Gallup poll on attitudes toward the poor, Alston and Dean (1972) reported that the only demographic characteristic that relate to attitudes was age. Those fifty years old and over were more trusting of welfare recipients, but sex, education, and occupation did not differentiate in terms of such attitudes. Schiltz's survey of 13 national polls also found that age, income, and education were only weakly 
related or not related at all to the public's attitudes toward income-maintenance programs (Schiltz, 1970:37). However, Feagin did find that antiwelfare attitudes were related to age, income, and education (Feagin, 1972b). His study on antiwelfare attitudes found that antiwelfarism increased with age, income, and education.

Studies on stigma perception by the recipients themselves had mixed findings regarding demographic and personal characteristics. In a study of 230 white women in Boston concerning stigma rating for 13 social welfare programs and proposals, Williamson (1974b) found that there was a weak tendency for those who were higher in socioeconomic status to believe that these programs and proposals were more stigmatizing than those who were low in socioeconomic status. Horan and Austin (1974), in their study of AFDC recipients, also found that both education and welfare history had positive effects on stigma, while work history has none. However, Kerbo (1976) and Handler and Hollingsworth (1969), in their respective studies of AFDC recipients, did not find background characteristics to be significantly related to stigma. In both studies, no significant relationships were found between stigma and background characteristics such as race, employment experience, education, and length of residence. Kerbo, however, did find that age was positively related to stigma, that those 30 years old and over had more stigma. 
This chapter examines the possible relationships between demographic and personal characteristics and stigma perception for both the OAA and SSI groups of the national sample, as well as the OAA group of the local sample. Despite the fact that the stigma feelings were low among the respondents, it was still important to determine why some program recipients felt stigma while others did not. Background characteristics explored in this chapter include recipients' age, sex, education, socioeconomic status, and length of time on assistance.

One additional non-demographic characteristic to be explored in this chapter was recipients' tendency to blame themselves for their poverty. Blaming the poor for their poverty was a major tenet of the cultural perspective of poverty. In studying AFDC recipients, Kerbo (1976) found that recipients who accepted the traditional ideology of blaming the poor for poverty were more likely to feel stigmatized by receiving welfare. Studies by Feagin (1972b) and Alston and Dean (1972) also reported that a majority of Americans held poor people themselves responsible for their poverty. However, Williamson (1974a) only found a weak support for the "economic self-interest" thesis, in which blaming the poor for their poverty was part of it. 
AGE AND STIGMA

All the respondents in both samples were elderly; in fact they were 65 years old and over. The following table shows the age distributions of both the national and the local samples.

\section{TABLE XXII}

DISTRIBUTIONS OF AGE-GROUPS, NATIONAL AND LOCAL SAMPLES

\begin{tabular}{|c|c|c|c|c|}
\hline & $\frac{\text { NAT IONAL }}{N}$ & $\frac{\text { SAMPLE }}{8}$ & $\frac{\text { LOCAI }}{N}$ & $\frac{\text { SAMPLE }}{\frac{8}{8}}$ \\
\hline $65-69$ & 2302 & 26.8 & 74 & 18.6 \\
\hline $70-74$ & 2349 & 27.3 & 96 & 24.2 \\
\hline $75-79$ & 1829 & 21.3 & 85 & 21.4 \\
\hline $80-84$ & 1190 & 13.9 & 84 & 21.2 \\
\hline \multirow[t]{2}{*}{$85+$} & 926 & 10.7 & 58 & 14.6 \\
\hline & 8593 & 100.0 & 397 & 100.0 \\
\hline Median & \multicolumn{2}{|c|}{73.6} & \multicolumn{2}{|c|}{75.9} \\
\hline
\end{tabular}

The table above shows both absolute and percent distributions for both samples by age-groups. The only major difference between the two samples was that respondents in the local sample were slightly older, which was reflected in the median age. The national sample had a median age of 73.6 years, compared with 75.9 years for the local sample. In testing the relationship between age and stigma, it was hypothesized that: 
The older the respondent, the more intense the feelings of stigma.

In his study of AFDC recipients, Kerbo (1976) found significant relationship between age and stigma, that older respondents had more stigma than younger ones. The same relationship was hypothesized in this study. The first test was applied to the OAA recipients of the national sample, using the statistic of Pearson's $r$. This statistic was appropriate because both variables (age, stigma index) were at least of the interval level. The findings were:

$$
\begin{aligned}
& r=.0564 \\
& N=3061 \\
& P=.001
\end{aligned}
$$

Both the sign and magnitude of $r$ were important in deciding whether the hypothesis could be supported. Age was measured in single years, and the OAA stigma index was measured in the reverse order, i.e. the higher the value, the less the stigma. For the hypothesis to be supported, a negative $r$ was needed. The magnitude of the correlation coefficient, $r$, showed the strength of the relationship, while the sign indicated the direction.

The value of $r$ ranges from 0 to $\pm 1 ; 0$ indicates no linear relationship and \pm 1 indicates a perfect linear relationship. With an $r$ of only .0564 and $P=.001$, there was a statistically significant but very weak relationship between 
age and stigma. Furthermore, this weak relationship was also in the opposite direction of the hypothesis, i.e. "younger" OAA recipients had more stigma than olfer ones. The second test, again using Pearson's correlation, $r$, was administered to the SSI group of the national sample. The findings were:

$$
\begin{aligned}
& r=.0139 \\
& \mathrm{~N}=2286 \\
& \mathrm{P}=.253
\end{aligned}
$$

As with the OAA group, there was only a very weak relationship between age and stigma in the SSI group of the national sample. Moreover, the relationship was also in the opposite direction of the hypothesis. However, this relationship was not statistically significant $(P=.253)$.

The third and last hypothesis testing concerns the OAA group of the local sample. Compared with the previous two groups, this local group had a much smaller sample size $(N=47)$. Using Pearson's correlation test, the results were:

$$
\begin{aligned}
& r=-.1001 \\
& N=47 \\
& P=.252
\end{aligned}
$$

The magnitude of $r(-.1)$ was bigger than those for the national sample, and the sign (negative) was in the same direction of the hypothesis. However, this relationship was not statistically significant $(P=.252)$. 
of the three hypotheses tested concerning age and stigma, one was statistically significant but in the opposite direction while the other two were not significant. But the significant relationship was so weak that it was almost nonexistent. In short, age was only very weakly related or not related at all to stigma. One possible reason for the lack of relationship between age and stigma in our samples could be that all our respondents were elderly ( 65 and over). So, even if age was related to stigma, such relationship could not be revealed because younger respondents were not present in our samples. 
SEX AND STIGMA

As can be expected from an elderly population, the majorities of both samples were females. In the national sample, 5751 respondents, or about 67 percent, were females. The proportion was even more pronounced in the local sample. of the 397 respondents, 307 or 77.3 percent were females. Such observations were not unusual in view of the fact that females generally had a longer life expectancy than males and that all the respondents were elderly. The difference in the two samples could be partly due to the fact that the local sample was more than two years older than the national sample.

Traditionally, the sex roles were different for men and women in the society. The man was usually the major breadwinner and the woman was more or less dependent on her husband for support. Following this reasoning, one could expect that male recipients would feel more troubled in receiving assistance than their female counterparts. To examine the possible relationship between sex and stigma, the hypothesis was:

That male recipients have more intense stigma than female recipients.

The statistical technique of Pearson's product-moment correlation, $r$, was employed to test this hypothesis on 
three groups: the $O A A$ and SSI groups of the national sample and the OAA group of the local sample. However, mixed results were obtained.

Administering the statistical test to the national OAA groups, the findings were:

$$
\begin{aligned}
& r=.0176 \\
& N=3061 \\
& P=.166
\end{aligned}
$$

With male measured as $I$ and female 2 , and stigma measured in the reversed order, i.e. the lower the value, the higher the stigma, a high, positive $r$ would indicate support for the hypothesis. However, an $r$ of .0176 , while pointing to the same direction of the hypothesis, showed that the relationship was almost nonexistent. Furthermore, it was not statistically significant at the .05 level $(P=.166)$. Regarding the SSI group of the national sample, the results of the hypothesis testing were not too different.

$$
\begin{aligned}
& r=-.0400 \\
& N=2286 \\
& P=.028
\end{aligned}
$$

Again, the small negative $r$ indicated that sex was only weakly related to stigma, pointing to the opposite direction of the hypothesis, i.e. female recipients had more stigma than their male counterparts. This weak relationship 
was also statistically significant at the .05 level $(p=.028$ ). In short, as far as the two groups in the national sample were concerned, sex was either weakly or not related to stigma at all.

However, when the statistical test was administered to the OAA group in the local sample, a clearer picture emerged. The findings were:

$$
\begin{aligned}
& r=-.3529 \\
& N=51 \\
& P=.005
\end{aligned}
$$

With an $r$ of almost -.36 , the relationship between sex and stigma was quite substantial in the local sample. Again, the original hypothesis was not supported. The negative I indicated that female recipients had more stigma than the male recipients. Furthermore, the relationship was statistically significant at the .05 level $(p=.005)$.

One question to be asked was: Was this observed relationship between sex and stigma in the local sample a spurious one? The relationship found would be a spurious one if a third variable, say education, was causing both sex and stigma to vary in such a matter that a negative correlation was obtained. One test for spuriousness was to control for the third variable. If the partial correlation between sex and stigma, after controlling for a third variable, was reduced to zero, or 
approximately zero, then one could conclude that the original observed relationship was spurious.

A partial correlation run was made controlling for education and length of time a recipient was on welfare. When education was controlled, the partial correlation between sex and stigma was $-.340(p=.007)$. With length of time on welfare controlled, the partial correlation was $-.348 \quad(P=.006)$ As such, there was only a minimal decrease in the value of the correlation coefficient when the effects of two other variables were controlled separately. Thus, one could conclude that the original relationship between sex and stigma was not a spurious one, that indeed female recipients felt more stigma than male recipients in the local sample.

Why would female recipients feel more stigmatized than male recipients? Could their stigmatization stem from a different process compared with the male recipients? No one interpretation was readily available. All recipients were at least 65 years old and the median age was almost 76 years. Could it be possible that male recipients were more receptive to public assistance since they had already made their contributions to society? Following the same line of reasoning, would female recipients feel more troubled to receive support from welfare instead of from their husbands $(77$ percent of the respondents were either widowed, divorced, or separated)? The reasons for this difference remained obscure. 
EDUCATION AND STIGMA

The third demographic variable to be examined was education. Education was measured in number of years of school. The local sample was slightly better educated than the national sample. The national sample had a median of 7.4 years of school, compared with 8.9 years for the local sample.

Horan and Austin (1974) found that education was related to stigma, that the more education a welfare recipient had, the more stigma he felt. Such finding was logical since the receipt of public assistance symbolized a certain amount of personal failure. Better education only makes it more difficult to project oneself as worthy of the assistance. Following this line of reasoning, the hypothesized relationship between education and stigma was:

The more educated the recipient, the more intense the feelings of stigma.

This hypothesis was supported when statistical testing was applied to all three groups of recipients. Again, Pearson's product-moment correlation was used. Results for the OAA group in the national sample were:

$$
\begin{aligned}
& \mathrm{r}=-.1835 \\
& \mathrm{~N}=.3180 \\
& \mathrm{P}=.001
\end{aligned}
$$


Since stigma was measured in the reverse order, i.e., a lower value in the stigma index means more stigma, and education in number of years of school, a negative correlation pointed to the same direction of the hypothesis. An $r$ of -.18 was fairly substantial for social science data. Furthermore, the relationship was statistically significant at the .05 level $(p=.001)$. When controlled for a third variable, the partial correlation did not drop substantally. The partial correlation was -.1814 $(p=.001)$ when age was controlled, -.1273 for SES $(p=.001)$, and $-.1708(p=.001)$ for length of time on welfare. It was therefore reasonable to conclude that the relationship between education and stigma was not spurious. Therefore, the hypothesis that education had a direct relationship with stigma was supported. Similar results were obtained when the statistical test was administered to the SSI group in the national sample.

$$
\begin{aligned}
& r=-.1143 \\
& N=2382 \\
& P=.001
\end{aligned}
$$

The only difference between the OAA group and the SSI group was a slightly smaller $r$ for the latter. But the relationship was statistically significant at the .05 level $(p=.001)$. When age, SES, and length of time on SSI were controlled separately, the partial coefficients showed only a small drop in value. This meant that the relationship between education and stigma was not spurious. 
The last hypothesis testing concerning education and stigma was that of the OAA group in the local sample. Again, significant findings were obtained:

$$
\begin{aligned}
& \mathrm{r}=-.2301 \\
& \mathrm{~N}=51 \\
& \mathrm{P}=.049
\end{aligned}
$$

The value of $r$ in the local sample was higher than either one of the national sample, indicating a stronger relationship between education and stigma. The negative correlation also showed a reverse relationship between education and stigma, the same direction as the hypothesis. Although the significance level was not as high as those in the national sample, it was still statistically significant at the .05 level $(p=.049)$. Results from partial correlation analyses also showed that the relationship was not spurious. The partial correlation was -.24 when age was controlled; it was -.21 for sex, and -.25 for length of time on welfare. They showed that the original observed relationship between education and stigma was hardly affected at all when effects of other variables were controlled.

All in all, the hypothesis was supported when applied to all three groups of respondents. The more educated the recipient, the more intense was his or her feelings of stigma. 
SOCIOECONOMIC STATUS AND STIGMA

The socioeconomic status (SES) index used in this study followed that developed by the U. S. Census Bureau in conjunction with the 1960 Population Census (see Chapter $V$ for detailed description of the index). The index could take values between 0 and 100. The SES scores obtained by this procedure indicated the position of the recipient in a given occupation, based on the education and income distributions for that occupation. The local sample had a substantially higher SES score than the national sample; the local sample had a median score of 50.3, compared with a score of 32 for the national sample.

Like the other demographic variables, hypothesis testing was applied to both the OAA and SSI groups of the national sample and the OAA group of the local sample. I,ike education, it was hypothesized that socioeconomic status had a direct relationship with stigma, i.e. those with a higher SES score also had more stigma. It was believed that SES would have the same relationship with stigma as education had. Those with higher SES scores would feel more disturbed to receive assistance because it represented failure on their part. The hypothesis was:

The higher the recipient on the census Bureau SES Scale, the more intense would be the stigma. 
Like previous tests, the first one was applied to the OAA group in the national sample. Results were very similar to that of education.

$$
\begin{aligned}
& r=-.1693 \\
& N=3180 \\
& P=.001
\end{aligned}
$$

With an $r$ of about. 17 , SES was fairly strongly related to stigrna. The negative correlation also indicated that the relationship was in the same direction of the hypothesis (since stigma was measured in the reversed order). In terms of statistical significance, the relationship was good at the .05 level $(p=.001)$. When effects of other variables such as age, sex, education and length of time on assistance were controlled separately, the partial correlations did not drop substantially, indicating that the original relationship was not spurious.

The results were not too different when the hypothesis was tested with the SSI group of the national sample.

$$
\begin{aligned}
& r=-.1292 \\
& N=2382 \\
& P=.001
\end{aligned}
$$

The only difference was a slightly smaller coefficient. Still, SES was still quite strongly related to stigma for the 
OAA recipients of the national sample. Those who had higher SES scores did have more stigma feelings. The relationship was significant at the .05 level. It was not spurious because the partial correlation coefficients did not drop substantially when effects of other variables were controlled.

The third and final test of the hypothesis concerned the OAA recipients of the local sample. Results from this test did not parallel those of the national sample.

$$
\begin{aligned}
& r=.0442 \\
& N=47 \\
& P=.384
\end{aligned}
$$

The value of the correlation was very small (.04) and the relationship was statistically insignificant at the .05 level $(p=.384)$. The only logical conclusion to be drawn was that SES was not related to stigma in the local sample.

The hypothesis that SES was directly related to stigma was supported in both the OAA and SSI groups of the national sample. In both groups there was a significant and fairly strong relationship between SES and stigma, that recipients with higher SES scores also had more stigma. However, this was not true with the local sample. In the local sample, there was a statistically insignificant relationship between SES and stigma. This could be due to the small sample size of the local sample $(\mathrm{N}=47)$, and the fact that local recipients nad to recollect their OAA experience two years after it was replaced by SSI. 


\section{LENGTH OF TIME ON ASSISTANCE}

AND STIGMA

The last demographic and personal characteristic examined was recipient's length of time on assistance. This variable was measured differently for the three groups of recipients. A direct comparison among them was therefore not appropriate. The following table shows distributions for the OAA group of the national sample.

TABLE XXIII

\section{LENGTH OF TIME ON WELFARE FOR OAA RECIPIENTS, NATIONAL SAMPLE}

$\begin{array}{llrrr}\text { Less Than } 6 \text { mos } & \text { (1) } & \frac{\mathrm{N}}{57} & \frac{8}{1.1} \\ 6 \text { Mos to } 1 \mathrm{yr} & \text { (2) } & 168 & 3.3 \\ 1 \text { to } 5 \text { years } & \text { (3) } & 1691 & 32.8 \\ 5 \text { to } 10 \text { yrs } & \text { (4) } & 1479 & 28.7 \\ 10+\text { yrs } & \text { (5) } & \frac{1755}{5150} & \frac{34.1}{100.0}\end{array}$

The above table shows that the majority of recipients were on OAA for five years or more (62.88). Less than 5 percent of them had less than one year of welfare experience. On the other hand, length of time on SSI was measured in months, from a low of one month to a high of twelve months. This was because the second wave interviews for the national sample were taken at the end of 1974 when the SSI program 
was in existence for only one year. The mean value was 10.9 months for SSI recipients. The welfare experience of the OAA recipients in the local sample was measured in number of years, with 12.2 years being the mean value. Horan and Austin (1974), in their study of welfare stigma on AFDC recipients, found that time on welfare was related to stigma. The same relationship was hypothesized in this study, although we suspect that the aged poor would behave and react differently in many ways from other poor groups, such as AFDC recipients. The belief that the elderly felt less stigmatized in receiving assistance did not necessarily mean that they enjoyed staying on welfare. Being on welfare for a prolonged period of time could produce cumulative effects and feelings of despair and loss of selfrespect. Those newly added to welfare rolls might not yet have time to adopt such attitudes associated with their recently acquired status. Thus, the hypothesis was:

The longer the recipient on welfare, the more intense would be his stigma feelings.

Again using Pearson's product-moment coefficient, the first test was applied to the OAA group of the national sample. The results were:

$$
\begin{aligned}
& r=.1372 \\
& N=3180 \\
& P=.001
\end{aligned}
$$


Since stigma was measured in the reversed order, the positive correlation indicated that time on welfare was related to stigma in the opposite direction of the hypothesis. That is, the longer the recipient was on welfare, the less intense would be the stigma. Thus, the hypothesis was not supported. The second test of the hypothesis was applied to the SSI recipients of the national sample, with the following results :

$$
\begin{aligned}
& r=.0315 \\
& N=2382 \\
& P=.062
\end{aligned}
$$

The relationship was so weak it was almost nonexistent $(r=.03)$. Furthermore, the relationship was statistically insignificant at the .05 level $(p=.062)$. In short, the length of time on SSI was hardly related to stigma. This finding was not surprising since SSI was only one year old at the time of interviews. The time span of one year was probably too short for its effect, if any, to show in stigma feelings.

The final test of the hypothesis was applied to the OAA group of the local sample. Results showed that the hypothesis was supported.

$$
\begin{aligned}
& \mathrm{r}=-.2629 \\
& \mathrm{~N}=51 \\
& \mathrm{P}=.029
\end{aligned}
$$


The magnitude of the correlation $(r=-.26)$ showed that there was a fairly strong relationship between time on OAA and stigma in the local sample in the same direction of the hypothesis. The relationship was also significant at the .05 level $(p=.029)$. There was no substantial drop in the partial coefficients when effects of other variables were controlled separately. This indicated that the original relationship was not spurious.

of the three groups tested, one group showed an insignificant relationship between time on assistance and stigma and the other two were significant. The hypothesis was supported by the OAA group of the local sample while the OAA group of the national sample showed a reversed relationship between the two variables. 
BLAMING THE POOR FOR POVERTY AND STIGMA

The relationship between blaming the poor for poverty and stigma was the last topic examined in this chapter. The question of blaming the poor for their poverty was asked only in the local sample. As a result, the hypothesis could only be tested using only the local sample. This hypothesis was formulated as:

Recipients who blame poverty as the individual's fault are more likely to have feelings of stigma.

The following table shows distributions in percentages and actual numbers for the local sample.

\section{TABLE XXIV}

\section{BLAMING POVERTY AS INDIVIDUAL'S FAULT, LOCAL SAMPLE}

\begin{tabular}{llrrr} 
Poverty Own Fault? & \multicolumn{1}{c}{$\mathrm{N}$} & $\frac{8}{7.7}$ \\
\cline { 2 - 3 } & (I) & 30 & & 7.7 \\
Agree Somewhat & (2) & 69 & 17.7 \\
Disagree Somewhat & (3) & 174 & 44.6 \\
Disagree Strongly & (4) & $\frac{117}{390}$ & $\frac{30.0}{100.0}$
\end{tabular}

The table above shows that most of the respondents in the local sample disagreed with the statement that poverty was an individual's fault. In fact, only 99 respondents or 25.4 percent agreed strongly or somewhat that poverty was one's 
own fault. Almost three-fourths of the respondents disagreed. Again, this finding has shown that the elderly poor behaved somewhat differently from the general population regarding their own plight. Because the elderly poor had internalized the "deserving poor" image, they believed that they were not to be blamed for their poverty. Pearson's product-moment correlation was used to test the relationship between blaming the poor for poverty and stigma.

$$
\begin{aligned}
& \mathrm{r}=-.1663 \\
& \mathrm{~N}=61 \\
& \mathrm{P}=.100
\end{aligned}
$$

The hypothesis was not supported by the above findings. First, the negative correlation pointed to the opposite direction of the hypothesis, i.e. recipients who blame poverty as the individual's fault are not likely to have more stigma. Second, the relationship was not statistically significant at the .05 level $(p=.100)$. 


\section{SUMMARY}

Many past research and studies have found that demographic and personal characteristics were not differentiating factors in ordering the public's attitudes toward the poor and stigma perception by the poor themselves. Some studies, however, found that the background characteristics were important factors. This chapter examined the possible linkages between five important demographic and personal characteristics and stigma perception in three groups of recipients: $O A A$ and SSI recipients of the national, and OAA recipients of the local sample. In this regard, fifteen specific hypotheses, instead of five, were tested against the three groups of respondents.

The statistical technique of Pearson's correlation coefficient was used in all the testings in this chapter. When a specific hypothesis was found to be statistically significant, partial correlation analysis was used to test the spuriousness of the original relationship. A relationship was spurious if, after controlling for the effect of a third variable, the partial correlation coefficient dropped to zero or near zero.

Of the fifteen demographic hypotheses tested in this chapter, ten were found to be significant statistically at 
the .05 level and five were statistically insignificant. Among the ten significant relationships found, six supported the hypotheses while the remaining four pointed to the opposite direction of the hypotheses.

Surprisingly, age was found to be essentially unrelated to stigma (one statistically significant relationship was too weak to mean anything). It was speculated that the true relationship between age and stigma could have been masked due to the fact that all the recipients were elderly. Sex was the second demographic variable examined and was found unrelated to stigma among respondents in the national sample. However, it was significantly related to stigma in the OAA group of the local sample. The relationship was in the opposite direction of the hypothesis, i.e. female respondents were found to have more stigma than male respondents. The reasons for this relationship remained obscure, although one possible reason could be that female recipients felt more disturbed to receive support from welfare instead of from their husbands.

Both education and socioeconomic status were found to be significantly related to stigma in both samples. The only exception was between SES and stigma among the OAA recipients of the local sample. Such findings were expected since the recipient of public assistance symbolized a certain amount of personal failure. Better educated recipients or recipients with high socioeconomic status might find it more difficult 
to accept assistance. The last background variable, length of time on assistance, was hypothesized to have a direct relationship with stigma. The findings were mixed. This hypothesis was supported only by the OAA group of the local sample. The reverse was true of the OAA group of the national sample and the relationship was not significant with the SSI group of the national sample. The last finding was understandable since the SSI was in existence for only one year at the time of interviews. The time period was probably too short to have any real effect on stigma perception.

This chapter has examined the relationships between five demographic and personal variables and stigma. It was shown that the elderly were not a unified group as many would like to believe. Other than age, they also had many diverging characteristics which had a bearing on stigma perception. For instance, education and socioeconomic status of the recipients, and to lesser extents sex and time on assistance, were significantly related to stigma.

The only non-demographic variable examined in this chapter was blaming poverty as one's own fault. It did not relate significantly with stigma feelings. Furthermore, it was found that recipients generally did not subscribe to the traditional ideology of blaming the poor for poverty. 
CHAPTER VIII

RATING OF AGENCIES AND PROGRAMS

\section{INTRODUCTION}

In this final chapter of data analysis, three remaining hypotheses are tested. The first one concerned program recipients' confidence in the Social Security Administration and local welfare agencies. This hypothesis is tested using the local sample. The second hypothesis to be tested, using the national sample, dealt with recipients' rating on the performance of the old Age Assistance program and the supplemental security Income program. The third and last topic to be examined would be non-recipients' choice of the OAA or SSI program for future use. This hypothesis is tested using both the national and local samples. 


\section{SOCIAL SECURITY ADMINISTRATION AND \\ LOCAL WELFARE DEPARTMENTS}

The Social Security Administration (SSA) has a long and distinguished record of efficiency and its operation of the Social Security program has created wide acceptability of the program. Location of the new Supplemental Security Income program within the SSA was specifically meant to overcome resistance and the stigma attached to the traditional welfare function. (Although there were some worries that SSI could contaminate the image of the Social Security Administration. See Hollister, 1974; Radin, 1974). On the other hand, local welfare departments seldom had high levels of public support. Street, et. al. believed that public welfare agencies derived a lower status in the public mind because of the fact of working with a disesteemed clientele (Street, et. al., 1979). In a study evaluating the welfare and Social Security programs, Katz, et. al., (1975) reported that almost 88 percent of the respondents were satisfied with the way the Social Security office handled their problems, compared with 61 percent who were satisfied with the welfare department. The same study also found that more than 88 percent of the respondents thought the Social Security office was efficient in handling their problems, compared with less than 71 percent for the welfare department (Katz, et. al., 1975: 68). 
In this study, it was also believed that respondents would have more confidence in the Social security Administration than the local welfare departments, thus the hypothesis:

That respondents have a higher level of confidence in the Social Security Administration than in the local welfare departments.

This hypothesis could be tested with the local sample only since the same questions were not asked of the national sample. The following table shows the percent distributions:

TABLE XXV

CONFIDENCE IN SSA AND IOCAL WELFARE

DEPARTMENTS, LOCAL SAMPLE

\begin{tabular}{|c|c|c|c|}
\hline & & Confid & ice in \\
\hline & & $\frac{\text { SSA }}{62}$ & WEL. DEPT \\
\hline A Great Deal & (1) & 61.38 & 37.48 \\
\hline Some & (2) & 35.0 & 31.3 \\
\hline Hardly Any & (3) & 3.7 & 31.3 \\
\hline & & 100.0 & 100.0 \\
\hline & & $(N=274)$ & $(\mathrm{N}=179)$ \\
\hline
\end{tabular}

The above table shows that respondents in the local sample obviously had more confidence in the social Security Administration then. More than 96 percent of the respondents had some or a great deal of confidence in SSA, compared with less than 69 percent for the welfare department. To determine whether such a difference was statistically significant, a $\underline{t}$ - test was performed. The table on the following page summarizes the results of the $t$ - test. 
TABLE XXVI

\section{T-TEST FOR DIFFERENCE IN CONFIDENCE IN SSA AND WELFARE DEPT., LOCAL SAMPLE}

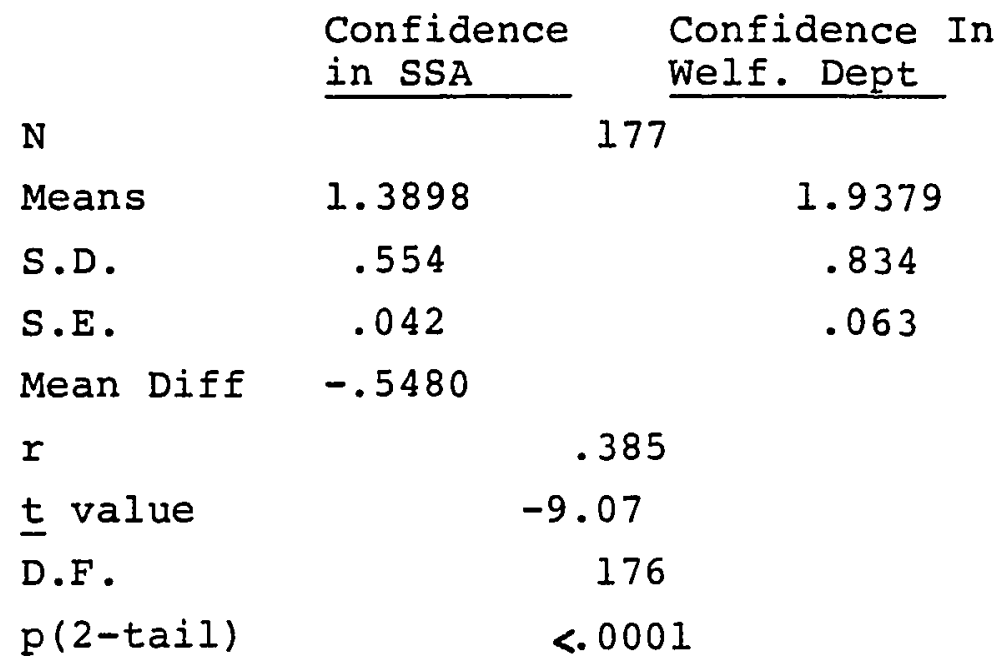

With 176 degrees of freedom and a two-tailed test, a $t$ value of 1.96 or bigger was needed for the relationship to be significant at the .05 level. Since a $t$ value of 9.07 was obtained, the mean difference was significant beyond the .0001 level. In other words, there was a significant difference in respondents' confidence between the Social Security Administration and the local welfare departments. This finding confirms the generally held belief that SSA enjoys a much higher reputation than local welfare departments. 
PERFORMANCE OF OAA AND SSI

Other than trying to overcome the alleged stigma attached to welfare, the new SSI program also provided uniform administration and standard eligibility, and higher income and wider coverage for beneficiaries. All these changes were designed to make the new program more acceptable to the pubiic and recipients. How was the new program viewed by the recipients so far? Were they any happier with SSI than OAA? In this study, it was hypothesized that recipients were generally more satisfied with the performance of SSI than OAA. Thus the hypothesis:

More respondents are satisfied with SSI's performance than they are with OAA.

The test of this hypothesis was applied to the national sample only as the same items were not present in the local sample. The following table shows the distributions for both the OAA and SSI recipients of the national sample. 
TABLE XXVII

\section{SATISFACTION WITH PERFORMANCE OF OAA} AND SSI PROGRAMS, INATIONAL SAMPLE

\begin{tabular}{cccc} 
& & \multicolumn{2}{c}{ Performance of } \\
& & OAA & SSI \\
Good (1) & 50.18 & 59.08 \\
Fair (2) & 36.18 & 33.08 \\
Poor (3) & $\underline{13.88}$ & $\frac{8.08}{100.08}$ & 100.8 \\
& & $(\mathrm{~N}=4650)$ & $(\mathrm{N}=4026)$
\end{tabular}

Proportionally more respondents were satisfied with the performance of SSI than with OAA in the national sample. FuIly 59 percent said they rated the performance of SSI as "good", compared to just over 50 percent for $O A A$. At the other end of the scale, almost 14 percent of the respondents said that the performance of OAA was "poor", compared to only 8 percent for SSI. Figures from this table suggest that recipients were quite satisfied with both the OAA and SSI programs. This finding was not surprising since it was found in Chapter VI that the stigma feelings were low even for the OAA recipients. Although more recipients were satisfied with the performance of SSI than OAA, the question remained: Was this difference significant? To answer this question, a paired t-test was performed. This statistical test compared the satisfaction for recipients who went through both programs. The summary statistics were: 
TABLE XXXIII

T-TEST COMPARING SATISFACTION OF PERFORMANCE
IN OAA AND SSI, NATIONAL SAMPLE

$\mathrm{N}$

Means

S.D.

S.E.

Mean Diff.

$r$

$t$ value

D.F.

p (2=taiI)
Satisfaction with OAA

Satisfaction with SSI

3451

1.6418

.715

.012
1.4825

.631

.011

With 3450 degrees of freedom and a $t \underline{\text { value of }}$ 11.43, the mean difference was statistically significant at the .0001 level. For recipients who went through both the $O A A$ and SSI programs, they were significantly more satisfied with the performance of the SSI program. 
FUTURE USE OF OAA AND SSI

One of the major criticisms directed at the welfare programs was that they deter beneficiaries from using them. Various studies have shown that participation rates were low among those who were eligible for public assistance (Piven and Cloward, 1972; Feagin, 1972a; Street, et. al., 1979; Horan and Austin, 1974; Wyers, 1976). Doubtlessly many reasons were responsible for such low use of the welfare programs, and stigma was a major reason. Various changes were made in the new SSI program so that it would be more acceptable to recipients. It was hoped that people who were reluctant to apply for OAA would be more willing to apply for SSI. Thus some of the more reluctant "deserving poor" could receive SSI benefits.

In this study, it was hypothesized that the current non-users would be more willing to use SSI in the future than the old OAA program. This hypothesis was applicable to both the national and the local samples:

More respondents would apply for SSI than OAA in the future.

All the non-recipients in the two samples were asked how they felt about asking for OAA or SSI in the future, based on what they knew about the two programs. The following table shows distributions for the national sample: 
TABLE XXIX

TO USE OAA AND SSI IN FUTURE

NATIONAI SAMPLE

\begin{tabular}{lrll} 
& & \multicolumn{2}{c}{ Future Use of } \\
Wouldn't Mind at all & (1) & $\frac{\text { OAA }}{38.28}$ & $\frac{\text { SSI }}{69.68}$ \\
Would use but dislike it(2) & 45.9 & 23.5 \\
Would Never do It & (3) & $\frac{15.9}{100.08}$ & $\frac{6.9}{100.08}$ \\
& & $(\mathrm{~N}=2895)$ & $(\mathrm{N}=2388)$
\end{tabular}

The table above clearly shows that current non-recipients preferred to use the SSI program in the future by a substantial margin. Almost 70 percent of the respondents said they would not mind at all to use the SSI program in the future, compared with only 38.2 percent for the OAA program. At the other end of the scale, almost 16 percent said that they would never apply for OAA in the future, while less than 7 percent said they would not use SSI.

To determine whether the difference was statistically significant, a paired t-test was performed. 
TABLE XXX

T-TEST COMPARING FUTURE USE OF

OAA AND SSI, NATIONAL SAMPLE

$\underline{O A A}$

$\mathrm{N}$

Means

S.D.

S.E.

Mean Diff

$r$

t value

D.F.

p (2-tail)
2162

SSI

1.3858

.616

.013

With 2161 degrees of freedom and a $\underline{t}$ value of 23.77 , the relationship was statistically significant (using a 2-tailed test) beyond the .0001 level. That is, there was a significant difference in non-recipients' choice of SSI over OAA in future use.

The same hypothesis was also applied to the local sample as well. Similar results were found, despite a slight difference in coding the responses. The following table shows distributions for the local sample. 
TABLE XXXI

TO USE OAA AND SSI IN FUTURE

LOCAL SAMPLE

\begin{tabular}{|c|c|c|c|}
\hline & & $\begin{array}{l}\text { Future } \\
\text { OAA }\end{array}$ & $\begin{array}{c}\text { Use of } \\
\text { SSI }\end{array}$ \\
\hline Without Second Thought & (1) & 2.48 & 23.88 \\
\hline If really need money & (2) & 24.8 & 59.8 \\
\hline Would Use but Dislike it & (3) & 58.9 & 12.8 \\
\hline Would Never do it & (4) & 13.9 & 3.7 \\
\hline & & $\begin{array}{l}100.0 \\
(N=331)\end{array}$ & $\begin{array}{l}100.0 \\
(\mathrm{~N}=164)\end{array}$ \\
\hline
\end{tabular}

Again, respondents preferred to use SSI over OAA in the future by a huge margin. While only 2.4 percent said they would use $O A A$ in the future without second thought, almost 24 percent said they would gladly use SSI. For those who would use assistance if they really needed money, it was about 25 percent for $O A A$ and 60 percent for SSI. On the other hand, only 3.7 percent said they would never apply for SSI in the future, compared with almost 14 percent for OAA. As such, there was a clear preference for SSI in future use by nonrecipients.

Again, to determine if the difference was statistically significant, a paired t-test was employed. This statistic provided a significance test for the respondents who provided relevant responses to both the OAA and SSI questions. 
TABLE XXXII

T-TEST COMPARING FUTURE USE OF
OAA AND SSI, IOCAL SAMPLE

$\underline{O A A} \quad \underline{S S I}$

N

158

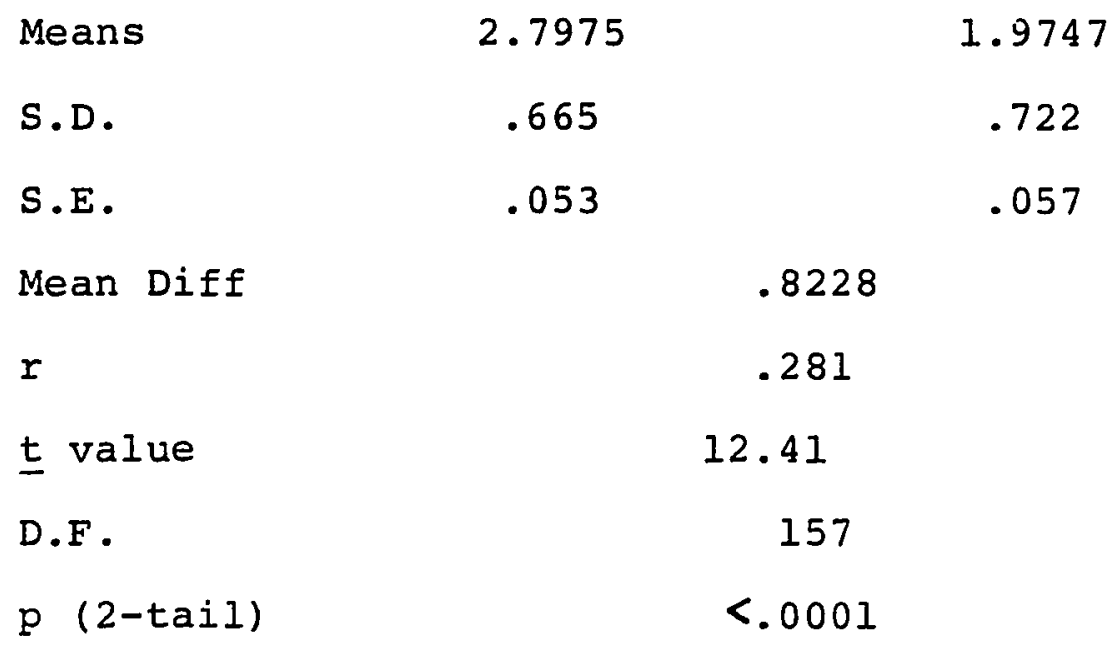

Just as expected, the difference was found to be statistically significant at the .05 level. With 157 degrees of

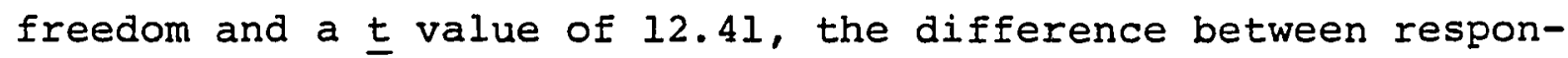
dents' choice of OAA and SSI was significant at the .000I level. Thus, the hypothesis was supported by both the national and local samples. 
SUMMARY

Three topics were examined in this chapter and the hypothesized results were obtained in each case. The topics considered were recipients' confidence in the social security Administration and local welfare departments, recipients' ratings on the performance of the old old Age Assistance program and the new Supplemental Security Income program; and non-recipients' choice of using the OAA or SSI programs in the future.

Various changes were made in designing the new SSI program. A major change was shifting administration of the assistance program from state and local welfare agencies to the federal Social Security Administration. It was hoped that the prestige of SSA could be brought to the welfare aid area. It was hypothesized in this study that recipients would have more confidence in SSA than in local welfare departments. It was found that more than 61 percent had a great deal of confidence in SSA, compared with only slightly more than 37 percent for local welfare departments. The difference was found to be statistically significant.

A related topic was recipients' rating on the performance of the $O A A$ and SSI programs. As hypothesized, recipients who went through both programs found the SSI program doing a better job than the OAA program. It was noted, however, 
that recipients generally found both the OAA and SSI programs performing well.

The third and last topic explored in this chapter was non-recipients' choice of the OAA and SSI program for future use. In both the national sample and the local sample, it was found that significantly more non-recipients preferred to use the SSI program in the future. These and previous findings have produced several significant implications which are discussed in the next chapter. 


\section{CHAPTER IX}

\section{CONCLUSIONS AND IMPLICATIONS OF STUDY}

\section{SUMMARY OF FINDINGS}

This study seeks to understand the relationship between welfare stigma and the elderly, using the supplemental Security Income (SSI) program for analysis. The federal SSI program went into effect in January 1974, replacing the state-administered welfare programs--old age assistance $(O A A)$, aid to blind $(A B)$, and aid to the permanently and totally disabled (APTD). This study is concerned primarily with comparisons between the old OAA program and the elderly portion of the new SSI program. Data for this study came from two surveys, a local survey of nearly 400 elderly respondents from Multnomah County, Oregon, and a national survey of nearly 8600 respondents.

The most important dependent variable in tinis study is welfare stigma. To facilitate subsequent data analysis, a welfare stigma index was constructed using factor-analytic technique for both the OAA and SSI groups of the national sample and the OAA group of the local sample. A socioeconomic status (SES) index was also constructed based on the recipient's former occupation, with income and education for that occupation adjusted. 
Specific findings from analysis of the data were presented in Chapters VI, VII, and VIII. Chapter VI discussed the respondents' perception of stigma. Topics examined included whether the recipients had intense feelings of stigma, whether there was any difference in stigma between the national and local samples, and between OAA and SSI recipients. The relationship between demographic and personal variables and stigma was examined in Chapter VII. Background characteristics explored include recipients' age, sex, education, socioeconomic status, and length of time on assistance. One non-demographic variable was also examined in this chapter: recipients' tendency to blame themselves for their poverty. Chapter VIII was devoted to recipients' ratings of agencies (Social security Administration vs. local welfare departments) and programs (OAA vs. SSI). Non-recipients' preference of the OAA or SSI program for future use was also examined. Major findings reported in the above three chapters are summarized below.

Perception of Stigma

Many past research and studies have reported that stigma was associated with welfare programs and that welfare recipients did feel stigmatized in receiving public assistance. However, this often cited welfare image was not substantiated by our data. When the three stigma items were analyzed separately, both the OAA and the SSI recipients of the national sample 
showed surprisingly low intensity of stigma feelings. Less than 28 percent of the OAA recipients felt bothered, 22.4 percent felt embarrassed, and slightly over 14 percent perceived community hostility toward welfare recipients. The proportions were even lower for the SSI recipients. Among this group, less than 14 percent said they felt bothered, 9.3 percent felt embarrassed, and less than 10 percent perceived community disrespect. Stigma feelings were higher for the OAA recipients of the local sample, with over 72 percent saying they felt bothered in receiving assistance. Still, less than 40 percent of the recipients said they felt embarrassed or perceived community disapproval. As such, it could not be said that all or even most of the welfare recipients felt humiliated by their welfare experience. This shows that there was not a single welfare image that could be applied indiscriminately to all welfare recipients. While AFDC recipients may feel stigmatized by their welfare recipiency, as many studies have found, this may not necessarily be true for OAA or SSI recipients. In testing the difference in stigma feelings between the OAA group and the SSI group of the national sample, using stigma indexes built with same weights, it was found that significantly less stigma was associated with the SSI recipients. This finding confirmed the belief that the introduction of SSI would further reduce stigma attached to the adult assistance program. 
Respondents of the local sample were found to have significantly more stigma than their cohorts in the national sample in two stigma items (bother, embarrassment). Thus, the hypothesis that there was no significant difference between the two samples in stigma was not supported. A number of reasons could be responsible for this difference, including different sample sizes, different background characteristics of the two samples, and the fact that recipients in the local sample had to recollect their OAA experience two years after the program was abolished.

Demographics and Stigma

Many studies have found that personal and demographic characteristics were not differentiating factors in people's attitudes toward the poor and welfare, and in recipients' stigma perception. In this study, relationships between five demographic and personal variables and stigma were explored. Despite the fact that stigma feelings were low among recipients, it was important to determine why some recipients felt more stigma than others.

Surprisingly, age was found to be essentially unrelated to stigma. Since all respondents in both samples were elderly, the true relationship between age and stigma could have been masked. Sex was found to be unrelated to stigma in the national sample. However, it was significantly related to stigma in the OAA group of the local sample. Furthermore, this 
relationship was pointing to the opposite direction of the hypothesis, i.e. female respondents were found to have more stigma than male respondents. The reasons for this relationship remained obscure.

Both education and socioeconomic status were significantly related to stigma in both the national and the local samples. The only exception was between SES and stigma in the OAA group of the local sample in which the relationship was not statistically significant. Such findings were expected since the receipt of assistance indicated failure on the part of the recipients. Recipients who were better educated or with higher socioeconomic status were likely to be uncomfortable in asking for assistance.

The last background variable examined was the length of time on assistance. Conflicting findings were found concerning its relationship with stigma. It was hypothesized that the longer the recipient was on assistance, the more stigma he or she would have. This hypothesis was supported only by the OAA group of the local sample. The reverse relationship was found with the OAA group of the national sample, and the relationship was not significant with the SSI group of the national sample. This finding was not unexpected since the SSI program was in existence for only one year at the time of interviews.

To blame poverty as one's own fault was the only nondemographic variable examined. Only 25.4 percent agreed with 
the statement that poverty was one's own fault. Furthermore, this variable did not relate significantly with stigma.

\section{Rating of Agencies and Programs}

Many changes incorporated into the new SSI program were calculated to promote new respectabil ty for elderly recipients and to make the program more acceptablu. One major change was to shift the administrative responsibility from local welfare agencies to the Social Security Administration. It was believed that the prestige of the Social Security Administration could be brought to the public assistance area and make SSI a more acceptable program.

It was hypothesized that respondents would have more confidence in the Social Security Administration than in local welfare agencies. This was indeed the case. More than 96 percent of the respondents in the local sample had a great deal of or some confidence in SSA, compared with less than 69 percent for local welfare agencies. The difference was statistically significant. This finding confirms the belief that SSA enjoys a much higher reputation than local welfare agencies.

Concerning the performance of the OAA and SSI programs, recipients who had experience in both programs generally were satisfied with both programs. Less than 14 percent rated the performance of OAA as "poor", compared to 8 percent for SSI. This finding was not surprising since it was found 
earlier that stigma feelings were low for both programs. Although recipients seemed satisfied with both programs, the difference was still statistically significant, i.e. more recipients were satisfied with the performance of SSI. Another indication of the acceptability of a program was people's willingness to use it. In this study, it was hypothesized that more current non-recipients would be willing to use SSI than OAA in the future. Indeed more non-recipients were found to prefer SSI to OAA. Almost 70 percent of the respondents in the national sample said they would not mind at all to use the SSI program in the future, compared with about 38 percent for OAA. A similar finding was obtained for the local sample. Both relationships were statistically significant. 


\section{IMEIICATIONS OF STUDY}

This study has both theoretical and practical significance. on the theoretical side, this study challenges the usefulness of labeling theory in explaining stigma perception of the elderly. The study identifies the need for additional empirical research in the study of stigma perception among other subgroups of the poor. Practically, this study provides additional information to support future welfare reform efforts. Specif-ically, this study demonstrates that certain types of assistance programs, such as SSI, are more acceptable to the recipients than others and therefore the design of social programs should be directed toward this goal. Another implication is that an improved SSI program can provide a basis for restructuring the Social Security system. Each of these is discussed in detail in the following pages.

Labeling Theory and the Elderly

This study provides important empirical evidence on how the elderly feel toward public assistance and clearly demonstrates that elderly welfare recipients do not subscribe to the generally negative welfare image. Labeling theory has often been used to explain welfare stigmatization. This theory states that once an individual is labeled, such as a welfare recipient, a self-fulfilling prophecy is initiated: 
others perceive and respond to the individual as a deviant; the individual internalizes the stigma. This perspective, however, has received little systematic evaluation and testing. Until this study, the work has been intuitive or theoretical. Much of the research literature assumed the link between public labeling and individual perception of stigma.

Findings from this study show that labeling theory cannot adequately explain the perception of stigma by the elderly. First, while the culturalist perspective of poverty finds the explanation of poverty in the characteristics of the poor themselves, the majority of the respondents in this study rejected this traditional ideology. Only one-fourth of the respondents (who were the elderly poor) believed that poverty was one's own fault. Second, when respondents were asked to rate the performance of the old Age Assistance program and the Supplemental Security Income program, the majority of them expressed satisfaction with both programs, although more respondents were satisfied with SSI. A third indication of the lack of negative welfare image was the low stigma feelings attached to both the OAA and SSI programs. The respondents did not feel stigmatized by being welfare recipients.

Both the elderly and members of segregated ghettos do not feel stigmatized in accepting welfare. Their lack of stigma stems from different processes. Bernard Beck (1967) asserted that the urban ghetto is likely to produce a sub- 
cultural isolation capable of reinforcing welfare dependency, in the sense of making it possible for people to enter "welfare careers" without feeling a moral burden in doing so.

The lack of stigma among the elderly welfare recipients derives from a different source. Rather than internalizing the stigma attached to the welfare role, the elderly recipients have internalized the publicly acceptable "deserving poor" image. From an historical review of welfare policies, it is clear that the elderly have been consistently identified as the deserving poor and been given assistance under most social programs. The aged poor are deemed as morally above reproach and poverty is not considered their own fault.

The English Poor Laws of 1834 established four types of poor people: the aged and impotent; children; able-bodied females; and able-bodied males (Waxman, 1977: 81). This classification indicated society's preferential treatment of the elderly among the poor. This attitude has also been reflected in the subsequent social welfare legislation and policies in the United States. For instance, among the categorical aid programs, the old Age Assistance program provided higher benefit levels and attached fewer conditions than other programs. Giving aid to the elderly does not conflict with the moral issue of work and self-reliance. The public accepts the idea that poverty among the aged is not due to lack of virtue, but is based on the theorem that they 
have already contributed to society.

The normally assumed relationship between dependency and stigmatization becomes either inoperative or irrelevant as far as the elderly poor are concerned. This finding is important because it shows that the labeling theory of welfare stigma is not applicable to all welfare recipients. The believe that a single negative welfare image exists is not supported by this study.

The Need to Study Other Groups

A second implication of this study is that more empirical studies are needed to understand fully the relationship between welfare and stigmatization for various poor suugroups. While studies concerning AFDC recipients are abundant, studies dealing specifically with the relationship between elderly and welfare stigma are not evident. Because of this lack of empirical data, the elderly have been categorized with other poor groups and presumed to possess high intensity of stigma feelings as welfare recipients.

This study demonstrates that elderly welfare recipients behave and perceive stigma differently from other poor groups. This study indicates that the relationship between welfare stigma and the elderly is more complex. This finding indicates that additional empirical research should be pursued in examining the stigma perception among other subgroups of the poor. Traditionally, the blind and the disabled are also regarded 
as the deserving poor. Do these two groups perceive welfare stigma the same way the elderly do? What about those who receive General Assistance? Do recipients of General Assistance have more stigma than AFDC recipients? Do urban recipients possess less stigma than rural recipients? The end product of more empirical studies of other groups would. enable a typology or paradigm of stigma perception among different poor groups to be constructed.

\section{A Basis for Future Program Evaluation}

A third and practical implication of this study is that it provides excellent baseline data to judge the program's future performance. The supplemental Security Income program is a relatively new program. Very little research has been done to assess its effects or acceptance by its recipients. Any comparative study between a local sample and a nationwide sample concerning SSI did not exist before this study. This study provides important baseline data for both the OAA and the SSI programs. Whatever SSI does or fails to do for its future participants should be judged in light of the conditions that existed in the previous welfare programs.

Universal vs. Class-Specific Programs

A fourth implication of this study is that it provides a basis for future reform efforts, especially in designing income-maintenance programs that provide adequate income to the beneficiaries with dignity. Findings from this study 
demonstrate that a social program stands a better chance of being accepted by both its beneficiaries and the public if it is designed as a universal program rather than a class-specific program. While the majority of the recipients feel satisfied with the performance of the old OAA program, the SSI program has shown considerable improvement in its acceptance by recipients. Stigma feelings are lower for SSI; more respondents are satisfied with SSI's performance; and more current non-recipients would pick SSI over OAA for future use. More respondents have confidence in the Social Security Administration than in local welfare agencies.

These findings imply that for a social program to be accepted by its beneficiaries, it should be designed as a universal program that serves a wide spectrum of the general population. For instance, the Social security program with its universal client group is more acceptable to its beneficiaries than the class-specific Old Age Assistance program. Although welfare payments are a legal right, this fact alone is not a strong enough incentive for people to feel good about applying. Social security benefits, however, are seen as an earned right to which any worker covered is entitled. Social security carries little of the stigma attached to welfare partly because it is seen as a benefit which the nonpoor, as well as the poor, can identify. Because social Security is universal or class-transcendent, it operates as 
integrative benefit. While the SSI program is not a universal program like social security, it emerges as an integrative program in the minds of its recipients. Administration of the SSI program by SSA, an agency that deals with a crosssection of the total population, and not only the poor, helps remove some of the negative feelings about public assistance.

One Basis to Restructure Social Security

A fifth implication from this study is that an improved SSI program can provide a basis for restructuring the social Security system. One of the current problems of the Social Security system is that it contains two incompatible functions, with the result that neither function is adequately performed (Hollister, 1974: 24). One function is to serve as a social transfer mechanism so that individuals may have income in their later years. The second function is redistribution so that some kind of income floor is provided for the poorest. Each function, however, is compromised by the constraints imposed by the other. The income redistribution function is compromised by the necessity of tying benefits to earnings. on the other hand, the function of transferring income toward old age is restricted in its effectiveness by its redistributive function.

The resulting benefit structure in the Social security system is heavily skewed toward the lower end of the earnings scale. Yet this program cannot end poverty for the aged except 
with the addition of new monies which would be of high cost to the nation. In this regard, SSI is able to produce relief for the Social security system. If the pressure to help the aged poor on the lower end of the Social Security benefit structure is removed through SSI, restructuring can begin so that Social security can meet the legitimate income replacement needs of the aged more effectively.

Joseph Pechman and others have proposed a "two-tier" system of income maintenance for the aged (Pechman, et. al..' 1968). They advocate that means-tested programs such as SSI can provide a basic income floor for the retired population. Social Security can then be transformed into an earningsrelated retirement program. SSI would aim at the welfare objective and Social Security at the insurance objective. such a two-tier system might make a breakthrough toward the improvement of the Social security system.

This study indicates that the elderly poor feel little stigma in utilizing SSI. Thus, the feasibility of establishing a two-tier system is possible from the beneficiaries' pointof-view since this study has shown that recipients would participate in the program and gain its benefits.

Because of longer life expectancy and lower birth rates, the number of aged grows not only absolutely but also as a proportion of the total population (see pp. 12-13). The elderly have been growing faster than any other group in the 
United States. The increasingly number of elderly will produce additional financial pressures on the current social Security system. Because current wage earners contribute funds to current beneficiaries, any changes in the workers/ retired beneficiaries ratio will create the need for additional funds from either employers or employees. An additional pressure is that Congress directly tied the Social Security system to the performance of the economy vith the cost of living formula. Ironically, the economy has become erratic which is likely to generate political pressure to change the Social Security system. Dissatisfication on the part of the currently employed may seek to create additional stigma or reduced benefits for those who are eligible for SSI. Counter pressures from the elderly may prevent any reduction of Social security benefits.

Traditionally, the elderly have been voting more actively than other groups. With more people joining their ranks, the elderly has become an increasingly important political force. They have joined special interest group organizations and have become very effective in lobbying for more programs to serve the elderly. One inevitable result may be an increase of benefits in old age income related programs, including Social security and SSI. This is quite likely to occur since the majority of U. S. workers are unable to save a portion of current income for the retirement years. 
These and other pressures may change Social Security and thus make the two-tier system of income-maintenance appealing. Two separate systems are needed to accomplish both the transfer and the redistribution functions at the lowest cost. Social Security would become strictly wage-related while the income support function would be transferred to a comprehensively reformed system of public assistance. Social security has become a mature system and covers nearly 95 percent of U.S. workers. It is no longer able to expect to identify new resources by extending coverage. Thus, policy-makers are likely to modify the system soon.

While such a two-tier system of income-maintenance may sound attractive and politically feasible, it is likely to produce inevitable consequences. First, the current difference between Social Security and SSI is intentionally blurred to make the latter program more acceptable to the recipients and the public. If the proposed two-tier system is established, it is likely to change both the public's perception and the elderly's perception of SSI. With a two-tier system, the differences between the insurance and the welfare systems would be emphasized. Public assistance would again become more visible to the public. At the same time, with more elderly getting benefits from SSI, more resources would be needed to run the program effectively. The public would have to support these increases through higher taxes. With a stable labor force and more resources committed 
to a successful SSI program, the public is likely to challenge the benefits given to poor elderly. They may no longer identify the elderly as deserving and may insist that stigma be attached to programs like SSI. For every benefit there is a cost. The cost for a successful SSI program could mean social stigma for the recipients in the future. 


\section{A SELECTED BIBLIOGRAPHY}

Alston; Jon $\mathrm{P}$. and $\mathrm{K}$. Imogene Dean. "Socioeconomic Factors Associated with Attitudes Toward Welfare Recipients and the Causes of Poverty," The Social Service Review 46, No. 1 (March 1972): 13-23.

Anderson, Martin. Welfare: The Political Economy of Welfare Reforms in the United States. Hoover Institution, Stanford University, 1978.

Axinn, June and Herman Levin. Social Welfare: A History of the American Response to Need. New York: Dodd, Meed and Company, 1975.

Ball, Robert M. "Income Maintenance for the Aged and Handicapped," Public Welfare 30, No. 1 (Winter 72): 33-38.

- Social Security Today and Tomorrow. New York: Columbia university Press, 1978 .

Barth, Michael C., George J. Carcagno and John I. Palmer. Toward an Effective Income Support: Problems, Prospects, and Choices. Madison, Wisconsin: Institute for Research on Poverty, 1974.

Bawden, D. Lee, Glen G. Cain and Leonard J. Hausman. "The Family Assistance Plan: An Analysis and Evaluation," Public Policy 19 (Spring 1971): 323-353.

Beck, Bernard. "Welfare as a Moral Category," Social Problems 14, No. 3 (Winter 1967): 258-277.

Becker, Howard (ed). The Other Side: Perspectives on Deviance. New York: Free Press, 1963.

Blalock, Hubert M. Social Statistics. New York: McGraw-Hill, 1960 .

(ed). Causal Models in Social Sciences. Chicago: Aldine, 1971.

Bohrnstedt, George W. "Structural Equations and the Analysis of Change," paper presented at the 28th Annual Meeting of the Gerontological Society in Louisville, Kentucky, October 26-30, 1975 . 
Boskin, Michael J. (ed). The Crisis in Social Security: problems and Prospects. San Francisco: Institute for Contemporary Studies, 1977.

Briar, Scott. "Welfare from Below: Recipients' View of the Public Welfare System," in Jacobus TenBroek (ed). The Law of the Poor. San Francisco: Chandler, 1966.

Brinker, Paul A. and Joseph J.Klas. Poverty, Manpower and Social Security. Austin, Texas: Austin Press, 1976.

Browning, Edgar $K$. Redistribution and the Welfare system. Washington, D.C.: American Enterprise Institute for Public Policy Research, 1975.

Burke, Vincent and Vee. Nixon's Good Deed: Welfare Reform. New York: Columbia University Press, 1974.

Campbell, Donald T., and Julian C. Stanley. Experimental and Quasi-Experimental Designs for Research. Chicago: Rand McNally, 1963.

Cardwell, James B. "The Supplemental Security Income Program," Tax Review 35, No. 6 (June 1974): 23-26.

Coser, Lewis A. "The Sociology of Poverty," Social Problems 13, No. 2 (Fall 1965): 140-148.

Davis, Nanette J. Sociological Constructions of Deviance. Dubuque, Iowa: Wm. C. Brown, 1975.

Elesh, David. "Poverty Theories and Income Maintenance: Validity and Policy Relevance," Madison, Wisconsin: Institute for Research on Poverty, 1970.

Feagin, Joe R. "America's Welfare Stereotypes," Social Science Quarterly 52, No. 4 (March 1972a): 921-933.

"Poverty: We Still Believe that God Helps Those Who Help Themselves," Psychology Today. November, 1972b: 101-110. (ed). The Urban Scence: Myths and Realities. New York: Random House, 1973. Subordinating the Poor: Welfare and American Relief. Englewood Cliffs, New Jersey: Prentice-Hall, 1975.

Fontana, Andrea. The Last Frontier: The Social Meaning of Growing old. Beverly Hills: Sage Publications, 1977. 
Goffman, Erving. "Embarrassment and Social Organization," American Journal of Sociology 62, No. 3 (November, 1956): 264-271. Prentice-Hali, 1963.

Gottlieb, Naomi. The Welfare Bind. New York: Columbia University Press, 1974.

Gouldner, Alvin W. "The Norm of Reciprocity," American Sociological Review 25, No. 2 (April 1960): 161-178.

Green, Christopher. Negative Taxes and the Poverty Problem. Washington, D.C.: The Brookings Institution, 1967.

Grønbjerg, Kirsten, David Street and Gerald D. Suttles. Poverty and Social Change. Chicago: The University of Chicago Press, 1978.

Handler, Joel F. and Ellen J. Hollingsworth, "Stigma, Privacy, and Other Attitudes of Welfare Recipients," Stanford Lew Review 22, No. 1 (November 1969): 1-19.

Poor": A Study of Welfare Administration. Chicago:
Markham, 1971.

Handler, Joel F. Reforming the Poor: Welfare Policy, Federalism and Morality. New York: Basic Books, 1972 .

Haveman, Robert $\mathrm{H}$. (ed). A Decade of Antipoverty Programs. New York: Academic Press, 1977.

Hawkins, Sue. "State Supplementation Under SSI, 1975," Social Security Bulletin 40, No. 2 (February 1977): 1220 .

Heffernan, W. Joseph. "The Failure of Welfare Reform: A Political Farce in Two Acts," Madison, Wisconsin: Institute for Research on Poverty, 1974.

- "A Historic Preface to Welfare Reform," Madison, Wisconsin: Institute for Research on Poverty, 1975.

Heise, David R. "Causal Inference From Panel Data," in Edgar Borgatta (ed). Sociological Methodology 1970. San Francisco: Jossey-Bass, 1970, pp. 3-37. 
Heise, Kenan. "Changing Perceptions of the Poor," Public Welfare 35, No. 1 (Winter 1977): 6-11.

Herman, Melvin and Michael Munk. Decision-Making in Poverty Programs. New York: Columbia University Press, 1968.

Herzog, Barbara Rieman. Aging and Income: Programs and Prospects for the Elderly. New York: Human Sciences Press, 1978.

Higgins, Joan. "Regulating the Poor Revisited," Journal of Social Policy 7, No. 2 (April 1978): 189-198.

Hollister, Robinson. "Social Mythology and Reform: Income Maintenance for the Aged," The Annals 415 (September 1974): 19-40.

Horan, Patrick M. and Patricia Lee Austin. "The Social Bases of Welfare Stigma," Social Problems 21, No. 5 (June 1974): 648-657.

Kallen, David J. and Dorothy Miller. "Public Attitudes Toward Welfare," Social Work 16, No. 3 (July 1971): 83-90.

Katz, Daniel, et.al. Bureaucratic Encounters. Survey Research Center, University of Michigan, Ann Arbor, Michigan, 1975.

Kennedy, Lenna D., Dorothea Thomas and Jack Schmulowitz. "Conversion to Supplemental Security Income from State Assistance: A Program Records Study," Social Security Bulletin June 1975, pp. 17-29.

Kerbo, Harold R. "The Stigma of Welfare and a Passive Poor," Sociology and Social Research 60, No. 2 (January 1976): 173-187.

Larner, Jeremy and Irving Howe (eds). Poverty: Views From the Left. New York: William Horrow, 1968.

Lebowitz, Barry D. and John L. Dobra. "Income Security for the Elderly," Paper presented at the loth International Congress of Gerontology, Jerusalem. June, 1975.

Lewis, Oscar = Five Families. New York: New American Library, 1959.

- "The Culture of Poverty," in Daniel P. Moynihan (ed) - On Understanding Poverty. New York: Basic Books, 1969, pp. 187-200. 
Lurie, Irene. Integrating Income Maintenance Programs. New York: Academic Press, 1975.

Iynn, Laurence E., Jr. "A Decade of Policy Developments in the Income-Maintenance System," in Robert H. Haveman (ed). A Decade of Federal Antipoverty Programs. New York: Academic Press, 1977, pp. 55-117.

Mandell, Betty Reid (ed). Welfare in America: Controlling the "Dangerous Classes". Englewood Cliffs, New Jersey: Prentice-Hall, 1975.

Marmor, Theodore R. and Martin Rein. "Reforming 'The Welfare Mess': The Fate of the Family Assistance Plan, 1969-72," in Allan P. Sindler (ed). Policy and Politics in

America: Six Case Studies. Boston: Little Brown, 1973, pp. 3-28.

Matza, David. "Poverty and Disrepute," in Robert $K$. Merton and Robert A. Nisbet (eds). Contemporary Social Problems. 2nd Edition, New York: Harcourt, Brace and World, 1966, pp. 619-669.

Merton, Robert K. Social Theory and Social Structure. Enlarged Edition. New York: The Free Press, 1968 .

Miller, walter B. "Lower Class Culture as a Generating Milieu of Gang Delinquency," Journal of Social Issues 14,

No. 1 (1958): 5-19.

Moynihan, Daniel P. "The Crises in Welfare," The Public Interest 10 (Winter 1968): 3-29. Basic Books, 1969 .

The Politics of a Guaranteed Income: The Nixon Administration and the Family Assistance Plan. New York: Random House, 1973.

Nam, Charles B. and Mary G. Powers. "Changes in the Relative Status Level of Horkers in the united States, 1950-1960," Social Forces 47, No. 2 (December 1968): 158-170.

Nam, Charles B., John LaRocque, Mary G. Powers and Joan Holmberg. "Occupational Status Scores: Stability and Change," from the 1975 Proceedings of the American Statistical Association, Social Science Section, pp. $570-575$. 
Neugarten, Bernice and Robert J. Havighurst. Social Policy, Social Ethics, And the Aging Society. Chicago: University of Chicago, n.d.

Ogren, Evelyn H. "Public Opinions About Public Welfare," Social Work 18, No. I (January 1973): 101-107.

Ozawa, Martha N. "SSI: Progress or Retreat?" Public Welfare 32, No. 2 (Spring 1974): 33-40.

Pechman, Joseph A., Henry J. Aaron and Michael K. Taussig. Social Security: Perspectives for Reform. Washington, D.C.: The Brookings Institution, 1968.

Percy, Charles H. Growing old in the Country of the Young. New York: McGraw-Hill, 1972.

Pinker, Robert. Social Theory and Social Policy. Iondon: Heinemann, 1971.

Piven, Frances Fox and Richard A. Cloward. Regulating The Poor. New York: Vintage Books, 1972.

Plotnick, Robert D. and Felicity Skidmore. Progress Against Poverty: A Review of the 1964-1974 Decade. New York: Academic Press, 1975.

Radin, Beryl A. "The Implementation of SSI: Guaranteed Income or Welfare," Public Welfare 32, No. 4 (Fall 1974): 7-19.

Rainwater, Lee. And the Poor Get Children. Chicago: Quadrangle Books. 1960.

- What Money Buys: Inequality and the Social Meaning of Income. New York: Basic Books, 1974.

Rein, Mildred. Work or Welfare? Factors in the Choice of AFDC Mothers. New York: Praeger, 1974. - "Determinants of the Work-Welfare Choice in AFDC," The Social Service Review 46, No. 4 (December 1972): 539-566.

Riessman, Frank. Strategies Against Poverty. New York: Random House, 1969 .

Rodman, Hyman. Lower-Class Families. New York: Oxford University Press, 1971. 
Schieber, Sylvester J. "First Year Impact of SSI on Economic Status of 1973 Adult Assistance Populations," Social Security Bulletin 41, No. 2 (February 1978): $\overline{18-46 .}$

Schlitz, Michael E. Public Attitudes Toward Social Security Security 1935-1965. Social Security Administration, Office of Research and Statistics, Research Report No. 33. Washington, D.C.: Government Printing Office, 1970.

Schorr, Alvin. "The Nonculture of Poverty," American Journal of Orthopsychiatry 34 , No. 5 (October 64): 907-912.

Simmel, Georg. "The Poor," Social Problems 13, No. 2 (Fall 1965): 118-140, Translated by Claire Jacobson.

Singer, Burton and Seymour Spilerman. "Some Methodological Issues in the Analysis of Longitudinal Surveys," Madison, Wisconsin: Institute for Research on Poverty, 1976.

Smith, Robert F. and W. Joseph Heffernan. "Work Incentives and Welfare Reform: The FAP Experience," Mississippi Valley Journal of Business and Economics. 1971: 11-24.

Smith, Vernon $K$. Welfare Work Incentives. Lansing, Michigan: Department of Social Services, 1974.

Social Security Administration. Social Security Programs in the United States. Washington, D.C.: Government Printing Office, 1973.

Spitzer, Carlton T. "Welfare's Bad Image and How to Change It," Public Welfare 35, No. 3 (Summer 1977): 42-48.

Steiner, Gilbert $Y$. Social Insecurity: The Politics of Welfare. Chicago: Rand MaNally, 1966.

The State of Welfare. Washington, D.C: : The Brookings Institution, 1971 .

Street, David, George T. Martin and Laura K. Gordon. The Welfare Industry: Functionaries and Recipients in Welfare Ald. Beverly Hills: Sage Publications, 1979.

Thernstrom, Stephen. "Poverty in Historical Perspective," in Daniel P. Moynihan (ed) . On Understanding Poverty. New York: Basic Books, 1969, pp. 160-186.

Tissue, Thomas. "The Survey of the Low-Income Aged and Disabled: An Introduction," Social Security Bulletin 40, No. 2 (February 1977): 3-10. 
Tissue, Thomas. A Last Look at Adult Welfare Recipients. Social Security Administration, Office of Research and Statistics, Washington, D.C.: Government Printing Office, 1978.

- "Response to Recipiency Under Welfare and SSI," Social Security Bulletin 41, No. 11 (November 1978): $3-15$.

Tropman, John E. "Reality or Projection?" Public Welfare 35, No. 1 (Winter 1977): 6-11.

U.S. Census Bureau. Historical Statistics of the United States. Washington, D.C.: Government Printing Office, 1949 .

- Historical Statistics of the United States, Colonial Times to 1957. Washington, D.C.: Government Printing Office, 1960 .

- Methodology and Scores of Socioeconomic Status. Working Paper No. 15. Washington, D.C.: Government Printing Office, 1963.

$\frac{\text { States, 1977. }}{\text { Office, 1977. }_{\text {Washington, D.C.: Government Printing }}}$

Waxman, Chaim I. The Stigma of Poverty: A Critique of Poverty Theories and Policies. New York: Pergamon, 1977.

Wells, Larry L. "Welfare Embarrassment," The Gerontologist 12, No. 2 (Summer 1972, part 1): 19

Williams, Walter. "The SSI Program: Potentially the Next Crucial Step Toward Social Security and Welfare Reform," Public Policy Paper \#5, Institute of Governmental Research, University of Washington, January 1973.

Williamson, John B. "Beliefs About the Motivation of the Poor and Attitudes Toward Poverty Policy," Social Problems 21, No. 5 (June 1974a): 634-647.

"The Stigma of Public Dependency: A Comparison of Alternative Forms of Public Aid to the Poor," Social Problems 22, No. 2 (December 1974b): 213-228. 
Williamson, John B. and Kathryn Hyers. "The Measurement and Meaning of Poverty," Social Problems 22, No. 5 (June 1975): 652-663.

Wyers, Norman I. "Underutilization in Income Maintenance Programs," Public Welfare 34, No. I (winter 1976): 41-46. 